\title{
Structural Aspects of Monomeric Platinum Coordination Complexes
}

\author{
Milan Melník, Peter Mikuš \\ Department of Pharmaceutical Analysis and Nuclear Pharmacy, Faculty of Pharmacy, Comenius University \\ in Bratislava, Bratislava, Slovak Republic \\ Email: qmelnik@stuba.sk
}

Received 6 April 2014; revised 11 April 2014; accepted 3 May 2014

Copyright $(0) 2014$ by authors and Scientific Research Publishing Inc.

This work is licensed under the Creative Commons Attribution International License (CC BY). http://creativecommons.org/licenses/by/4.0/

(c) (i) Open Access

\section{Abstract}

This review covers structural parameters of almost two thousand monomeric Pt coordination complexes. The $\mathrm{Pt}$ is found in the oxidation states zero, $+1,+2,+3$ and +4 , from which oxidation state +2 by far prevails. There is a wide variety of donor atom ligands from uni-, bi-, ter- and tetradentate with over seventeen types of donor atoms, from which by far prevails $\mathrm{P}$ and $\mathrm{N}$ donor ligands and chlorine atom. The $\mathrm{Pt}(0)$ atoms are two-, three- and four-coordinated; $\mathrm{Pt}(\mathrm{I})$ and $\mathrm{Pt}(\mathrm{III})$ are only four-coordinated, Pt(II) are four- and five-coordinated, and Pt(IV) are five- and six-coordinated. About $10 \%$ of these complexes exist as isomers. Included are distortion (65\%), cis-trans $(30 \%)$, mixed isomers and ligand isomerism. The structural parameters are discussed in terms of the coordination about the platinum atom, and correlations are drawn between donor atom, bond length and interbond angles with attention to any trans-effect.

\section{Keywords}

Structure, Platinum, Monomeric, Isomers, Trans-Effect

\section{Introduction}

It is well known that platinum has played a crucial role in the development of many branches of science. Reliable platinum crucibles were vital in classical analysis which laid the foundation of modern chemistry. Platinum exists in a wide range of oxidation states from zero to six; of which +2 and +4 are the most common, particularly in coordination chemistry. Platinum(II) has a strong preference for square planar coordination chemistry, of which the kinetic inertness has allowed extensive use of these complexes in the characterization of geometrical (cis-trans) isomerism and reaction mechanistic. Much work in this field has come from the Russian school such as the contributions of Chernayeav. In the 1920s he noticed that when there are alternative positions at which an 
incoming ligand might be a substitution, the position chosen depends not so much on the two ligands directly involved as on the nature of the inactive ligand trans to that position. This became known as the "trans effect" and has had a considerable influence on the synthetic chemistry of platinum(II).

A resurgence of interest in complexes of platinum started in 1969 when Rosenberg and co-workers discovered the anti-tumor activity of $\mathrm{PtCl}_{2}\left(\mathrm{NH}_{3}\right)_{2}$, known as "cisplatin" [1]. This stimulated considerable research activity into the chemistry of platinum which has resulted in the determination of a considerable number of structures by diffraction technique. Since structure is often related to chemical and biological activity it seemed appropriate to prepare a comprehensive overview of such structures. Because of the huge number of structures involved this review covers only a variety of monomeric platinum coordination complexes.

The aim of this survey is to correlate the structural information available and to try to identify factors which may be responsible for the observed stereochemistry.

\section{Monomeric Platinum Coordination Complexes}

The huge area of structural parameters of monomeric platinum coordination complexes has been surveyed [2]-[5] with over two thousand examples noted. In this paper we brifly summarize these structures. In the series of monomeric platinum coordination compounds the platinum is found in oxidation states zero, $+1,+2$ (most common), +3 , and +4 .

\section{1. $\operatorname{Pt}(0)$ Complexes}

There are over thirty monomeric $\operatorname{Pt}(0)$ complexes for which structural data are available [1]. These complexes crystallized in six crystal classes: monoclinic (19 examples), triclinic (10 examples), orthorhombic (2 examples), tetragonal, hexagonal and rhombohedral each (1 example). Thirty four $\operatorname{Pt}(0)$ complexes show a variety of stereo-chemistries about a Pt(0) atom, linear, almost linear, trigonal planar, T-shaped and tetrahedral with varying degrees of distortion. Structure of $\mathrm{Pt}\left(\mathrm{Bu}_{2}^{t} \mathrm{Ph}\right)$, is shown in Figure 1 [6] as an example. Two unidentate bulkybdi-tert-butylphenylphosphine directly coordinated to the central $\operatorname{Pt}(0)$ atom whit the mean $\operatorname{Pt}(0)-\mathrm{P}$ bond distances of $2.23 \AA$ and P-Pt-P bond angle is $177.0^{\circ}$. As can be see there is a number of Pt ... H interactions which stabilized the respective structure. The linear, almost linear as well as trigonal planar (Y shape) geometries are building up only by monodentate P-donor ligands. The mean $\mathrm{Pt}(0)$-P bond distances and P-Pt-P bond angles are: $2.249 \AA$ and $180.0^{\circ}$ (linear); $2.240 \AA$ and $168.7^{\circ}\left( \pm 8.3^{\circ}\right)$ (almost linear); $2.270 \AA$ and $120^{\circ}\left( \pm 5^{\circ}\right)$. T-shape geometry about $\mathrm{Pt}(0)$ atom is created by two monodentate $\mathrm{P}$-donor ligands and $\mathrm{SO}_{2}$ ligand $\left(\mathrm{PtP}_{2} \mathrm{~S}\right)$. The $\mathrm{Pt}-\mathrm{P}$ bond distance is $2.307 \AA$ (ave) and Pt-S is 2.295(1) $\AA$. The P-Pt-P bond angle is $165.7^{\circ}$ and the mean P-Pt-S bond angle is $96.2^{\circ}$.

There are twenty five examples in which $\operatorname{Pt}(0)$ atoms are tetrahedrally coordinated. In fourteen of them a distorted tetrahedral environment about $\mathrm{Pt}(0)$ is created solely by bulky phosphine molecules $\left(\mathrm{PtP}_{4}\right)$. These can be subdivided into the four groups with four unidentate, two unidentate plus one bidentate, two bidentate and one unidentate plus one tridentate. A tetrahedral geometry occurs about the $\mathrm{Pt}(0)$, distorted to varying degrees depending on the ligand involved. For unidentate ligands an almost regular tetrahedral geometry is observed deviating from $109.5^{\circ}$ by only $0.6^{\circ}$ with the mean Pt-P bond distance of $2.254 \AA$. For the chelated derivatives the distortion depends on the size of the P-Pt-P bite angles of the ligands. The mean Pt-P bond distance in the series of bidentate P-donor ligands elongated with the decrease in number of atoms in the respective metallocycle: $2.248 \AA$ (nine- $\left.\mathrm{PC}_{8} \mathrm{P}\right)<2.296 \AA$ (six- $\left.\mathrm{PC}_{3} \mathrm{P}\right)<2.360 \AA$ (three-PP). The mean P-Pt-Pt bite angle closes in the same order: $115.3^{\circ}>97.4^{\circ}>53.1^{\circ}$ and at the same time the distortion of the respective tetrahedral increases.

There are three derivatives in which each $\mathrm{Pt}(0)$ atom has heterogeneous inner sphere $\left(\mathrm{PtP}_{3} \mathrm{~S}\right)$. In two of them three unidentate $\mathrm{PPh}_{3}$ ligands with $\mathrm{SO}_{2}$ created such sphere. The mean Pt-P and Pt-S bond distances are 2.313 and $2.384 \AA$, respectively. The mean P-Pt-P and P-Pt-S bond angles are $118.6^{\circ}$ and $96.8^{\circ}$. In the third derivative the $\mathrm{PtP}_{3} \mathrm{~S}$ chromophore is build up by two unidentate $\mathrm{PPh}_{3}$ ligands and one bidentate ligand with $\mathrm{P}$ and $\mathrm{S}$ donor sites. Here the $\mathrm{Pt}-\mathrm{PPh}_{3}$ bond distances are quite different at 2.252 and $2.387 \AA$ because of a trans effect. The former is opposite $\mathrm{S}$ and the latter opposite of the bidentate ligand: The P-Pt-S bond angles range from $52.8(1)^{\circ}$ (three-membered) to $160.4(1)^{\circ}$ and the P-Pt-P bond angles from $103.5(1)^{\circ}$ to $147.9(1)^{\circ}$. In another three derivatives two unidentate $\mathrm{P}$ donor ligands with bidentate $\mathrm{O}_{2}$ molecule created $\mathrm{PtO}_{2} \mathrm{P}_{2}$ chromophore. Structure of $\mathrm{Pt}\left(\eta^{2}-\mathrm{O}_{2}\right)\left(\mathrm{PPh}_{3}\right)_{2} \cdot 2 \mathrm{CHCl}_{3}$ is shown in Figure 2 [7] as an example. The molecule of oxygen plus two unidentate bulky triphenylphosphine ligands are coordinated to the central $\operatorname{Pt}(0)$ atom. The molecule has a two-fold axis of symmetry through the Pt atom and the O-O axis. The mean Pt-P and Pt-O bond distances are 2.260 and 2.01 


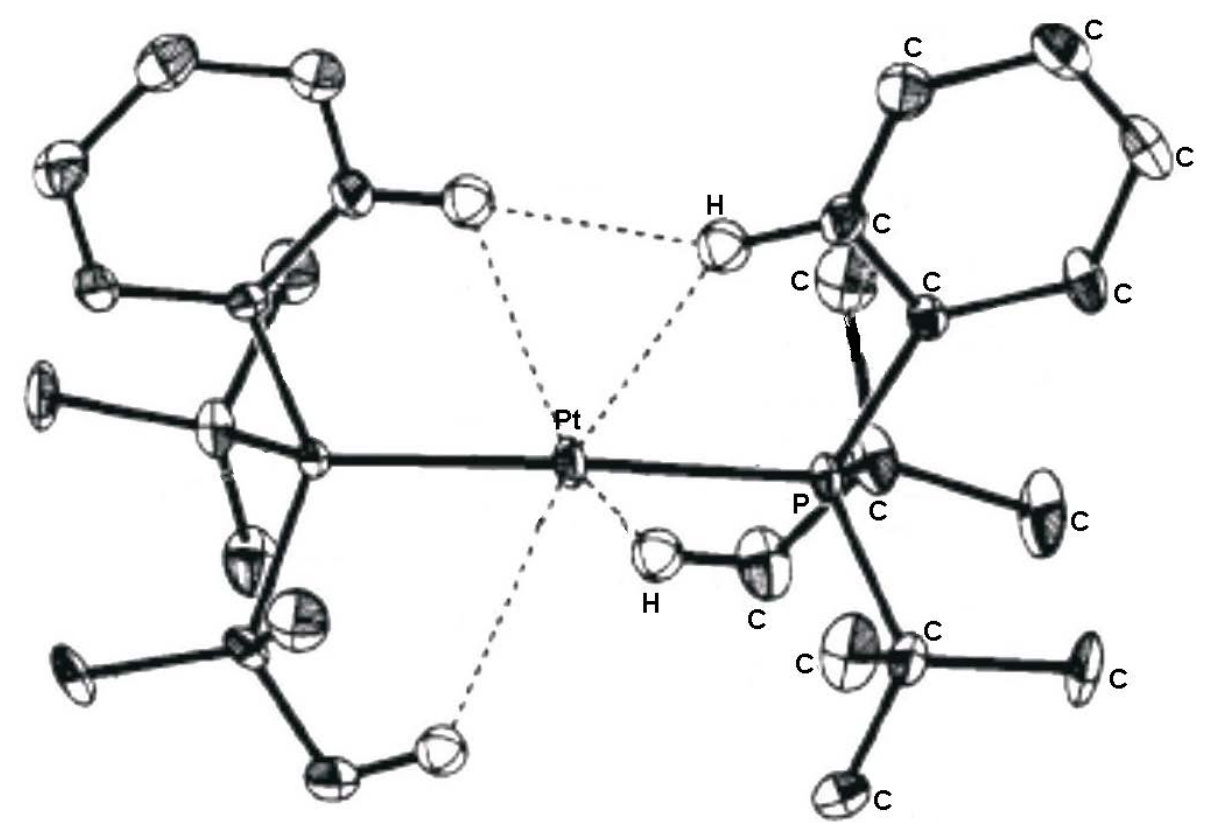

Figure 1. Structure of $\mathrm{Pt}\left(\mathrm{Bu}_{2}^{\mathrm{t}} \mathrm{Ph}\right)_{2}$ [3].

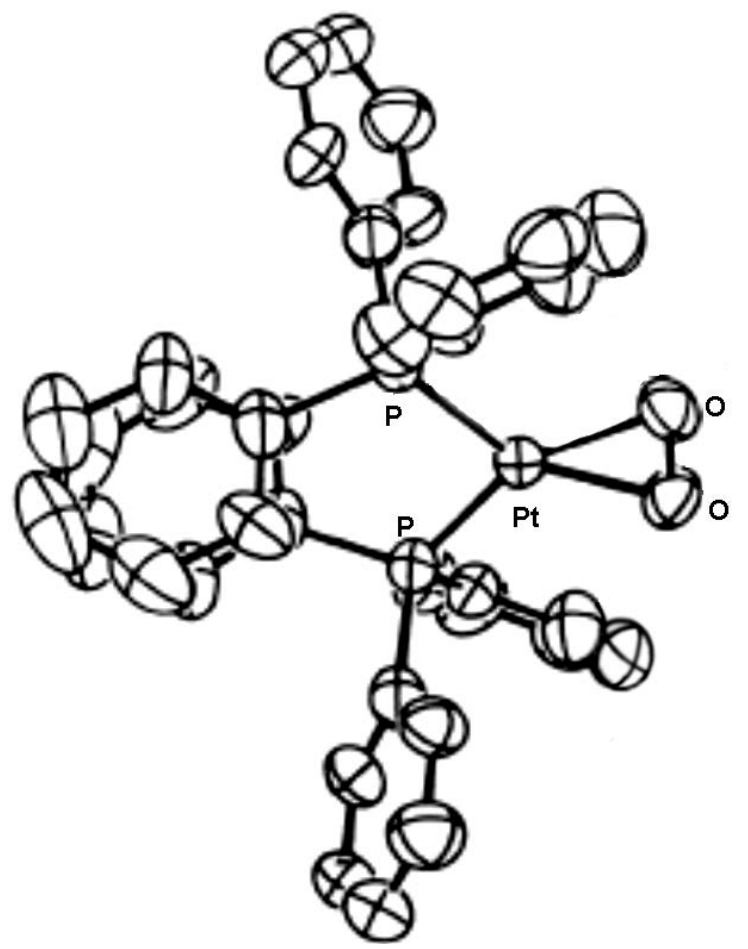

Figure 2. Structure of $\mathrm{Pt}\left(\eta^{2}-\mathrm{O}_{2}\right)\left(\mathrm{PPh}_{3}\right)_{2}$ [4].

A. The mean O-Pt-O bite angle is $42.8^{\circ}$. The mean P-Pt-P and O-Pt-P bond angles are $101.2^{\circ}$ and $107.8^{\circ}$.

There is an example in which pairs of $\mathrm{PMe}_{2} \mathrm{Ph}$ and pyrazole form $\mathrm{PtN}_{2} \mathrm{P}_{2}$ chromophore with the mean Pt-N and Pt-P bond distances of 2.027 and $2.305 \AA$, with the mean N-Pt-P bond angle of $91.7^{\circ}$. In another derivative two $\mathrm{PPh}_{3}$ ligands with two $\mathrm{SO}_{2}$ molecule build up a distorted tetrahedral geometry about $\mathrm{Pt}(0)$ atom $\left(\mathrm{PtS}_{2} \mathrm{P}_{2}\right)$. The mean Pt-S and Pt-P bond distances are 2.428 and $2.315 \AA$. The L-Pt-L bond angles open in the order: $96.3^{\circ}$ $(\mathrm{S}-\mathrm{Pt}-\mathrm{P})<106.3^{\circ}(\mathrm{S}-\mathrm{Pt}-\mathrm{S})<158.6^{\circ}$ (P-Pt-P). 
The remaining three $\mathrm{Pt}(0)$ derivatives have a pair of $\mathrm{PPh}_{3}$ ligands and heterobidentate ligand giving the following isosceles triangles: PtON angle $40.0^{\circ}$, PtNS angle of $43.1^{\circ}$ and PtCS angle $45.5^{\circ}$. The angle increases with increasing sum of covalent radii of the ligand atoms and with increasing average Pt-L bond distance, for example: 1.48 and $2.058 \AA(\mathrm{O}+\mathrm{N})<1.77$ and $2.194 \AA(\mathrm{N}+\mathrm{S})<1.79$ and $2.196 \AA(\mathrm{C}+\mathrm{S})$. The mean Pt-P bond distance is $2.276 \AA$. The sum of all four Pt-L bond distances increases in the order: $8.63 \AA\left(\mathrm{PtP}_{2} \mathrm{ON}\right)<$ $8.945 \AA\left(\mathrm{PtP}_{2} \mathrm{NS}\right)<8.98 \AA\left(\mathrm{PtP}_{2} \mathrm{CS}\right)$. In the same order a distortion of the respective tetrahedral geometry decreases.

The most common donor atom is $\mathrm{P}$. The mean $\mathrm{Pt}(0)-\mathrm{P}$ bond distance for monodentate ligands elongated in the order: $2.24 \AA$ (two-) $<2.275 \AA$ (four-) $<2.28 \AA$ (three-coordinate). In the four-coordinated derivatives the mean $\mathrm{Pt}(0)$-L bond distance elongated in the order: $2.10 \AA\left(\eta^{2}-\mathrm{O}_{2}\right)<2.03 \AA(\mathrm{NL})<2.275 \AA(\mathrm{PL})<2.29 \AA\left(\eta^{2}-\mathrm{PL}\right)<$ $2.41 \AA\left(\mathrm{SO}_{2}\right)$.

\subsection{Pt(I) Complexes}

There are two examples in which $\mathrm{Pt}(\mathrm{I})$ atom is four-coordinated. In one of the examples two 2,2'-bipyridine ligands in complex cation $\left[\mathrm{Pt}\left(\eta^{2} \text {-bpy) }\right]^{+}\right.$created a distorted square-planar configuration $\left(\mathrm{PtN}_{4}\right)$. The mean Pt-N bond distance is 2.029(7) $\AA$, and the ring N-Pt-N internal angle is $79.2(4)^{\circ}$. A distorted tetrahedral geometry about the $\mathrm{Pt}(\mathrm{I})$ atom, in $\mathrm{Pt}\left(\mathrm{PPh}_{3}\right)_{2}\left(\eta^{2}\right.$-1,2,3,4-tetraphenyl-1,2-dihydro-1,2-diphosphate) is created by two monodentate $\mathrm{PPh}_{3}$ ligands and a bidentate diphosphate ligand with mean Pt-P bond distances at 2.32(I) and 2.285(I) $\AA$, respectively. The P-Pt-P bond angles range from $82.67(3)^{\circ}$ (five-membered metallocycle) to $140.95(6)^{\circ}$.

\subsection{Pt(II) Complexes-Four Coordinated}

There are over one thousand and six hundred four-coordinated Pt(II) complexes for which structural parameters are available. Their structural parameters were detail analyzed and classified by us [2]-[5]. Therefore in this section will be only briefly summarized these structures. The inner coordination sphere about the $\mathrm{Pt}(\mathrm{II})$ atoms is very variable: $\mathrm{PtA}_{4}, \mathrm{PtA}_{3} \mathrm{~B}, \mathrm{PtA}_{2} \mathrm{BCD}$ and even PtABCD. The PtA $\mathrm{A}_{4}$ derivatives include those with homogeneous or quasi-homogeneous coordination spheres (i.e. different ligands) but with the same donor atoms.

\subsection{1. $\mathrm{PtA}_{4}(\mathrm{~A}=\mathrm{0}, \mathrm{N}, \mathrm{C}, \mathrm{Cl}, \mathrm{S}, \mathrm{P}, \mathrm{Br}$, Se or As)}

There are only four $\mathrm{Pt}(\mathrm{II})$ derivatives with $\mathrm{PtO}_{4}$ inner coordination sphere. In each of them a pair of bidentate $-\mathrm{O}, \mathrm{O}$ ' donor ligands create a square planar arrangement about the $\mathrm{Pt}(\mathrm{II})$ atom. In one derivative two 3,5-di-tertbutyl-1,2-semiquinone ligands creating two five-membered metallocyclic rings with mean O-Pt-O bond angles of $81.3(2)^{\circ}$. The mean derivatives a bidentate O-donor ligands (acetylacetonatate, benzoyltrifluoroacetonate) form a six-membered metallocycles with mean O-Pt-O bond angle of $94.8(6)^{\circ}$. The mean Pt-O bond distance of $2.012 \AA$ is about $0.045 \AA$ longer than that found in the former derivative.

There are almost two hundred and sixty $\mathrm{PtN}_{4}$ derivatives, which can be divided into the six groups: $\mathrm{Pt}\left(\eta^{1}-\mathrm{NL}\right)_{4}$; $\operatorname{Pt}\left(\eta^{1}-\mathrm{NL}\right)_{2}\left(\eta^{2}-\mathrm{NL}\right) ; \operatorname{Pt}\left(\eta^{2}-\mathrm{NL}\right)_{2} ; \operatorname{Pt}\left(\eta^{2}-\mathrm{NL}\right)\left(\eta^{2}-\mathrm{NL}\right) ; \operatorname{Pt}\left(\eta^{3}-\mathrm{NL}\right)\left(\eta^{1}-\mathrm{NL}\right)$ and $\operatorname{Pt}\left(\eta^{4}-\mathrm{NL}\right)$. The $\operatorname{Pt}\left(\eta^{1}-\mathrm{NL}\right)_{4}$ derivatives (over one hundred) can be subdivided into two main groups: (a) with a homogeneous coordination sphere (all four N-donor ligands are identical); (b) with a quasi-homogeneous coordination sphere. The (b) group can be divided into four subgroups: $\left(\mathrm{b}_{1}\right)$ three identical ligands plus one other $\mathrm{PtN}_{3} \mathrm{~N}^{\prime}$; $\left(\mathrm{b}_{2}\right)$ two pairs of identical ligands $\mathrm{PtN}_{2} \mathrm{~N}_{2}^{\prime}$; $\left(\mathrm{b}_{3}\right)$ one identical pair and two different ligands $\mathrm{PtN}_{2} \mathrm{~N}^{\prime} \mathrm{N}^{\prime \prime}$; $\left(\mathrm{b}_{4}\right)$ all ligands different.

The (a) group is most often created by four amine ligands, in several other cases four alkyl N-donor ligands, or aryl N-donor ligands used. The mean Pt-N bond distances elongated in the order: $2.01 \AA$ (N-alkyl) $<2.02 \AA$ $(\mathrm{N}$-aryl $)<2.055 \AA\left(\mathrm{NH}_{3}\right)$. The mean cis-N-Pt-N bond angle depart from the $90.0^{\circ}$ by $1.4^{\circ}(\mathrm{N}$-aryl $)<2.0^{\circ}(\mathrm{N}-$ alkyl $<2.3^{\circ}\left(\mathrm{NH}_{3}\right)$, which indicated that the distortion of the respective square-planar geometry increases in the given order.

There are only three derivatives belonging to the $\left(\mathrm{b}_{1}\right)$ subgroup $\left(\mathrm{PtN}_{3} \mathrm{~N}^{\prime}\right)$. The mean Pt-N bond distance is 2.05 $\AA$ and cis-N-Pt-N angle depart from $90.0^{\circ}$ by $2.4^{\circ}$.

The most common type subgroup is actually $\left(\mathrm{b}_{2}\right), \operatorname{Pt}\left(\eta^{1}-\mathrm{NL}\right)_{2}\left(\eta^{1}-\mathrm{NL}\right)_{2}$. Practically all examples are of the composition $\left[\mathrm{Pt}\left(\mathrm{NH}_{3}\right)_{2}\left(\eta^{1}-\mathrm{NL}\right)_{2}\right]^{2+}$ with both cis- (22 examples) and trans- (10 examples) derivatives. The mean Pt- $\mathrm{NH}_{3}$ bond distance in the cis-derivatives is $2.04 \AA$, which is slightly shorter than in the trans-derivatives at $2.06 \AA$. The mean depart of cis- $\mathrm{H}_{2} \mathrm{~N}-\mathrm{Pt}-\mathrm{NH}_{3}$ bond angle from $90.0^{\circ}$ is $1.7^{\circ}$. The mean trans-N-Pt-N bond angle in those cis-derivatives is $177.5^{\circ}$. The depart of trans- $\mathrm{H}_{3} \mathrm{~N}-\mathrm{Pt}-\mathrm{NH}_{3}$ bond derivatives in the series of trans- 
$\left[\mathrm{Pt}\left(\mathrm{NH}_{3}\right)_{2}\left(\eta^{1}-\mathrm{NL}\right)_{2}\right]^{2+}$ from $180.0^{\circ}$ is $0.3 \%$ and cis- $\mathrm{H}_{3} \mathrm{~N}-\mathrm{Pt}-\mathrm{NL}$ bond angle depart from $90.0^{\circ}$ by $11.5^{\circ}$. For the composition $\left[\mathrm{Pt}\left(\mathrm{MeNH}_{2}\right)_{2}\left(\eta^{1}-\mathrm{NL}\right)_{2}\right]^{2+}$ only trans-derivatives (seven examples) are found, with a mean $\mathrm{Pt}-\mathrm{N}\left(\mathrm{H}_{2} \mathrm{Me}\right)$ bond distance of $2.06 \AA$. The mean trans-N-Pt-N bond angle is $176.7^{\circ}$ and cis-N-Pt-N bond angle depart from 90.0 by $3.3^{\circ}$ (mean).

Several derivatives have the $\left(\mathrm{b}_{3}\right)$ type composition $\left[\mathrm{Pt}\left(\mathrm{NH}_{3}\right)_{2}\left(\eta^{1}-\mathrm{NL}^{\prime}\right)\left(\eta^{1}-\mathrm{NL}\right)\right]^{2+}$ and again exhibit cis- $(9$ examples) as well as trans- (6 examples). The mean Pt-N $\left(\mathrm{H}_{3}\right)$ bond distances for both cis and trans derivatives are the same at $2.05 \AA$ in this case. Once again, for the compositions [Pt( $\left.\mathrm{MeNH}_{2}\right)_{2}\left(\eta^{1}-\mathrm{NL}\right)\left(\eta^{1}-\mathrm{NL} "\right)(3$ examples) only trans derivatives are found again with mean Pt- $\mathrm{N}\left(\mathrm{H}_{2} \mathrm{Me}\right)$ bond distances of $2.06 \AA$.

Finally there is only one example which belongs to the $\left(\mathrm{b}_{4}\right)$ subgroup and that is $\left[\mathrm{Pt}\left(\mathrm{NH}_{3}\right)\right.$ (1-methylcytosine)(9-methyladenine)(9-ethylguaninate) $]^{+},\left[\mathrm{Pt}\left(\mathrm{NH}_{3}\right)(1-\mathrm{MeC})(9-\mathrm{MeA})(9-\mathrm{EtG})\right]^{+}$. Most of the compounds represent a hypothetical interaction of cis-Pt(II) with two biomolecules (nucleobases), which can be considered a model for the interaction of a transition metal with DNA in an inter- and intra-strand fashion simultaneously. The data in this section reveals the rich $\mathrm{Pt}(\mathrm{II})$ chemistry of $\mathrm{N}$-donor ligands with a dominant $\mathrm{NH}_{3}$ ligand and different nucleobases [2]. The mean Pt-N bond distances elongate in the sequence: $2.015 \AA$ (9-EtG) $<2.02 \AA$ $(9-\mathrm{MeA})<2.03 \AA(1-\mathrm{MeC})<2.035 \AA(\mathrm{NL})<2.04 \AA\left(\mathrm{NH}_{2} \mathrm{Me}\right) \sim 2.04 \AA\left(\mathrm{NH}_{3}\right)$ for the cis-derivative. For the trans-derivatives the order is: $2.01 \AA(9-\mathrm{EtG})<2.015 \AA(\mathrm{NL})<2.03 \AA(9-\mathrm{MeA})<2.04 \AA(1-\mathrm{MeC})<2.05 \AA$ $\left(\mathrm{NH}_{3}\right)<2.06 \AA\left(\mathrm{NH}_{2} \mathrm{Me}\right)$.

There are over forty derivatives of $\mathrm{Pt}\left(\eta^{2}-\mathrm{NL}\right)\left(\eta^{1}-\mathrm{NL}\right)_{2}$ type: for which structural parameters are available [2]. Structure of $\mathrm{Pt}\left(\eta^{2}-4,4^{\prime}-\mathrm{Ph}_{2} \mathrm{bpy}\right)\left(3,5-\mathrm{Me}_{2} \mathrm{py}\right)_{2}\left(\mathrm{PF}_{6}\right)_{2}$ is shown in Figure 3 as an example [8]. The crystallographic asymmetric unit contains the dicationic complex of Pt(II). There are interactions with both the hexafluorophosphate anions on each axial position at a distance of 3.40(1) and 2.58(3) $\AA$, respectively. The most common bidentate ligands are 2,2'-bipyridyl (by) and its derivatives for the unsaturated -N,N'donor ligands (8 examples), and ethylenediamine (en) and its derivatives for the saturated -N,N'donor ligands (17 examples). The mean values of Pt-N bond distance and N-Pt-N bond angle found in the cis-Pt $\left(\eta^{2}\right.$-bpy $)\left(\eta^{1}-\mathrm{NL}\right)_{2}$ derivatives of $2.005 \AA$ and $80.5^{\circ}$ are smaller than those found in the $\operatorname{cis}-\mathrm{Pt}\left(\eta^{2}-\mathrm{en}\right)\left(\eta^{1}-\mathrm{NL}\right)_{2}$ derivatives with the values of $2.04 \AA$ and $84.0^{\circ}$, respectively. The mean Pt-N bond distance in the series of monodentate ligands elongate in the order: $2.005 \AA$ $(\mathrm{NCX})<2.015 \AA$ (pyridine, pyrazole) $<2.02 \AA$ (N-nucleoside) $<2.05 \AA\left(\mathrm{NH}_{3}\right)$.

There are seventy-five examples in which a square planar arrangement created by two pairs of the same tridentate ligands $\operatorname{Pt}\left(\eta^{3}-\mathrm{NL}\right)_{2}$ or different bidentate ligands $\operatorname{Pt}\left(\eta^{2}-\mathrm{NL}\right)\left(\eta^{2}-\mathrm{NL}\right.$ '), occurs about the $\operatorname{Pt}(\mathrm{II})$ atom with varying degrees of distortion. In $\mathrm{Pt}\left(\eta^{2}-\mathrm{NL}\right)_{2}$ derivatives are examples in which a pair of bidentate $-\mathrm{N}, \mathrm{N}$ 'donor atoms giving two four-membered metallocyclic rings with the mean N-Pt-N bite angle of $63.7^{\circ}$ and the mean Pt-N bond distance of $2.033 \AA$, typical of purely $\sigma$-bonding between metal and nitrogen atoms.

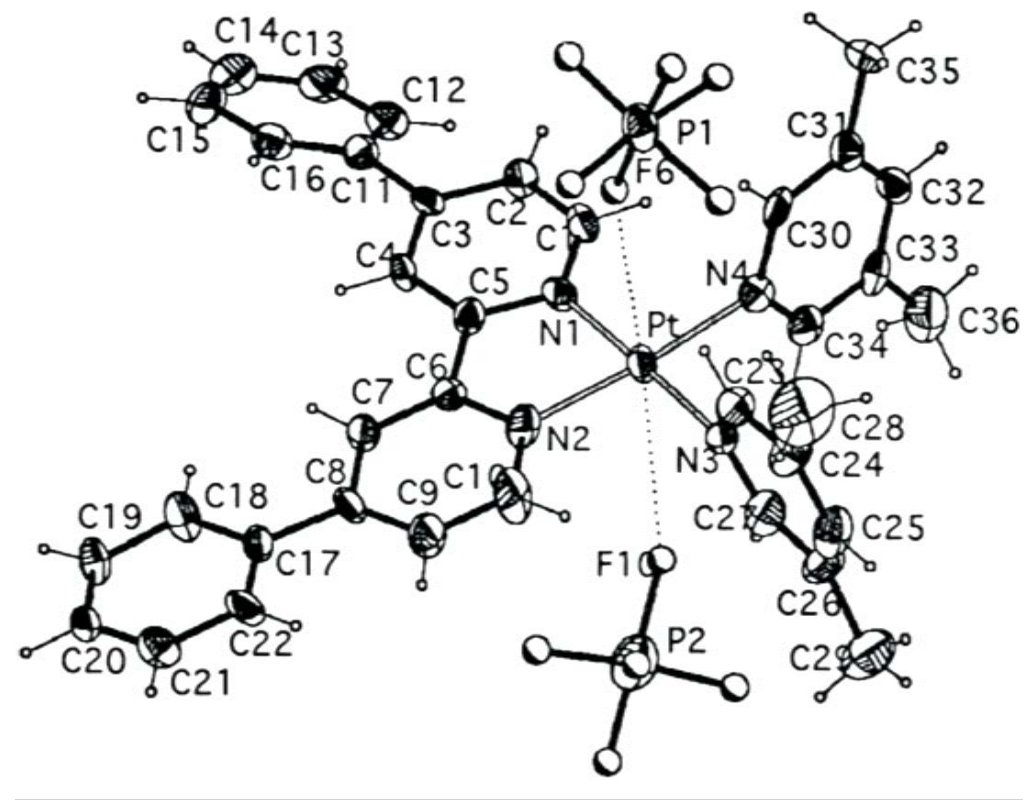

Figure 3. Structure of $\mathrm{Pt}\left(\eta^{2}-4,4^{\prime}-\mathrm{Ph}_{2}\right.$ bpy $)\left(3,5-\mathrm{Me}_{2} \mathrm{py}\right)_{2}\left(\mathrm{PF}_{6}\right)_{2}[6]$. 
In some derivatives with two non-equivalent N,N'-donor ligands form four- and five- in another one five- and seven- and some other six- and seven-membered metallocyclic rings, respectively, with the Pt(II) atom. The mean values of N-Pt-N bite angles are $63.5^{\circ}$ (four-), $83.0^{\circ}$ (five-), $92.0^{\circ}$ (six-) and $87.9^{\circ}$ (seven-membered). The $\sim 4^{\circ}$ closure of the seven-membered ring reflects its greater flexibility. The six-membered chelate ring is in the chair conformation.

The data in $\operatorname{Pt}\left(\eta^{2}-\mathrm{NL}\right)_{2}$ and $\operatorname{Pt}\left(\eta^{2}-\mathrm{NL}\right)\left(\eta^{2}-\mathrm{NL}\right)^{\prime}$ indicate the most common situation with the N,N'-donor ligands and $\mathrm{Pt}(\mathrm{II})$ in the five-membered metallocyclic ring. In the unsaturated chelate ligands the mean values of the Pt-N bond distances and N-Pt-N bite angles are $1.995 \AA$ and $78.5^{\circ}$, which are smaller than those found in the saturated chelate ligands of $2.05 \AA$ and $82.2^{\circ}$. The respective mean values for the six-membered metallocyclic rings are $2.045 \AA$ and $89.7^{\circ}$.

In the series of $\operatorname{Pt}\left(\eta^{3}-\mathrm{NL}\right)(\mathrm{NL})$ derivatives are actually two groups, one where the tridentate ligand is 2,2': 6',2"-terpyridine (5 examples) and the other, where the tridentate ligand is diethylenetriamine (11 examples). In those derivatives with terpyridine as the tridentate ligand, the central $\mathrm{N}$ atom is usually much closer to the Pt(II) atom than the remaining two outer $\mathrm{N}$ atoms, with mean values of Pt-N of 1.94 and $2.03 \AA$, respectively. The mean values of five-membered metallocyclic ring $\mathrm{N}-\mathrm{Pt}-\mathrm{N}$ angle is 80.8 (range $80.0^{\circ}-81.8^{\circ}$ ).

In those derivatives with diethylene triamine as the tridentae ligand, the central $\mathrm{N}$ atom of the chelate is again closer to the Pt(II) atom than the outer $\mathrm{N}$ atoms are, with mean Pt-N values of 1.99 and $2.05 \AA$, respectively. Both of these are somewhat longer than the terpyridine case in which $\pi$-effects are believed to play a role. The mean value of the five-membered metallocyclic N-Pt-N ring angle is also slightly larger at $84.7^{\circ}$ (range $84.3^{\circ}$ $85.7^{\circ}$ ). However it does mean than these derivatives are somewhat less distorted from the ideal square-planar geometry than the terpyridine derivatives.

There are over twenty $\operatorname{Pt}\left(\eta^{4}-\mathrm{NL}\right)$ derivatives in which a single tetradentate ligand provides a square-planar environment around a Pt(II) atom. These derivatives are divided into two groups, one with three metallocyclic rings (8 examples) and the other with four metallocyclic rings (15 examples). In the four derivatives of the former type of derivative, three five-membered metallocyclic rings are found with mean intra Pt-N bond distances of $1.985 \AA$ and mean inter Pt-N bond distances of $2.045 \AA$. The N-Pt-N bond angles range from $78.5(3)^{\circ}$ to $88.9(4)^{\circ}$ with the mean value of $82.8^{\circ}$. The remaining four derivatives of this type have a middle six-membered metallocycle and two outer five-member chelate rings with mean N-Pt-N values of $97.6^{\circ}$ and $79.6^{\circ}$, respectively. The mean Pt-N bond distances are $1.99 \AA$ for intra-N atoms and $2.01 \AA$ for inter-N atoms. In one derivative $\left[\mathrm{Pt}\left(\eta^{4} \text {-AID seco-corrinoid }\right)\right]^{+}$tetradentate ligand makes three six-membered rings with $\mathrm{N}-\mathrm{Pt}-\mathrm{N}$ bond angles of $91^{\circ}$ (central), $89^{\circ}$ and $91^{\circ}$ (outer) and mean Pt-N bond distances of $2.00 \AA$ (metallocycle) and $2.02 \AA$.

In the second group with four metallocyclic rings the most common are those which form two pairs of rings, five- and six-membered in trans positions (7 examples). The mean N-Pt-N value for the former is $84.3^{\circ}$ (range $83^{\circ}$ to $85^{\circ}$ ) and for the latter is $95.5^{\circ}$ (range $95^{\circ}$ to $96.4^{\circ}$ ), as expected. The mean Pt-N bond distance is $2.04 \AA$ (range 1.97 to $2.10 \AA$ ). In $\operatorname{Pt}\left(\eta^{4}\right.$-tetrapropylporphycene) has a 16-membered macrocycle which creates two pairs of metallocyclic rings, five- and seven-membered in trans positions with mean values of $84.9^{\circ}$ and $95.1^{\circ}$, respectively. In the remaining seven derivatives of this group a 16-membered macrocycle creates four six-membered metallocyclic rings with $\mathrm{Pt}(\mathrm{II})$ atoms of mean $\mathrm{N}-\mathrm{Pt}-\mathrm{N}$ value of $90.0^{\circ}$ (range $88^{\circ}$ to $92^{\circ}$ ) and the mean $\mathrm{Pt}-\mathrm{N}$ bond distance of $2.00 \AA$ (range 1.97 to $2.035 \AA$ ).

There are almost thirty, mostly black, derivatives where four cyamide groups are arranged in a square planar geometry around a $\mathrm{Pt}(\mathrm{II})$ atom $\left(\mathrm{PtC}_{4}\right)$. For half of them only unit cell parameters are reported in the original papers. For the others the Pt-C(N) bond distances range from 1.93 to $2.15 \AA$ with an average value of $1.99 \AA$. The cis and trans C-Pt-C bond angles range from $86^{\circ}$ to $94^{\circ}$ /average $90^{\circ}$ and $176^{\circ}$ to $180^{\circ}$, respectively.

In another thirty derivatives with colors from red to yellow, four chlorine atoms create a square-planar environment for the $\mathrm{Pt}(\mathrm{II})$ atom. The $\left[\mathrm{PtCl}_{4}\right]^{2-}$ anions exist in the crystal state only with bulky ligand cations [2]. The mean Pt-Cl bond distance is $2.30 \AA$ (range 2.23 zo $2.32 \AA$ ). The cis and trans Cl-Pt-Cl bond angles depart from the ideal values of $90^{\circ}$ and $180^{\circ}$ by $1.9^{\circ}$ and $2.9^{\circ}$, respectively. Thus the $\mathrm{PtCl}_{4}$ anionic moiety is somewhat less distorted than the tetra-cyano analogue (vide supra). The mean Pt-Cl bond distance is about $0.3 \AA$ longer than the Pt-C bond distance, in correlation with the respective covalent radii of the donor atoms of $0.99 \AA$ for $\mathrm{Cl}$ and $0.77 \AA$ A for C.

There are more than sixty derivatives in which square-planar geometry is realized by mono-, bi- and tetradentate S-donor ligand. Thirteen derivatives have only monodentate ligands, $\mathrm{Pt}\left(\eta^{1}-\mathrm{SL}\right)_{4}$. The Pt(II)-S bond distances range from 2.30 to $2.34 \AA$ (average $2.32 \AA$ ). The maximum deviation of cis and trans S-Pt-S bond angles from 
the ideal values of $90^{\circ}$ and $180^{\circ}$ are $9^{\circ}$ and $10^{\circ}$, respectively. Two derivatives use one bidentate and two monodentate ligand to form a distorted square planar geometry about each Pt(II) atom. In one the geometry about the $\mathrm{Pt}(\mathrm{II})$ atom is more distorted than in other. This is because of the chelate rings, which is in the former is fourmembered and in the latter six-membered, with S-Pt-S bite angles of $75.6^{\circ}$ and $88.6^{\circ}$, respectively.

The most common derivative are those with a pair of bidentate ligands about the $\mathrm{Pt}(\mathrm{II})$ atoms. The size of the chelate rings include four-membered moieties (7 examples) with a mean Pt-S bond distance of $2.32 \AA$ and S-Pt-S bite angle of $75.0^{\circ}$ for $\mathrm{RCS}_{2}$ ligands and $2.34 \AA$ and $83.6^{\circ}$, respectively for $\mathrm{RPS}_{2}$ ligands. In the $\left[\mathrm{Pt}\left(\eta^{2}-\mathrm{S}_{4}\right)_{2}\right]^{2-}$ anion the mean S-Pt-S bite angle is $93.4^{\circ}$.

A $\left[\mathrm{Pt}\left(\eta^{2}-\mathrm{C}_{5} \mathrm{H}_{9} \mathrm{~S}_{2}\right)\left(\eta^{2}-\mathrm{C}_{5} \mathrm{H}_{9} \mathrm{~S}_{3}\right)\right.$ has a distorted square planar arrangement of four- (the former ligand) and five(the latter ligand)-membered chelate rings. The S-Pt-S bite angles within the two rings are $73.0^{\circ}$ and $93.6^{\circ}$, respectively, and the two Pt-S bond distances are correspondingly different at 2.323 and $2.242 \AA$, respectively.

In thirty derivatives two bidentate ligands form two five-membered rings about the $\mathrm{Pt}(\mathrm{II})$ atoms, and represent the most common arrangement for the $\mathrm{PtS}_{4}$ chromophores. The Pt-S bond distances range from 2.24 to $2.32 \AA$ with a mean value of $2.29 \AA$. The S-Pt-S bond angles range from $86.5^{\circ}$ to $92.0^{\circ}$ (average $89.3^{\circ}$ ).

There are some derivatives ( 3 examples) in which a pair of bidentate ligands form two six-membered chelate rings. All three differ in the ring atoms involved with the ring angle opens in the order: $90.0^{\circ}$ (SPNPS) $<92.7^{\circ}$ $(\mathrm{SCNCS})<97.5^{\circ}\left(\mathrm{SC}_{3} \mathrm{~S}\right)$. In the same order the mean Pt-S bond distance shortened: $2.335 \AA>2.295 \AA>2.280$ Å.

In the remaining nine derivatives a tetradentate ligand is bonded to the $\mathrm{Pt}(\mathrm{II})$ atom. In one derivative the tetradentate 1,3-bis(2-mercaptophenylthio)-2-propanol ligand forms three chelate rings, two five-membered and one six-membered, with the angles of $89.3^{\circ}$ and $90.2^{\circ}$, respectively. In all others a tetradentate ligand creates four chelate rings about the $\mathrm{Pt}(\mathrm{II})$ atom. In another two derivatives the macrocycles creating four five-membered rings of mean S-Pt-S bond angle of $88.9^{\circ}$ and the mean Pt-S bond distance of $2.287 \AA$. There is also example, in which macrocycle forms four six-membered chelate rings with a mean S-Pt-S value of $98.9^{\circ}$. In another derivative are present two pairs of non-equivalent chelate rings (five- and seven-) in trans position with an $87.5^{\circ}$ angle and $92.8^{\circ}$, respectively. In two derivatives tetradentate macrocycles create also pairs of non-equivalent chelate rings of six- and eight-members in trans related positions. Finally there is an example, with three five- and one ten-membered chelate rings.

There are forty Pt(II) derivatives mostly colorless with mono-, bi- and tetradentate P donor ligands, bidentate being most common. In eight derivatives four monodentate ligands form a square planar arrangement about the $\mathrm{Pt}(\mathrm{II})$ atom. The mean Pt-P bond distance is $2.32 \AA$ (range 2.20 to $2.37 \AA$ ). The deviations of cis and trans P-Pt-P bond angles from ideal $\left(92^{\circ}\right.$ and $\left.180^{\circ}\right)$ are $4^{\circ}$ and $13^{\circ}$.

Four derivatives contain two bidentate ligands, both PNP, forming four-membered metallocyclic rings with a mean P-Pt-P angle of $70.4^{\circ}$. The mean Pt-P bond distance is $2.298 \AA$. In another two derivatives two bidentate ligands, both PCP, give four-membered rings with mean P-Pt-P angle of $70.7^{\circ}$ and mean Pt-P bond distance of $2.313 \AA$. Two dissimilar bidentate ligands are found in five derivatives with a distorted square planar geometry around the Pt(II) atoms. In each derivative there is a four-membered ring, PNP plus five-PCCP; PCP plus PCCP; PNP plus PCHCP; and PNP plus PNPNP. The bond distances and angles reflect the covalent radii of the atoms involved. Fourteen derivatives have a pair of bidentate ligands, both PCCP, given five-membered metallocyclic rings with mean P-Pt-P angles of $84.3^{\circ}$ (range $82.0^{\circ}$ to $86.3^{\circ}$ ). The mean Pt-P bond distances range from 2.280 to $2.335 \AA$ (average $2.31 \AA$ ).

Pair of six-membered metallocyclic rings is found in three derivatives with mean P-Pt-P angles of $90.0^{\circ}$ (POBOP) in two derivatives, and $80.7^{\circ}$ (PCNCP) in the third one. The mean Pt-P bond distance is $2.31 \AA$ (range 2.297 to $2.314 \AA$ ).

There are three derivatives which contain a tetradentate ligand. In two of them a macrocycle forms three fivemembered rings with mean P-Pt-P angle of $84.3^{\circ}$. The mean Pt-P bond distance $2.266 \AA$ for intra $\mathrm{P}$ atoms are shorter by $0.006 \AA$ than those for inter P atoms (2.327 $\AA$ ), as expected. In the third derivative a 14-membered macrocycle creates a five- and a six-membered chelate rings in trans positions about the central $\mathrm{Pt}(\mathrm{II})$ atom.

There are two examples which contain $\left[\mathrm{PtBr}_{4}\right]^{2-}$ anion. The mean Pt-Br bond distance is $2.42 \AA$. The cis- and tras $\mathrm{Br}-\mathrm{Pt}-\mathrm{Br}$ angles depart from the ideal values $\left(90^{\circ}\right.$ and $\left.180^{\circ}\right)$ by $1.4^{\circ}$ and $2.8^{\circ}$, respectively.

There are seven derivatives with the $\mathrm{PtSe}_{4}$ chromophore. In one of them four selenourea molecules form a square planar geometry about Pt(II) with mean Pt-Se bond distance of $2.44 \AA$. The cis and trans Se-Pt-Se bond angles deviate from ideal by $5^{\circ}$ and $7^{\circ}$, respectively. In another one two $\left(\mathrm{Bu}^{\mathrm{i}}\right)_{2} \mathrm{NCSe}_{2}$ ligands provide two four- 
membered chelate rings with the Pt(II) atom, the Se-Pt-Se bond angles have a mean value of $77.8^{\circ}$ and the two pair of Pt-Se bonds are at 2.426 and $2.429 \AA$.

The structure of the $\left[\mathrm{Pt}\left\{\eta^{2}-\mathrm{MeSe}\left(\mathrm{CH}_{2}\right)_{3} \mathrm{SeMe}\right\}_{2}\right]^{2+}$ cation shows the $\mathrm{Pt}(\mathrm{II})$ atom occupying a crystallographic inversion centre and coordinated to an array of four Se donor ligands with Pt-Se distances of 2.414 and $2.421 \AA$. The angles around the central $\mathrm{Pt}(\mathrm{II})$ atom do not deviate significantly from $90^{\circ}$ or $180^{\circ}$, reflecting the good match of the six-membered chelate rings formed by the diseleno ligands.

In two derivatives, where two bidentate $\mathrm{N}\left(\mathrm{SePPH}_{2}\right)_{2}$ ligands are bonded to a $\mathrm{Pt}(\mathrm{II})$ atom there is a moticeable distortion in the coordination geometry with ligand bite angles of $99.5^{\circ}$ and other angles being $80.5^{\circ}$. Structure of $\left[\mathrm{Pt}\left\{\eta^{4}-[16]-\mathrm{aneSe}_{4}\right\}\right]^{2+}$ is shown in Figure 4 [9]. The $\mathrm{Pt}(\mathrm{II})$ atom lies precisely in the $\mathrm{Se}_{4}$ coordination plane. The Se-Pt-Se angles are all within $1.2^{\circ}$ of the ideal values of $90^{\circ}$ and $180^{\circ}$, indicating a good size match between the crown and the $\mathrm{Pt}(\mathrm{II})$ radius. In $\left[\mathrm{Pt}\left\{\eta^{4}-[16] \mathrm{aneSe} \mathrm{S}_{4}\right\}\right]^{2+}$ the $\mathrm{Pt}(\mathrm{II})$ atom lies precisely in the $\mathrm{Se}_{4}$ coordination plane. The Se-Pt-Se angles are all within $1.2^{\circ}$ of the ideal values of $90^{\circ}$ and $180^{\circ}$, indicating a good size match between the crown and the $\mathrm{Pt}(\mathrm{II})$ radius.

Only one derivative exists with a $\mathrm{PtAs}_{4}$ chromophore. Here the $\mathrm{Pt}(\mathrm{II})$ atom is in approximately square planar geometry, bonded to four As atoms from two o-phenylenebisdimethylarsine ligands. The five-membered ligand bite angles are $84.2^{\circ}$ and the other angles are $97.1^{\circ}$. The mean Pt-As bond distance is $2.375 \AA$.

The overall data in 2.3 chapter includes over four hundred and thirty $\mathrm{Pt}(\mathrm{II})$ complexes $\left(\mathrm{PtA}_{4}\right)$. The frequency of examples for the donor atoms are: $\mathrm{As}(1)<\mathrm{Br}(2)<\mathrm{O}(4)<\mathrm{Se}(7)<\mathrm{Cl}(30)<\mathrm{CN}(31)<\mathrm{P}(41)<\mathrm{S}(63)<\mathrm{N}(258)$. The ligands range from monodentate through bi-, tri- and tetradentate. There is a tendency for Pt-L to increase in value with the covalent radius of the coordinating atom. In the N-donor ligand series it is also noted that the unsaturated ligands have smaller Pt-N bond distances than the saturated ligand as expected. The mean Pt-L bond distances of the monodentate ligands are in the sequence: $2.03 \AA(\mathrm{N}, 0.75 \AA)<2.30 \AA(\mathrm{Cl}, 0.99 \AA)<2.32 \AA$ (S, $1.02 \AA)<2.33 \AA(\mathrm{P}, 1.06 \AA)<2.42 \AA(\mathrm{Br}, 1.14 \AA)<2.44 \AA$ (Se, $1.16 \AA)$. A somewhat shorter value is observed for Pt-C in the cyanide derivative of $1.99 \AA$. The Pt(II)-L bond distances of the bidentate (chelate) ligands are in the sequence: $2.00 \AA$ (NL, unsaturate) $<2.03 \AA(\mathrm{OL})<2.04 \AA\left(\mathrm{RNH}_{2}, \mathrm{NH}_{3}\right)<2.05 \AA$ (NL, saturated) $<2.30 \AA$ $(\mathrm{SL})<2.32 \AA$ (PL). The chelate L-Pt(I)-L ring angle values for four-membered opens in the order: $69.0^{\circ}$ (PNP) $<70.8^{\circ}(\mathrm{PCP})<74.7^{\circ}(\mathrm{PBP})<75.0^{\circ}(\mathrm{SCS})<83.6^{\circ}(\mathrm{SPS})$; for five-membered: $79.0^{\circ}\left(\mathrm{NC}_{2} \mathrm{~N}\right.$, unsaturate $)<81.3^{\circ}$ $\left(\mathrm{OC}_{2} \mathrm{O}\right)<83.3^{\circ}\left(\mathrm{NC}_{2} \mathrm{~N}\right.$, saturate $)<84.2^{\circ}\left(\mathrm{PC}_{2} \mathrm{P}\right)<86.5^{\circ}(\mathrm{SCPS})<89.3^{\circ}\left(\mathrm{SC}_{2} \mathrm{~S}\right)<93.4^{\circ}\left(\mathrm{SS}_{2} \mathrm{~S}\right)<93.6^{\circ}\left(\mathrm{SSCS}^{\circ}\right.$; and for six-membered: $86.5^{\circ}$ (PNPNP) $<88.5^{\circ}(\mathrm{PCHCP})<89.5^{\circ}\left(\mathrm{NC}_{3} \mathrm{~N}\right)<91.3^{\circ}\left(\mathrm{PC}_{3} \mathrm{P}\right)<93.7^{\circ}\left(\mathrm{SC}_{3} \mathrm{~S}\right)<94.8^{\circ}$ $\left(\mathrm{OC}_{3} \mathrm{O}\right)$. The chelate ring angles close with increasing covalent radii of the atoms involved in these rings, but opens with increasing number of atoms as expected.

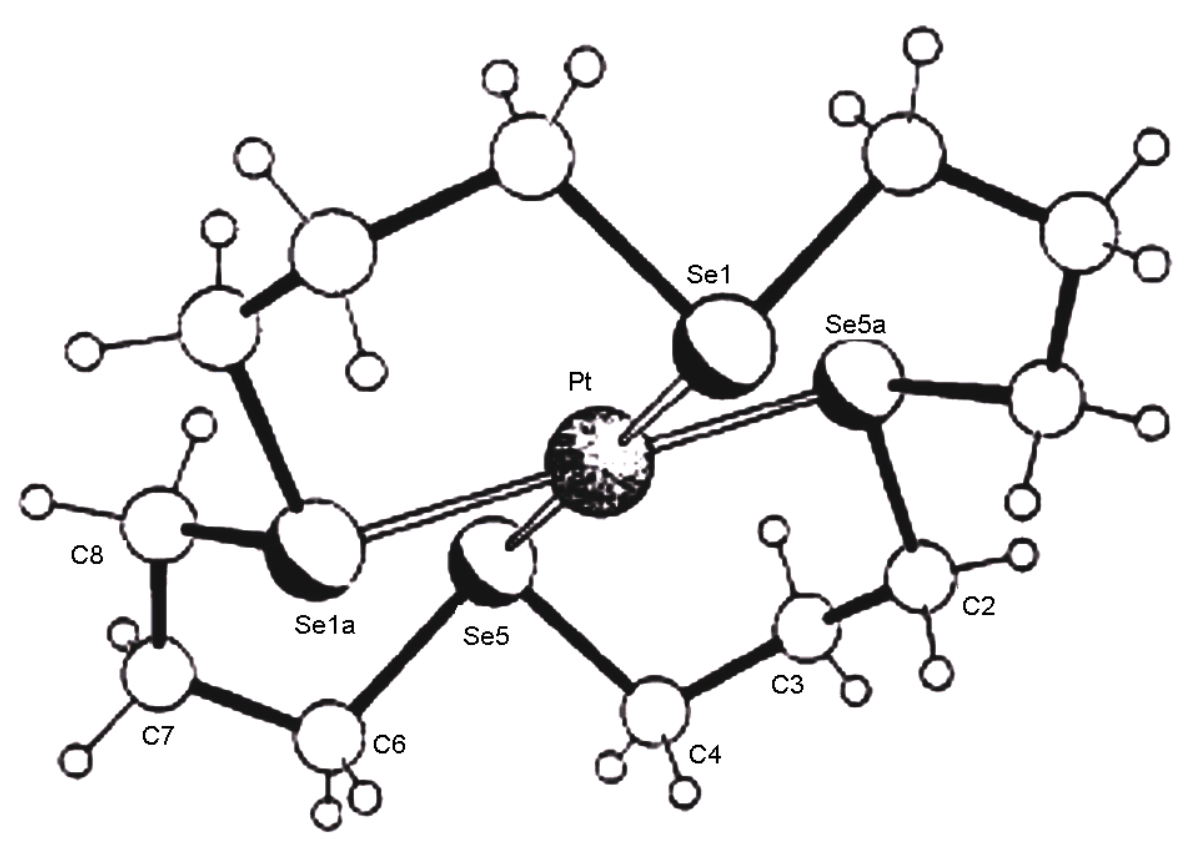

Figure 4. Structure of $\left[\operatorname{Pt}\left\{\eta^{4}-[16]-\mathrm{aneSe}_{4}\right\}\right]^{2+}[7]$. 
There are two types of tridentate ligands, both with $\mathrm{N}$-donor atoms, terpyridine and diethylenetriamine. The former is unsaturated and the latter is saturated, and the electronic effects can be seen in both the Pt-N bond distances and the N-Pt-N ring angles. In the former the Pt-N bond distances are shorter and the chelate ring angle smaller than in the latter. In both the Pt-N bond distances with the central $\mathrm{N}$ atom are shorter/(mean value 1.94 and $2.03 \AA$ ) than with the outer $\mathrm{N}$ atoms (mean values 1.99 and $2.05 \AA$ ) of the ligand. The respective N-Pt-N ring angles are $80.8^{\circ}$ and $84.6^{\circ}$, respectively.

There are three types of homo-tetradentate ligands with $\mathrm{N}, \mathrm{S}$ and $\mathrm{P}$ donor atoms. The mean Pt-N bond distances and N-Pt-N chelate ring angles are $2.01 \AA$, $83.8^{\circ}$ (five-) and $93.0^{\circ}$ (six-membered rings). The mean Pt-S and S-Pt-S values are $2.30 \AA, 88.6^{\circ}$. The mean Pt-P and P-Pt-P values are $2.29 \AA$ and $84.3^{\circ}$.

\subsection{2. $\mathrm{PtO}_{3} \mathrm{X}(\mathrm{X}=\mathrm{N}, \mathrm{P}, \mathrm{Br}$ or $\mathrm{I}), \mathrm{PtN} \mathrm{N}_{3} \mathrm{X}(\mathrm{X}=\mathrm{O}, \mathrm{C}, \mathrm{Cl}, \mathrm{S}, \mathrm{Br}$ or I $)$}

There are over one hundred and seventy derivatives of the composition $\operatorname{Pt}_{3} \mathrm{~B}$. Their structural parameters were detail classified and analyzed in [3] and therefore in this section will be only in short version outline.

Only four derivatives of $\mathrm{PtO}_{3} \mathrm{X}$ composition are known. In one derivative the 2,6-pyridine dicarboxylate(-2)anion acts as a tridentate ligand via the ring $\mathrm{N}$ atom and an $\mathrm{O}$ atom from each of the carboxylate groups. The water molecule completes the square planar geometry about the Pt(II) atom. The tridentate ligand creates two five-membered metallocyclic rings with the mean O-Pt-N bite angle of $81.9 \AA$. The central Pt-N bond distance of $1.898 \AA$ is about $0.130 \AA$ shorter than the outer Pt-O bonds ( $2.028 \AA$ ave). The $\mathrm{Pt}-\mathrm{OH}_{2}$ bond distance is $2.053 \AA$ A.

The other three derivatives have the composition $\mathrm{Pt}\left(\eta^{2}\right.$-hfac $)\left(\eta^{1}-\mathrm{hfac}\right) \mathrm{X}\left(\mathrm{X}=\mathrm{Pcy}_{3}, \mathrm{Br}\right.$ or I) and are isostructural. The mean Pt-O bond distances for bidentate hexafluoropentadionate (hfac) and $2.005 \AA$ for monodentate (hfac). The mean value of the O-Pt-O bite angle is $92.0^{\circ}$ (six-membered ring). The Pt-X bond distance elongated in the order: $2.232 \AA(\mathrm{X}=\mathrm{P})<2.395 \AA(\mathrm{Br})<2.567 \AA$ (I) which follow well covalent radii of the respective atoms.

Almost seventy derivatives have the composition $\mathrm{PtN}_{3} \mathrm{X}$. Fifteen have the $\mathrm{PtN}_{3} \mathrm{O}$ chromophore. In two of them cis- $\left[\mathrm{Pt}\left(\mathrm{NH}_{3}\right)_{2}(1-\mathrm{MeC})(\mathrm{OH})\right]^{+}$and cis- $\left[\mathrm{Pt}\left(\mathrm{NH}_{3}\right)_{2}(1-\mathrm{MeC}) \cdot\left(\mathrm{H}_{2} \mathrm{O}\right)\right]^{2+}$ a square planar geometry consists of four unidentate ligands. The mean Pt- $\mathrm{NH}_{3}$ bond distance is $2.027 \AA$ and $\mathrm{Pt}-\mathrm{N}(\mathrm{MeC})$ is $2.034 \AA$. The $\mathrm{Pt}-\mathrm{O}(\mathrm{H})$ and $\mathrm{Pt}-\mathrm{O}\left(\mathrm{H}_{2}\right)$ bond distances are 2.027 and $2.052 \AA$, respectively. The depart of the cis and trans angles from the ideal $\left(90^{\circ}\right.$ and $\left.180^{\circ}\right)$ are $2.3^{\circ}$ and $3.4^{\circ}$, respectively. Another six derivatives have the composition $\operatorname{Pt}\left(\mathrm{NH}_{3}\right)_{2}\left\{\eta^{2}-\right.$ $\mathrm{N}, \mathrm{O}(\mathrm{L})\}$ have a cis arrangement. The bidentate ligands create a five-membered metallocyclic ring about each $\mathrm{Pt}(\mathrm{II})$ atom with mean O-Pt-N bond angles of $83.1^{\circ}$ (range $81.0^{\circ}$ to $85.2^{\circ}$ ). Surprisingly perhaps the mean Pt-O and Pt-N bond distances of the bidentate ligands are the same of $2.018 \AA$ (range 1.980 - $2.055 \AA$ (O) and 1.95 $2.06 \AA(\mathrm{N}))$.

A square planar geometry with a $\mathrm{PtN}_{3} \mathrm{O}$ chromophore in one derivative is created by a bidentate ethylenediamine-N,N' molecule with a five-membered chelate ring (N-Pt-N, $\left.84.6^{\circ}\right)$ and monodentate uracylate- $\mathrm{N}$ and a water molecule. In the next set of derivatives (3 examples) a pair of non-equivalent bidentate ligands form a square planar arrangement about the Pt(II) atoms, with five-membered rings (N-Pt-N and N-Pt-O), in one example a five-(N-Pt-O) and six-(N-Pt-N) membered rings. Another three examples contain one tridentate (N-donor) and an O-donor ligand. Each of the tridentate ligands, terpyridine (trpy) or diethylenetriamine (dien) include the Pt(II) atom in a pair of five-membered rings with mean angles of $79.7^{\circ}$ (trpy) and $85.7^{\circ}$ (dien). These values reflect an electronic effect of the respective ligands, trpy-unsaturated in the first case and saturated dien in the latter two cases. This effect can, also be seen in the mean Pt-N bond distances of 1.92 and $2.07 \AA$ (trpy), and 1.99 and 2.05 $\AA$ (dien) for the central and satellite $\mathrm{N}$-atoms.

There is only one example with $\mathrm{PtN}_{3} \mathrm{C}$ chromophore, build up by bidentate o-phenantroline-N,N'ligand with average Pt-N bond distance of $2.032 \AA$, and one monodentate o-phenanthroline (Pt-N 2.053 $\AA$ ). The CN ligand completes the square planar arrangement about the Pt(II) atom (Pt-C $1.93 \AA$ ).

There are forty derivatives with the $\mathrm{PtN}_{3} \mathrm{Cl}$ chromophore. In twenty five derivatives a square planar arrangement about the $\mathrm{Pt}(\mathrm{II})$ atom is created by three unidentate $-\mathrm{N}$ donor ligands with the mean Pt-N bond distance of $2.12 \AA$ and a chlorine atom which completed a square-planar geometry. The mean Pt-Cl bond distance is 2.293 $\AA$. The cis and trans angles depart from the ideal values $\left(90^{\circ}\right.$ and $\left.180^{\circ}\right)$ by $2.2^{\circ}$ and $2.9^{\circ}$, respectively.

There are nine derivatives $\left[\mathrm{Pt}\left(\eta^{2} \text {-ethylenediamine }\right)\left(\eta^{1}-\mathrm{NL}\right) \mathrm{Cl}\right]^{+}$in which bidentate $-\mathrm{N}, \mathrm{N}^{\prime}$ ligand with monodentate $-\mathrm{N}$ donor ligand and a $\mathrm{Cl}^{-}$created a distorted square planar environment about each $\mathrm{Pt}(\mathrm{II})$ atom. The mean Pt-N(en), Pt-N (monodentate) and Pt-Cl bond distances are 2.045, 2.020 and 2.308 Å. The ethylenedia- 
mine created a five-membered metallocyclic ring with the mean N-Pt-N bite angle of $83.7^{\circ}$.

In another four derivatives tridentate terpyridine $-\mathrm{N}, \mathrm{N}^{\prime}, \mathrm{N}^{\prime}$ ligand with a chlorine atom created a distorted square planar geometry about Pt(II ) atom. The mean Pt-N bond distances are $1.94 \AA$ (central) and $2.02 \AA$ (outer) with the mean five-membered ring angle (N-Pt-N) of $81.2^{\circ}$. There is also an example in which diethylenetriamine acts as a tridentate ligand with the Pt-N (central) and mean PtN (outer) distances of 2.002 and $2.063 \AA$, which are somewhat longer than those found for terpyridine, as expected. Also the mean N-Pt-N bite angle is somewhat more open $\left(84.0^{\circ}\right)$.

There are two derivatives in which tridentate terpyridine ligand with monodentate $-\mathrm{S}\left(\mathrm{CH}_{2}\right)_{2} \mathrm{OH}$ ligand created a

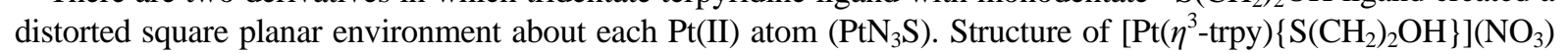
is shown in Figure 5 [10]. The Pt(II) atom is in slightly distorted square planar environment with the three $\mathrm{N}$ atoms of the terpyridine the $\mathrm{S}$ atom of mercaptoethanol. The average N-Pt-N angle is $80.7^{\circ}$ and the average $\mathrm{N}-\mathrm{Pt}-\mathrm{S}$ angle is $99.3^{\circ}$. The Pt-N bond distance to the central atom at $1.968 \AA$ is about $0.06 \AA$ shorter than to the outer $\mathrm{N}$ atoms (2.027 $\AA$ ). The Pt-S bond distance is 2.303(2) $\AA$.

In two derivatives, three $\mathrm{N}$ atoms of diethylenetriamine and one $\mathrm{Br}$ atom form a square planar geometry about the $\mathrm{Pt}(\mathrm{II})$ atom $\left(\mathrm{PtN}_{3} \mathrm{Br}\right)$. The mean Pt-N bond distances are 1.98 and $2.07 \AA$ for the central and outer $\mathrm{N}$ atoms, respectively. The N-Pt-N angles are $84.8^{\circ}$ and N-Pt-Br angles are $95.4^{\circ}$.

There are eight derivatives with a $\mathrm{PtN}_{3} \mathrm{I}$ chromophore. Two of them have monodentate ligands forming the square planar environment about the Pt(II) atom. The mean Pt-N and Pt-I bond distances are 2.04 and $2.565 \AA$, respectively. The cis and trans angles depart from the ideal $\left(90^{\circ}\right.$ and $\left.180^{\circ}\right)$ by $2.5^{\circ}$ and $3.9^{\circ}$. In another two derivatives one bidentate ethylenediamine $-\mathrm{N}, \mathrm{N}^{\prime}$ ligand and one pyridine plus the iodine atom form an approximate square planar environment with five-membered chelate ring of average N-Pt-N bite angle $89.3^{\circ}$. The mean Pt-N (en), Pt-N (py) and Pt-I bond distances are 2.055, 2.022 and $2.604 \AA$.

In the remaining four derivatives, substituted diethylenetriamine molecules coordinate in a tridentate fashion and with iodine atom complete the $\mathrm{PtN}_{3} \mathrm{I}$ chromophore. The mean Pt-N bond distances are $2.01 \AA$ (central) and $2.06 \AA$ (outer) with mean N-Pt-N bite angles of $85.0^{\circ}$ for five-membered chelate ring. The mean Pt-I bond distance is $2.591 \AA$.

The overall data in this subgroup shows the frequency of types of chromophore increasing in the order: $\mathrm{PtN}_{3} \mathrm{C}(1)<\mathrm{PtN}_{3} \mathrm{~S}(2) \sim \mathrm{PtN}_{3} \mathrm{Br}(2)<\mathrm{PtO}_{3} \mathrm{~N}(4)<\mathrm{PtN}_{3} \mathrm{I}(8)<\mathrm{PtN}_{3} \mathrm{O}(15)<\mathrm{PtN} \mathrm{Cl}_{3} \mathrm{Cl}(40)$. The mean Pt-N bond distance elongated in the order: $1.98 \AA\left(\eta^{3}\right.$-trpy $)<2.03 \AA$ (NL, $\eta^{3}$-dien $)<2.04 \AA\left(\mathrm{NH}_{3}, \eta^{2}\right.$-NL). The chelate fivemembered rings (N-Pt-N open in the order: $80.9^{\circ}\left(\eta^{3}\right.$-trpy) $<83.8^{\circ}\left(\eta^{2}\right.$-NL $)<85.3^{\circ}$ ( $\eta^{3}$-dien). In the series of monodentate ligands the mean Pt-L bond distance increases with increasing covalent radii of the coordinated atoms: $2.02 \AA(\mathrm{O}, 0.73 \AA)<2.03 \AA(\mathrm{N}, 0.75 \AA)<2.30 \AA(\mathrm{Cl}, 0.99 \AA)<2.42 \AA(\mathrm{Br}, 1.14 \AA)<2.59 \AA(\mathrm{I}, 1.33 \AA)$.

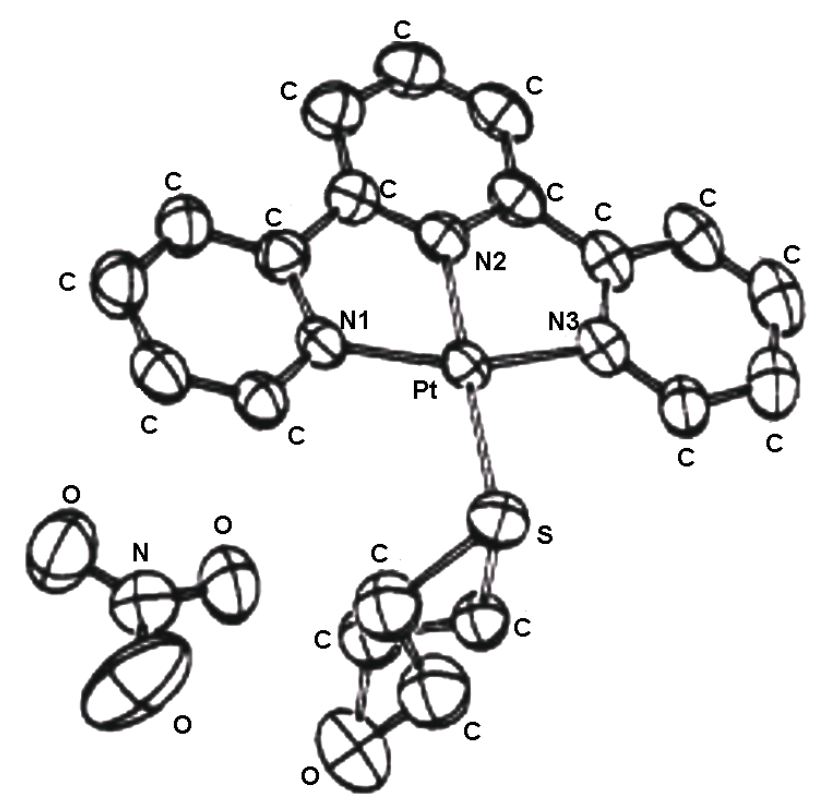

Figure 5. Structure of $\left[\mathrm{Pt}\left(\eta^{3}-\operatorname{trpy}\right)\left\{\mathrm{S}\left(\mathrm{CH}_{2}\right)_{2} \mathrm{OH}\right\}\right]\left(\mathrm{NO}_{3}\right)[9]$. 


\subsection{3. $\mathrm{PtCl}_{3} \mathrm{X}(\mathrm{X}=\mathrm{N}$, S or $\mathrm{P}), \mathrm{PtS}_{3} \mathrm{X}(\mathrm{X}=\mathrm{O}, \mathrm{N}, \mathrm{Cl}, \mathrm{P}, \mathrm{As}$ or $\mathrm{I})$}

The number of $\mathrm{PtCl}_{3} \mathrm{X}$ derivatives decreases in the order: $\mathrm{PtCl}_{3} \mathrm{~N}(30)>\mathrm{PtCl}_{3} \mathrm{~S}$ (15) $>\mathrm{PtCl}_{3} \mathrm{P}(2)$. Parts from $\mathrm{Cl}$ atoms, the most common monodentate ligands are $\mathrm{N}$-donor nucleobases, and dimethylsulphoxide as $\mathrm{S}$-donor. There is a trans effect on the Pt-Cl bond distances. The influence of the effect increases in the order: $\mathrm{N}<\mathrm{S}<\mathrm{P}$, increasing the Pt-Cl distances in the same order with the mean values $2.302 \AA$ (trans to $\mathrm{N}$ ) $<2.324 \AA$ (trans to S) $<2.380 \AA$ (trans to P). The mean values of the Pt-Cl distances trans to each other are essentially the same in all three types of chromophore, at $2.30 \AA$. The mean Cl-Pt-X angles also follow a similar trend, opening in the order: $89.4^{\circ}(\mathrm{X}=\mathrm{N})<91.0^{\circ}(\mathrm{X}=\mathrm{S})<91.5^{\circ}(\mathrm{X}=\mathrm{P})$. The mean Pt-L bond distance elongated in the order: $2.03 \AA$ $(\mathrm{NL})<2.205 \AA(\mathrm{SL})<2.215 \AA(\mathrm{PL})<2.30 \AA(\mathrm{Cl})$.

There are twelve examples with $\mathrm{PtS}_{3} \mathrm{X}$ chromophore (X = O (x2), N (x1), Cl (x3), P (x4), As nad I each (x1). There is complex, in which two 2-hydroxy-3-mercaptopyridine ligands, coordinated to $\mathrm{Pt}(\mathrm{II})$ only via the $\mathrm{S}$ atoms, while a third deprotonated, 2-hydroxy-3-mercaptopyridyne ligand chelates via the $\mathrm{S}$ and $\mathrm{O}$ atoms. This ambidentate behavior produced a slightly distorted square planar $\mathrm{PtS}_{3} \mathrm{O}$ coordination arrangement, and is the only example with such a chromophore. The mean Pt-S $\left(\eta^{1}-\mathrm{SL}\right)$ bond distance is $2.294 \AA$, and Pt-L $\left(\eta^{2}\right)$ bond distances are $2.284 \AA$ (S) and $2.049 \AA(\mathrm{O})$. The chelate ligand create five-membered metallocyclic ring with the S-Pt-O bite angle of $85.7^{\circ}$.

In another derivative 2,6-bis(methylthiomethyl)pyridine acts as a tridentate SNS ligand with the S atoms in trans positions to each other. The fourth coordination site, trans to the $\mathrm{N}$ atom, is occupied by the $\mathrm{S}$ atom of a SCN group. The Pt-S, Pt-N and Pt-S(CN) bond distances are $2.285 \AA$ (ave), 2.014 and $2.289 \AA$. The mean S-Pt-N angle is $85.7^{\circ}$.

There are three derivatives with the $\mathrm{PtS}_{3} \mathrm{Cl}$ chromophore. One has three monodentate $\mathrm{S}$ donor ligands $(\mathrm{N}-$ propyl-O-ethylthiocarbamate) plus the $\mathrm{Cl}$ atom. A second has one bi-( $\left.\mathrm{Et}_{2} \mathrm{NCS}_{2}\right)$ and one monodentate $\left(\mathrm{MeS}_{2} \mathrm{CNEt}\right)$ $\mathrm{S}$ donor ligands plus the $\mathrm{Cl}$ atom. The third has one tridentate $\mathrm{S}$ donor ligand (2,12-dimethyl-3,7,11-trithiadecane) (dmtt) plus the $\mathrm{Cl}$ atom. All create a distorted square planar environment about the $\mathrm{Pt}(\mathrm{II})$ atom.

Three derivatives of the composition $\left[\mathrm{Pt}\left(\eta^{3}-\mathrm{dmtt}\right) \mathrm{X}\right] \mathrm{BF}_{4}\left(\mathrm{X}=\mathrm{Cl}, \mathrm{PPh}_{3}\right.$ or I) are isostructural. The dmtt molecule in each coordinates in a tridentate fashion and forms two six-membered chelate rings about the $\mathrm{Pt}(\mathrm{II})$ atom. In another one derivative bidentate (EtO) ${ }_{2} \mathrm{PS}_{2}$ and monodentate (EtO) ${ }_{2} \mathrm{PS}_{2}$ plus $\mathrm{Ph}_{2} \mathrm{AsCH}_{2} \mathrm{CH}_{2} \mathrm{P}(\mathrm{S}) \mathrm{Ph}_{2}$ ligand created about the $\mathrm{Pt}(\mathrm{II})$ atom a distorted square planar $\mathrm{PtS}_{3} \mathrm{As}$ chromophore. The Pt-S distances trans to As is significantly longer $(2.373 \AA)$ than the other Pt-S distances (2.335 $\AA$ ave). The relevant S-Pt-S bite angle is $83.2^{\circ}$.

The relevant data in this subgroup show that the mean Pt-S bond distance elongated in the order: $2.304 \AA$ $\left(\eta^{3}-\mathrm{SL}\right)<2.305 \AA\left(\eta^{1}-\mathrm{SL}\right)<2.340 \AA\left(\eta^{2}-\mathrm{SL}\right)$. The mean value of the Pt-L bond distance for the monodentate ligands elongated in the order: $2.26 \AA(\mathrm{PL})<2.305 \AA(\mathrm{SL})<2.33 \AA(\mathrm{Cl})<2.35 \AA$ (AsL) $<2.60 \AA$ (I).

\subsection{4. $\mathrm{PtP}_{3} \mathrm{X}\left(\mathrm{X}=\mathrm{H}, \mathrm{F}, \mathrm{Cl}, \mathrm{S}, \mathrm{Br}\right.$ or I), $\mathrm{PtBr}_{3} \mathrm{X}$ ( $\mathrm{X}=\mathrm{N}$ or $\left.\mathrm{S}\right), \mathrm{PtI}_{3} \mathrm{X}(\mathrm{X}=\mathrm{P}$ or $\mathrm{Sb})$}

Thirty derivatives with $\mathrm{PtP}_{3} \mathrm{X}$ chromophores are known. Seven of them have $\mathrm{PtP}_{3} \mathrm{H}$ chromophore. In six $\mathrm{PtP}_{3} \mathrm{H}$ examples only monodentate $\mathrm{PR}_{3}(\mathrm{R}=\mathrm{Me}$, Et, $\mathrm{Ph}$ or cy) with $\mathrm{H}$ atom created a distorted square-planar environment about the $\mathrm{Pt}(\mathrm{II})$ atom. The Pt-P bond distances trans to the $\mathrm{H}$ atom are longer than the other, with mean values of $2.335 \AA$ and $2.290 \AA$, respectively. In one example a bidentate $\mathrm{P}_{7}$ ligand with $\mathrm{PPh}_{3}$ plus $\mathrm{H}$ atom create a distorted square planar geometry about the Pt(II) atom. The $\mathrm{P}_{7}$ ligand creates four-membered ring with the P-Pt-P bite angle of $78.2^{\circ}$. A similar effect was found in this derivative with Pt-P bond distances of $2.42 \AA$ (trans to $\mathrm{H}$ ) and $2.40 \AA$ (trans to $\mathrm{P}$ ).

Colorless $\left[\mathrm{Pt}\left(\mathrm{PEt}_{3}\right)_{3} \mathrm{~F}\right] \mathrm{BF}_{4}$ is the only example with the $\mathrm{PtP}_{3} \mathrm{~F}$ chromophore. The Pt-P bond distance trans to the $\mathrm{F}$ atom is $2.239 \AA$ which is about $0.098 \AA$ shorter than the other two with mean value of $2.337 \AA$ (trans to P).

There are fifteen derivatives with the $\mathrm{PtP}_{3} \mathrm{Cl}$ chromophore, by far the most common in this series. In eight of these, only monodentate ligands form a square planar environment about the $\mathrm{Pt}(\mathrm{II})$ atom. The remaining seven derivatives have one bidentate $-\mathrm{P}, \mathrm{P}^{\prime}$ with one monodentate $\mathrm{P}$ donor plus the $\mathrm{Cl}$ atom. There are four types of chelate ligands, those forming 4-membered PCP chelate rings (2 examples), with P-Pt-P bite angle of 71.5 ; 4membered $\mathrm{PN}$ ( 2 exemples) with bite angle of $70.0^{\circ} ; 5$-membered $\mathrm{PC}_{2} \mathrm{P}$ ( 2 examples) with bite angle of $85.8^{\circ}$, and 6-membered $\mathrm{PC}_{3} \mathrm{P}\left(1\right.$ example) with bite angle of $92.4^{\circ}$, respectively. For the monodentate ligands, the mean $\mathrm{Pt}-\mathrm{P}$ bond distance trans to the $\mathrm{Cl}$ atom is $2.24 \AA$. A similar trend is observed for the bidentate ligands (P,P') 
with the values of 2.24 and $2.295 \AA$, respectively. The mean Pt-Cl bond distance, which is trans to the P atom, is $2.345 \AA$.

There are three derivatives with the $\mathrm{PtP}_{3} \mathrm{~S}$ chromophore. In one derivative three $\mathrm{PMe}_{2} \mathrm{Ph}$ ligands plus $\mathrm{SO}_{2}$ form a distorted square planar arrangement about the $\mathrm{Pt}(\mathrm{II})$ atom. In another one two bidentate ligands $\left(\mathrm{Ph}_{2} \mathrm{PCH}_{2} \mathrm{PPh}_{2}-\mathrm{P}, \mathrm{P}^{\prime}\right.$, and $\left.\mathrm{Ph}_{2} \mathrm{PN}(\mathrm{Et}) \mathrm{C}=\mathrm{N}(\mathrm{Et}) \mathrm{S}-\mathrm{P}, \mathrm{S}\right)$ form such chromophore. The significant distortion from an ideal square planar arrangement of the donor atoms is apparently due to the P-Pt-P bite angles, $71.4^{\circ}$ (PCP) and $85.7^{\circ}$ (PNCS). In the third one derivative, tridentate $\mathrm{PhP}\left(\mathrm{CH}_{2} \mathrm{CH}_{2} \mathrm{PPh}_{2}\right)_{2}-\mathrm{P}, \mathrm{P}^{\prime}, \mathrm{P}^{\prime \prime}$ ligand with monodentate $\mathrm{Et}_{2} \mathrm{NCS}_{2}$-S donor atom created a distorted square planar geometry $\left(\mathrm{PtP}_{3} \mathrm{~S}\right)$. The tridentate ligand forms two fivemembered rings with the mean P-Pt-P bite angle of $85.0^{\circ}$. The trans influence of the $\mathrm{S}$ atom is not as simple as for the $\mathrm{Cl}$ atom. In the first $\mathrm{PtP}_{3} \mathrm{~S}$ derivative (all four ligands are monodentate) the Pt-P bond distance trans to $\mathrm{S}$ atom is $2.324 \AA$, which is $0.039 \AA$ longer than the other Pt-P bonds (2.324 $\AA$ ave). Conversely, in remaining two derivatives, the former Pt-P bond is shorter than the latter (Pt-P) with mean values of 2.268 and $2.298 \AA$, respectively.

There also three derivatives with $\mathrm{PtP}_{3} \mathrm{Br}$ chromophore. In two of them three monodentate ligands $\left(\mathrm{C}_{13} \mathrm{H}_{11} \mathrm{P}\right.$, $\mathrm{C}_{14} \mathrm{H}_{13} \mathrm{P}$ ) plus $\mathrm{Br}$ atom created a distorted square planar geometry about the $\mathrm{Pt}(\mathrm{II})$ atom. In remaining one derivative, one bidentate $-\mathrm{P}, \mathrm{P}^{\prime}\left(\mathrm{Bu}_{2}^{\mathrm{t}} \mathrm{PP}=\mathrm{PBu}_{2}^{\mathrm{t}}\right)$, one $\mathrm{PPh}_{3}$ plus $\mathrm{Br}$ atom form a distorted square planar geometry at the $\mathrm{Pt}(\mathrm{II})$ atom $\left(\mathrm{PtP}_{3} \mathrm{Br}\right)$. The mean Pt-P bond distance trans to the $\mathrm{Br}$ atom at $2.245 \AA$ is about $0.083 \AA$ shorter than the other Pt-P distances (2.328 $\AA$, ave).

There is only one example in which monodentate ligands form a distorted square planar geometry at the $\mathrm{Pt}(\mathrm{II})$ atom $\left(\mathrm{PtP}_{3} \mathrm{I}\right)$. The Pt-P bond distance trans to the I atom at $2.257 \AA$ is about $0.083 \AA$ shorter than the other Pt-P bond distances ( $2.343 \AA$, ave).

Overall, the data of $\mathrm{PtP}_{3} \mathrm{X}$ derivatives show that the mean Pt-L bond distance elongated with the covalent radius of the donor atom (in parentheses) except $\mathrm{Cl}$ and $\mathrm{S}$ atoms in the sequence: $1.75 \AA$ ( $\mathrm{H}, 0.37 \AA$ ) $<2.04 \AA$ (F, $0.72 \AA)<2.31 \AA(\mathrm{P}, 1.05 \AA)<2.345 \AA(\mathrm{Cl}, 0.99 \AA)<2.37 \AA(\mathrm{S}, 1.02 \AA)<2.53 \AA(\mathrm{Br}, 1.14 \AA)<2.64 \AA(\mathrm{I}$, $1.33 \AA)$.

There are seven derivatives with $\mathrm{PtBr}_{3} \mathrm{~N}$ chromophore. In one derivative the MeCN molecule acts as a $\mathrm{N}$ donor ligand with Pt-N bond distance of 1.98 the shortest in the $\mathrm{PtBr}_{3} \mathrm{~N}$ group. The $\mathrm{Pt}-\mathrm{Br}$ bond distance trans to NCMe ligand is $2.393 \AA$, which is shortest than the other $\mathrm{Pt}-\mathrm{Br}$ bond distances (2.429 $\AA$, ave). This difference of $0.036 \AA$ is the largest in this group, indicating the larger trans influence of the MeCN group than that of other $\mathrm{N}$-donor ligands, which have mean values of 2.420 and $2.425 \AA$, respectively. The Pt-N bond distances range from 2.00 to $2.02 \AA$ and Pt-Br from 2.417 to $2.432 \AA$.

There are two derivatives $\left[\mathrm{PtBr}_{3}\left(\mathrm{Et}_{2} \mathrm{SO}\right)\right]^{-}$and $\left[\mathrm{PtBr}_{3}\left(\mathrm{Ph}_{2} \mathrm{SO}\right)\right]^{-}$which have the chromophore $\mathrm{PtBr}_{3} \mathrm{~S}$ in a square planar geometry. The mean $\mathrm{Pt}-\mathrm{Br}$ bond distance trans to the $\mathrm{S}$ atom is $2.435 \AA$, somewhat longer than the other values (mean $2.420 \AA$ ). The Pt-S bond distances are $2.220 \AA$ (ave).

The largest donor atoms assemblies in this section are given by the chromophores $\mathrm{PtI}_{3} \mathrm{P}$ and $\mathrm{PtI}_{3} \mathrm{Sb}$. This have square planar geometries also, with the Pt-I bond distances trans to P atom of $2.662 \AA$ and trans to Sb atom of $2.637 \AA$. These are longer than the other Pt-I bond distances, which have mean values of 2.590 and $2.596 \AA$, respectively. The differences ( $0.072 \AA$ trans to $\mathrm{P}$ and $0.041 \AA$ trans to Sb) indicate a stronger trans effect for $\mathrm{PPh}_{3}$ than $\mathrm{SbPh}_{3}$. The Pt-P and Pt-Sb bond distances are 2.225 and $2.507 \AA$, respectively.

The overall of the data in 2.3.2, 2.3.3 and 2.3.4 subgroups includes over one hundred and seventy Pt(II) complexes of the composition $\mathrm{PtA}_{3} \mathrm{~B}$. Platinum(II) is considered a soft Lewis acid, but it interacts with a large number of Lewis bases from both soft through to hard. The number of derivatives with a particular A-donor donor increases in the order: $\mathrm{A}=\mathrm{I}(2)<\mathrm{O}(4)<\mathrm{Br}(9)<\mathrm{S}(11)<\mathrm{P}(30)<\mathrm{Cl}(47)<\mathrm{N}(68)$. The $\mathrm{B}$ type atoms are more variable. Noticeable, in the series of the $\mathrm{Pt}_{3} \mathrm{~B}$ type chromophores the distortion of the respective square planar geometry about the $\mathrm{Pt}(\mathrm{II})$ atom reflects the dentate of the coordinated ligands. The mean values of deviations of the cis and trans L-Pt-L bond angles from the ideal $\left(90^{\circ}\right.$ and $\left.180^{\circ}\right)$ are: $4.3^{\circ}$ and $1.7^{\circ}$ (L are monodentate) $<8.3^{\circ}$ and $7.3^{\circ}$ (one $\mathrm{L}$ forms 6 -membered ring) $<13.3^{\circ}$ and $7.4^{\circ}$ (5-membered ring) $<20.0^{\circ}$ and $8.6^{\circ}$ (4-membered ring). In the same order the distortion increases as expected.

\subsection{5. $\mathrm{PtH}_{2} \mathrm{P}_{2}, \mathrm{PtO}_{2} \mathrm{X}_{2}\left(\mathrm{X}=\mathrm{N}, \mathrm{Cl}, \mathrm{S}, \mathrm{P}\right.$ or As), $\mathrm{PtN}_{2} \mathrm{X}_{2}(\mathrm{X}=\mathrm{C}, \mathrm{Cl}, \mathrm{S}, \mathrm{P}, \mathrm{Br}$ or I)}

There are four hundred and twenty derivatives of the composition $\mathrm{PtA}_{2} \mathrm{~B}_{2}$. Their structural parameters were classified and analyzed in details [3] [4] and therefore in this chapter will be only briefly summarized.

There are three trans derivatives of the composition $\mathrm{Pt}(\mathrm{H})_{2}(\mathrm{PL})_{2}$. Two pairs of monodentate $\mathrm{H}$ atoms and $\mathrm{P}$ 
atoms $\left(\mathrm{PR}_{3}\right)$ form distorted a square planar geometry about the $\mathrm{Pt}(\mathrm{II})$ atom. Unfortunately, only for one derivative are data for Pt-H and H-Pt-H are given. The mean Pt-H bond distance is $1.55 \AA$ and the mean $\mathrm{H}-\mathrm{Pt}-\mathrm{P}\left(\mathrm{Pr}^{\mathrm{i}}\right)_{3}$ bond angle is $95^{\circ}$. The mean Pt-P bond distances for remaining two $\left(\mathrm{PMe}_{3}\right)$ and $\left(\mathrm{PBu}_{3}^{\mathrm{t}}\right)$ are 2.259 and $2.252 \AA$, respectively. The trans-P-Pt-P bond angle in both derivatives is exact linear, $180.0^{\circ}$.

There are one hundred and twenty six derivatives of the composition $\mathrm{PtO}_{2} \mathrm{X}_{2}$. The number of examples increases in the order of $\mathrm{X}$ atoms: $\mathrm{Cl}(2), \mathrm{As}(2)<\mathrm{S}(7)<\mathrm{P}(45)<\mathrm{N}(70)$. In this series the $\mathrm{PtO}_{2} \mathrm{~N}_{2}$ the derivatives can be divided into eight subgroups by the way in which the ligands are coordinated in a square planar fashion with varying degrees of distortion. The sug-groups are four monodentate ligands (1 example); monodentate O-donor and bidentate $\mathrm{N}$-donor ligands with a five-member chelate ring (5 examples); bidentate O-donor (fivemembered ring) and monodentate $\mathrm{N}$-donor ligands (5 examples); bidentate O-donor and $\mathrm{N}$-donor ligands with five-membered rings (8 examples); bidentate $\mathrm{O}$-donor with six-membered rings and bidentate $\mathrm{N}$-donor ligands with five-membered chelate rings (20 examples), bidentate O-donor (six- membered ring) and bidentate $\mathrm{N}$-donor (seven-membered rings (2 examples)); heterobidentate $\mathrm{O}, \mathrm{N}$-donors with five-membered rings (15 examples); tridentate $\mathrm{O}, \mathrm{N}$ ligand (five- and six-membered rings) plus a monodentate $\mathrm{N}$-donor ligand (1 example). Structure of $\operatorname{Pt}\left(\eta^{2}\right.$-cbdc) $\left(\eta^{2}-1,4\right.$-dach) is shown in Figure 6 as an example [11]. The $\operatorname{Pt}(\mathrm{II})$ atom has a slighly distorted square planar geometry with two adjacent corners being occupied by two $\mathrm{N}$ atoms of cis-1,4-dach (diaminocyclohexane) ligand. The remaining two corners are occupied by $\mathrm{O}$ atoms of the cbdc (1,1-cyclobutane dicarboxylate). The dach moiety is in a twist boat configuration. The data of 1,4-dach forms seven and the cbdc forms six membered rings with N-Pt-N $98.8(4)^{\circ}$ and O-Pt-O of $89.2(3)^{\circ}$. The mean value of the Pt-L bond distances elongated in the order: $1.97 \AA\left(\eta^{2}\right.$-N, unsaturated $)<2.04 \AA\left(\eta^{1}-\mathrm{OL}\right)$. The mean values of the Pt-O vs Pt-N bond distances in heterobi- and heterotridentate ligands are: 2.02 vs $2.00 \AA$ and 2.00 vs $2.02 \AA$, respectively. The chelate rings $(\mathrm{N}-\mathrm{Pt}-\mathrm{N})$ open in the order: $80.5^{\circ}$ (five-membered, unsaturated) $<83.8^{\circ}$ (five-membered saturated) $<92.8^{\circ}$ (six-membered) $<98.7^{\circ}$ (seven-membered). For O-Pt-N the values are: $81.3^{\circ}$ (five-) $<93.0^{\circ}$ (sixmembered).

Two examples are only derivatives of the $\mathrm{PtO}_{2} \mathrm{Cl}_{2}$ type. In one two derivative monodentate O-donor ligands and two $\mathrm{Cl}$ atoms in trans position form an almost ideal square planar geometry about the $\mathrm{Pt}(\mathrm{II})$ atom. In the other the oxalate ligand is a bidentate O-donor, giving a distorted square-planar arrangement with two $\mathrm{Cl}$ atoms in cis positions. The mean Pt-O and Pt-Cl bond distances are: $2.02 \AA\left(\eta^{1}-\mathrm{OL}\right)<2.035 \AA\left(\eta^{2}-\mathrm{OL}\right)<2.286 \AA(\mathrm{Cl})$. The O-Pt-O bite angle is $82.8(1)^{\circ}$.

In another seven derivatives a distorted square planar environment about the $\mathrm{Pt}(\mathrm{II})$ atom has a $\mathrm{PtO}_{2} \mathrm{~S}_{2}$ chromophore. Four molecules of dimethylsulphoxide (dmso) form a cis configuration about $\mathrm{Pt}(\mathrm{II})$ so that two of the ligands are O-donors while the other two, as is more common in platinum chemistry, act as S-donor ligands. In another case a pair of $\mathrm{NO}_{3}$ groups act as O-donors while a pair of dmso molecules act as S-donors. Two more derivatives have a bidentate O-donor ligands and monodentate S-donor ligands. The remaining three examples have a pair of heterobidentate, O- and S-donor ligands. The mean Pt-L bond distance elongated in the order: $2.025 \AA\left(\eta^{2}\right.$-OL $)<2.048 \AA\left(\eta^{1}\right.$-Odmso $)<2.214 \AA\left(\eta^{1}\right.$-Sdmso $)<2.329 \AA$ (SCN). The O-Pt-O and O-Pt-S bite angles are $88.3^{\circ}$ and $94.4^{\circ}$, respectively. The mean Pt-O and Pt-S values (for heterobidentate) are 2.00 nd $2.24 \AA$, respectively.

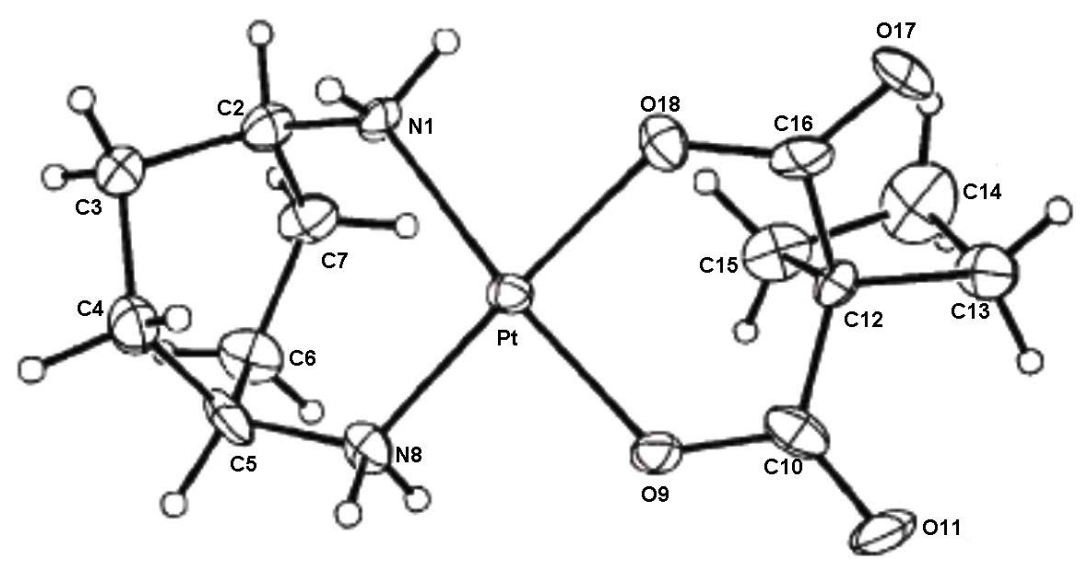

Figure 6. Structure of $\operatorname{Pt}\left(\eta^{2}\right.$-cbdc $)\left(\eta^{2}-1,4-\right.$ dach $)[11]$. 
There are forty five derivatives with the $\mathrm{PtO}_{2} \mathrm{P}_{2}$ square planar chromophore. A wide range of examples are found with various degrees of distortion from ideal geometry. Four monodentate ligands are used (2 examples); or one bidentate O-donor ligand, with two monodentate P-donor ligands, including four-membered chelate ring (8 examples), five-membered chelate ring (11 examples) or six-membered chelate ring (2 examples). Similarly, there are examples with a bidentate P-donor ligand plus two monodentate O-donor ligands: four-membered (1 example), or five-membered chelate ring (3 examples). Several examples have a bidentate O-donor plus a bidentate P-donor ligand: both five-membered chelate rings (3 examples); four-membered O-donor chelate ring plus a six-membered P-donor chelate ring (2 examples); seven-membered O-donor ring and five-membered P-donor ring (1 example), and eight-membered O-donor ring plus five-membered P-donor ring (1 example). Also there are mixed examples: two hetero-O,P-donor ligands with five-membered rings (seven examples), and a tridentate $\mathrm{O}, \mathrm{P}, \mathrm{P}^{\prime}$-donor ligand with five- and six-membered rings, O-Pt-P (1 example).

The most common ligands is the $\mathrm{RCO}_{2}$ group (four-membered chelate rings) and $\mathrm{PPh}_{3}$. The mean $\mathrm{Pt}-\mathrm{L}$ bond distance elongated in the sequence: $2.06 \AA\left(\eta^{2}-\mathrm{OL}\right)<2.11 \AA\left(\eta^{1}-\mathrm{OL}\right)<2.21 \AA\left(\eta^{2}-\mathrm{PL}\right)<2.24 \AA\left(\eta^{1}\right.$-PL $)$. The four-membered chelate rings open in the order: $65^{\circ}(\mathrm{OCO})<71.2^{\circ}(\mathrm{OPO})<74^{\circ}(\mathrm{PCP})<74.3^{\circ}(\mathrm{OSeO})$. For the five-membered chelate rings the order is: $78.0^{\circ}(\mathrm{ONNO})<80.5^{\circ}(\mathrm{OCNO})<81.8^{\circ}(\mathrm{OCCO})<84.2^{\circ}(\mathrm{OCCP})<$ $85.5^{\circ}(\mathrm{ONPP})<87.0^{\circ}(\mathrm{PCCP})$. The six-membered chelate rings are $86.0^{\circ}\left(\mathrm{OC}_{3} \mathrm{P}\right)$ and $95.8^{\circ}\left(\mathrm{PC}_{3} \mathrm{P}\right)$.

Two derivatives are found for the $\mathrm{PtO}_{2} \mathrm{As}_{2}$ square planar chromophore. In both examples only monodentate ligand are involved with mean $\mathrm{Pt}-\mathrm{O}$ and $\mathrm{Pt}-\mathrm{As}$ bond distances of 2.05 and $2.33 \AA$, respectively.

There are three hundred $\mathrm{PtN}_{2} \mathrm{X}_{2}$ (X = C (x7), N (x190), S (x34), $\mathrm{P}(\mathrm{x} 40), \mathrm{Br}(\mathrm{x} 10)$, I (x19) for which structural parameters are available. There are only seven derivatives with the $\mathrm{PtN}_{2} \mathrm{C}_{2}$ chromophore and a square-planar geometry. In only one derivative two monodentate $\mathrm{N}$-donor ligands with two $\mathrm{CN}$ groups create a square-planar geometry about Pt(II) atom. The Pt-N and the mean Pt-C bond distances are $2.045 \AA\left(\mathrm{NH}_{3}\right), 2.047 \AA\left(\mathrm{NH}_{2} \mathrm{Me}\right)$ and $1.978 \AA(\mathrm{CN})$. In the remaining six derivatives a pair of bidentate N-donor ligand (mostly 2,2'-bipyridine) with two CN groups create a distorted square planar geometry about the Pt(II) atom. The mean Pt-N and Pt-C bond distances are 2.035 and $1.95 \AA$. The five-membered chelate rings have the mean N-Pt-N bite angles of $80.0^{\circ}$.

There are over one hundred and eighty derivatives with the $\mathrm{PtN}_{2} \mathrm{Cl}_{2}$ chromophore. Those derivatives can be divided into two main types, the first with only monodentate ligands with both cis and trans arrangements (112 examples) and the second with bidentate N,N'-donor ligands.

There are three types of bidentate ligands, the majority giving a five-membered chelate ring with $\mathrm{Pt}(\mathrm{II})$ atom (65 examples), some with a six-membered ring (10 examples) and a few with a seven-membered ring (4 examples). With such a high number (over 180) of derivatives especially those with a $\mathrm{PtN}_{2} \mathrm{Cl}_{2}$ chromophore, one of the main goals has been a search for a soluble less toxic analogue of cis platin. The establishment of a relationship between structure and antitumor activity and the bonding possibilities to nucleic acid derivatives, have also been major objectives in the synthesis and characterization of these new $\operatorname{Pt}(\mathrm{II})$ compounds.

The mean Pt-N bond distances for monodentate N-donor ligands are somewhat shorter in cis than in trans derivatives, with values 1.990 vs $1.995 \AA$ (NL-unsaturated); 2.05 vs $2.06 \AA$ (NL, saturated). On the other hand the mean Pt-Cl values are 2.295 vs $2.290 \AA$. These values are somewhat shorter than those for Pt-Cl bonds found in cis derivatives involving a bidentate $\mathrm{N}, \mathrm{N}$-donor ligand. The mean $\mathrm{Pt}-\mathrm{Cl}$ bond distance elongated with a closing of the bidentate chelate ring angle as a result of steric interactions: $2.295 \AA$ (seven-) $<2.315 \AA$ (six-) $<2.340 \AA$ (five-membered chelate ring). The mean Pt-N bond distances and the N-Pt-N bite angles reflect both steric and electronic effects. The mean values are $2.00 \AA$ and $80^{\circ}$ (NL, unsaturated, $2.05 \AA$ and $83.8^{\circ}$ for NL-saturated), both with five-membered chelate ring. The values for six- and seven-membered chelate rings are $2.03 \AA$ and $90.5^{\circ}$, and $2.01 \AA$ and $88.5^{\circ}$, respectively.

There are over thirty derivatives with the $\mathrm{PtN}_{2} \mathrm{~S}_{2}$ chromophore. The types of ligand situations found in these derivatives can be separated into the following: mono $\mathrm{N}$-donors with mono S-donor ligands (5 examples); mono $\mathrm{N}$-donor with bidentate S-donor lignds (four-membered) (2 examples); bidentate $\mathrm{N}$-donor (five-) and bidentate S-donor (four-membered); (2 examples); bidentate N-donor and bidentate S-donor (both five-membered) (5 examples); heterobidentate N,S-donors (five-membered) (7 examples); tri-derivative S, N, S donor (six-membered) plus monodentate $\mathrm{N}$ donor (2 examples); tetra-derivative $\mathrm{S}, \mathrm{N}, \mathrm{N}, \mathrm{S}$-donor (five-membered rings) (1 example); tetra N, N, S, S (five- and eight-membered) (1 example), and tetra derivative N,N,S,S (six- and eight-membered) (1 example).

There are cis (24 examples) and trans (9 examples). The mean Pt-N bond distances are $2.057 \AA\left(\eta^{1}-\mathrm{NL}\right)$ and 
$2.06 \AA\left(\eta^{2}\right.$-NL). The mean Pt-S bond distances are $2.245 \AA$ ( $\eta^{2}$-SL, five-) and $2.270 \AA$ ( $\eta^{2}$-SL, four-membered chelate ring). For heterobidentate N,S the mean Pt-N and Pt-S bonds are 1.98 and $2.29 \AA$ ). The mean values for tridentate $\mathrm{NS}_{2}$ ligands, Pt-N vs Pt-S bonds are 1.99 vs $2.29 \AA$. The mean values for cis tetradentate $\mathrm{N}_{2} \mathrm{~S}_{2}(\mathrm{Pt}-\mathrm{N}$ vs Pt-S) are 1.97 vs $2.25 \AA$. For trans tetradentate $\left(\mathrm{N}_{2} \mathrm{~S}_{2}\right)$ the values are 2.02 vs $2.29 \AA$. The mean values of the L-Pt-L bite angles open in the order: $77.0^{\circ}(\mathrm{SCS})<91.5^{\circ}(\mathrm{NCCN})<82.5^{\circ}(\mathrm{NNCS})<85.3^{\circ}(\mathrm{NCCS})<89.0^{\circ}$ $(\mathrm{SCCS})<92.0^{\circ}(\mathrm{NCCCN})<102.4^{\circ}\left(\mathrm{SC}_{2} \mathrm{SC}_{2} \mathrm{~S}\right)$.

There are thirty six derivatives with the $\mathrm{PtN}_{2} \mathrm{P}_{2}$ chromophore. Each $\mathrm{Pt}(\mathrm{II})$ atom has a square planar environment with varying degree of distortion. The ligand arrays can be subdivided into several groups: all monodentate ligands (14 examples); monodentate $\mathrm{N}$-donors and bidentate P-donors with five-membered rings (3 examples); the same but six-membered rings (4 examples); bidentate (five-membered $\mathrm{N}$-donors with bidentate (five-membered ring) P-donors (4 examples); heterobidentate N,P-donors with five-membered rings (6 examples), and the same with six-membered rings (1 example). Structure of $\mathrm{Pt}\left\{\eta^{2}-(\mathrm{HN})_{2} \mathrm{SO}_{2}\left(\mathrm{PMePh}_{2}\right)_{2}\right.$ is shown in Figure 7 [12] as an example. The $\mathrm{PtN}_{2} \mathrm{~S}$ ring is essentially planar with a maximum deviation of $0.03 \AA$ from the plane, the $\mathrm{O}_{2}$ atoms lying equidistant above and below the plane. The ring is rotated about $5^{\circ}$ with respect to the $\mathrm{P}(1)-\mathrm{Pt}-(\mathrm{P}(2)$ plane. The mean Pt-L bond distances for monodentate ligands (cis vs trans) are 2.08 vs $2.00(\mathrm{~L}=\mathrm{N})$ and 2.27 vs 2.34 $\AA(\mathrm{L}=\mathrm{P})$. While the Pt-N bond distance is shorter in cis than trans, the opposite is true for the Pt-P bonds. The mean Pt-L bond distances for homobidentate ligands are $2.068 \AA\left(\eta^{2}-\mathrm{NL}\right)$ and $2.255 \AA\left(\eta^{2}\right.$-PL). For heterobidentate $-\mathrm{N}, \mathrm{P}$ ligands (cis vs trans) are 2.08 vs $2.01 \AA$ (N) and 2.240 vs $2.285 \AA$ (P). The men N-Pt-N bite angles open in the order: $72.0^{\circ}(\mathrm{NSN})<76.5^{\circ}\left(\mathrm{NN}_{2} \mathrm{~N}\right)<79.0^{\circ}\left(\mathrm{NC}_{2} \mathrm{~N}\right)<85.0^{\circ}\left(\mathrm{NC}_{3} \mathrm{~N}\right)<88.7^{\circ}(\mathrm{NSNSN})<89.5^{\circ}$ (NCNPN). The mean P-Pt-P bite angles open in the order: $85.0^{\circ}\left(\mathrm{PC}_{2} \mathrm{P}\right)<94.2^{\circ}\left(\mathrm{PC}_{3} \mathrm{P}\right)$; and the mean N-Pt-P bite angles in the order: $79.5^{\circ}(\mathrm{NCNP})<83.5^{\circ}\left(\mathrm{NC}_{2} \mathrm{P}\right)<89.0^{\circ}\left(\mathrm{NNC}_{2} \mathrm{P}\right)$.

There are ten derivatives with $\mathrm{PtN}_{2} \mathrm{Br}_{2}$ chromophore. Seven of these have only monodentate ligands in a square planar array around $\mathrm{Pt}(\mathrm{II})$ atoms. Some derivatives have a cis arrangement (3 examples) and remaining four a trans arrangement. The mean Pt-N bond distances (cis vs trans) are equal at $2.02 \AA$, where as the Pt-Br bond distances are at 2.405 vs $2.430 \AA$, respectively. The trans derivatives are less distorted tha $\mathrm{n}$ the cis. The mean L-Pt-L bond distances departs from the ideal $\left(90^{\circ}\right.$ and $180^{\circ}$ ) (trans vs cis) by $0.7^{\circ}$ and $0.0^{\circ}$ vs $4.4^{\circ}$ and $3.0^{\circ}$, respectively.

Remaining three derivatives have a bidentate N-donor ligand with a five-membered chelate ring plus two $\mathrm{Br}$ atoms in a distorted square planar geometry about the Pt(II) atoms. The mean Pt-N bond distance for the bidentate ligands is $2.045 \AA$ and the mean N-Pt-N bite angle is $811.4^{\circ}$.

There is nineteen examples with the $\mathrm{PtN}_{2} \mathrm{I}_{2}$ chromophore, which can be subdivided by ligand type as follows: monodentate $\mathrm{N}$-donor ligands (8 examples); bidentate $\mathrm{N}$-donor ligands with five-membered chelate rings (7 examples); bidentate $\mathrm{N}$-donor with six-membered rings (3 examples), and bidentate $\mathrm{N}$-donors with twelvemembered ring ( 1 example). There are derivatives which have cis (3 examples) or trans (5 examples) configurations for the monodentate $\mathrm{N}$-donor systems, the bidentate $\mathrm{N}$-donors being all cis as expected.

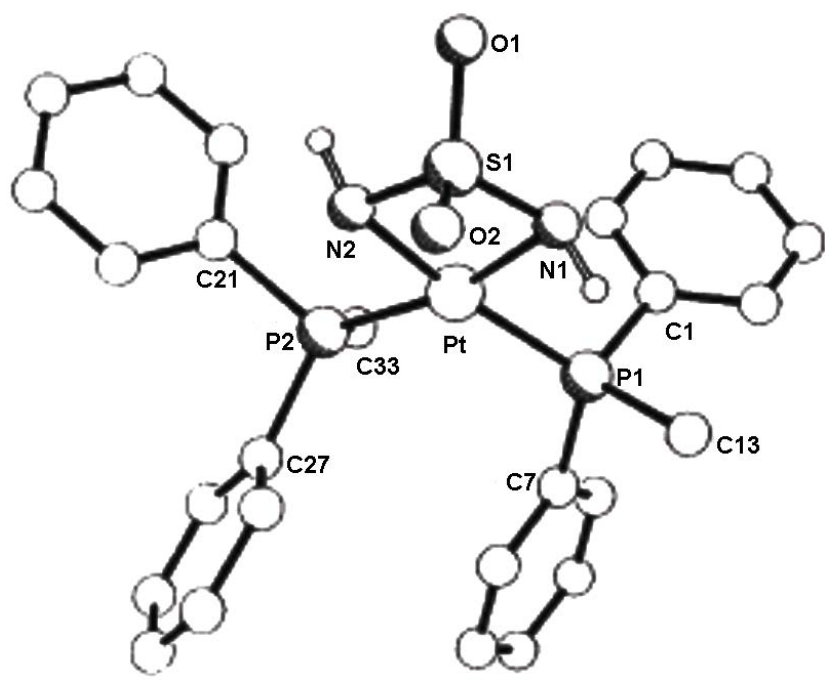

Figure 7. Structure of $\mathrm{Pt}\left\{\eta^{2}-(\mathrm{HN})_{2} \mathrm{SO}_{2}\left(\mathrm{PMePh}_{2}\right)_{2}\right.$ [12]. 
The mean Pt-N bond distances are $2.04 \AA\left(\eta^{1}\right.$-NL, trans $)<2.055 \AA\left(\eta^{2}\right.$-NL, five-membered ring $)<2.07 \AA$ ( $\eta^{2}$-NL, six-membered ring) $<2.075 \AA\left(\eta^{1}\right.$-NL, cis). The mean Pt-I bond distances are $2.600 \AA$ (trans) and 2.585 $\AA$ (cis). The mean N-Pt-N bite angles are $77.3^{\circ}$ (five-) and $91.4^{\circ}$ (six-membered ring).

\subsection{6. $\mathrm{PtC}_{2} \mathrm{X}_{2}(\mathrm{X}=\mathrm{Cl}, \mathrm{S}, \mathrm{P}$ or $\mathrm{I}), \mathrm{PtB}_{2} \mathrm{P}_{2}, \mathrm{PtCl}_{2} \mathrm{X}_{2}(\mathrm{X}=\mathrm{S}, \mathrm{P}$, Se or $\mathrm{As})$}

A cis- $\mathrm{Pt}(\mathrm{CNPh})_{2} \mathrm{Cl}_{2}$ complex is only example where two $\mathrm{PhNC}$ ligands with a pair of $\mathrm{Cl}$ atoms create a square planar environment around the $\mathrm{Pt}(\mathrm{II})$ atom, $\mathrm{PtC}_{2} \mathrm{Cl}_{2}$. The mean Pt-L bond distances are $1.89 \AA(\mathrm{L}=\mathrm{C})$ and 2.308 $\AA$ (Cl). The cis- and trans bond angles departs from the ideal values $\left(90^{\circ}\right.$ and $\left.180^{\circ}\right)$ by $1.9^{\circ}$ and $2.1^{\circ}$ respectively. In another cis-Pt(CNMe $)_{2}\left(\eta^{2}\right.$-mnt), (mnt = 1,2-dicarbomethoxyethylene-1,2-dithiolate), two CNMe ligands with a bidentate $\eta^{2}$-mnt $\left(\mathrm{S}, \mathrm{S}^{\prime}\right)$ ligand to give a distorted square plane $\left(\mathrm{PtC}_{2} \mathrm{~S}_{2}\right)$. The chelating ligand forms a fivemembered metallocycle which is mostly responsible for the observed distortion. The mean Pt-C and Pt-S bond distances are $1.95 \AA$ and $2.279 \AA$.

There are six examples with the $\mathrm{PtC}_{2} \mathrm{P}_{2}$ chromophore. In five trans-Pt(CN)$)_{2}(\mathrm{PL})_{2}$ complexes only monodentate ligands create a square planar arrangement about the Pt(II) atom. The mean Pt-L bond distances are $1.98 \AA$ $(\mathrm{L}=\mathrm{CN})$ and $2.320 \AA$ (PL). The remaining example is cis- in which a pair of CN groups with bidentate P,P' (bis (diphenylphosphine)-methylamine) create a highly distorted square planar arrangement about the $\mathrm{Pt}(\mathrm{II})$ atom $\left(\mathrm{PtC}_{2} \mathrm{P}_{2}\right)$. The mean Pt-C and Pt-P bond distances are 1.98 and $2.270 \AA$, respectively. The five-membered metallocycle has P-Pt-P bite angle of $70.7^{\circ}$.

In two cis-derivatives two CNR lignds plus two I atoms form a square plane about $\mathrm{Pt}(\mathrm{II})$ to give a $\mathrm{PtC}_{2} \mathrm{I}_{2}$ chromophore. The mean Pt-L bond distances are 1.96 and $2.600 \AA$ (I), respectively.

There are eleven $\mathrm{PtB}_{2} \mathrm{P}_{2}$ derivatives with a square planar geometry about the $\mathrm{Pt}(\mathrm{II})$ atom and only with a cis configuration. In nine of the derivatives only monodentate ligands are involved, $\mathrm{PPh}_{3}$ and two B-donor ligands (mostly B(catecholate)). In the remaining two examples, one has a bidentate five-membered ring 1,2-bis(diphenylphosphine)ethane-(dppe) P,P' ligand and the other a seven-membered ring, 1,4-bis(diphenylphosphine)butan (dppb) ligand. The mean B-Pt-B and P-Pt-P bond angles are $76.5^{\circ}$ and $100.7^{\circ}$, which are comparable with those found in derivatives in which only monodentate ligands are involved, mean values being $77.0^{\circ}$ (range $73.3^{\circ}$ $80.0^{\circ}$ ) and $103.0^{\circ}$ (range $99.3^{\circ}-107.3^{\circ}$ ), respectively. However, in the $\eta^{2}$-dppe derivative the P-Pt-P bite angle is reduced to $85.4^{\circ}$ and B-Pt-B angle opens to $81.0^{\circ}$ as a result of five-membered metallocyclic ring. The mean Pt-P bond distance elongated in the order: $2.320 \AA\left(\eta^{2}\right.$-dppe $)<2.340 \AA\left(\eta^{2} \mathrm{dppb}\right)<2.360^{\circ}\left(\mathrm{PPh}_{3}\right)$. The mean Pt-B bond distance is $2.055 \AA$.

There are almost forty compounds with the $\mathrm{PtCl}_{2} \mathrm{~S}_{2}$ chromophore. More then half have monodentate S-donor ligands and many of these have cis-configuration. The remainders have a bidentate $\left(\mathrm{S}, \mathrm{S}^{\prime}\right)$ ligand bonded to the $\mathrm{Pt}(\mathrm{II})$ atom. Bidentate chelate ligands, forms four-, five-, six- and even eleven-membered metallocycles. Each $\mathrm{P}(\mathrm{II})$ atom has a square planar environment with a different degree of distortion. The mean S-Pt-S bite angles are $76.3^{\circ}$ (four-) $<87.0^{\circ}$ (eleven-) $<90.0^{\circ}$ (five-) $<100.5^{\circ}$ (six-membered). Clearly the conformation of the largest, eleven-membered, ring is fairly rigid at an angle of $87.0^{\circ}$

The mean Pt-Cl bond distance of $2.300 \AA$ in these derivatives with a trans configuration is shorter than that found for the cis-configuration (2.309 $\AA$ for monodentate ligands and $2.317 \AA$ for bidentate ligands). The mean Pt-S bond distances show an opposite trend. Here the trans-configuration value of $2.302 \AA$ for monodentate ligands is longer than that found for cis-configuration, $2.255 \AA$ for monodentate and $2.540 \AA$ for bidentate.

Overall, the sum of all Pt-L bond distances (2x Pt-Cl plus 2x Pt-S) are somewhat smaller for cis than trans derivatives, 9.126 vs $9.204 \AA$ (monodentate) and $9.112 \AA$ (bidentate). The S-Pt-S bond angles in monodentate cis-derivatives range from $87^{\circ}$ to $94.5^{\circ}$ (average $91.5^{\circ}$ ), which is larger than the Cl-Pt-Cl bond angles in this series $\left(87^{\circ}-90.5^{\circ}\right.$ average $\left.88.5^{\circ}\right)$. The cis-Cl-Pt-Cl bond angles in the bidentate series are larger, at $90^{\circ}$ to $93.5^{\circ}$ (average $91.5^{\circ}$ ).

There ate over one hundred and twenty examples with the $\mathrm{PtCl}_{2} \mathrm{P}_{2}$ chromophore. For the $\mathrm{PtCl}_{2} \mathrm{P}_{2}$ derivatives the most common is a predominantly cis-arranged pair of monodentate P-donor ligand (84 examples). For the remainder, bidentate P-donor ligands are involved with four-membered chelate rings (2 examples), five-membered (11 examples), six-membered (2 examples), seven-membered (7 examples), eight-membered (2 examples), ninemembered (2 examples), twelve-membered (3 examples), fifteen-membered (2 examples), seventeen-membered (1 example) and even twenty-membered metallocyclic rings (2 examples). Each Pt(II) atom has a square planar environment with varying degrees of distortion. The cis derivatives (91 examples) tend to be more crowded than the trans derivatives (34 examples) as seen by comparing the sum of the Pt-L bond distances at $9.16 \AA$ and 9.24 
$\AA$, respectively. The mean Pt-Cl and monodentate Pt-P bond distances are 2.347 and $2.332 \AA$, respectively for cis, and 2.308 and $2.313 \AA$ respectively, for trans. For bidentate P-donor ligands the respective values are 2.350 and $2.231 \AA$ for cis, 2.309 and $2.307 \AA$ for trans.

There are at least two contributing factors to the size of the L-Pt-L bond angles, both ligand based. One of the steric constraints imposed on the ligand and the other is the need to a accommodate bidentates where appropriate. Comparing the bidentate P-Pt-P angles it is seen that it there is an increase in value as the size of the metallocyclic ring increases. This parallels an increase in Pt-P bond distance: $74.0^{\circ}$ and $2.230 \AA$ (six-) $<97.0^{\circ}$ and $2.235 \AA$ (seven-) $<102.2^{\circ}$ and $2.240 \AA$ (eight-membered metallocyclic ring). For the cis monodentate derivatives the P-Pt-P bond angles range from $87^{\circ}$ to $107^{\circ}$ (average $97^{\circ}$ ) and $\mathrm{Cl}-\mathrm{Pt}-\mathrm{Cl}$ bond angles from $82^{\circ}$ to $92^{\circ}$ (average $\left.88^{\circ}\right)$.

Five derivatives contain the $\mathrm{PtCl}_{2} \mathrm{Se}_{2}$ chromophore with a square planar geometry. In three of these, one cis and two trans, two monodentate Se-donor ligands are involved. The other two examples are cis with a bidentate Se donor ligand as before, the cis derivatives are less crowded than the trans derivatives as evidenced by the sum of the Pt-L distances of 9.385 and $9.445 \AA$, respectively. The mean Se-Pt-Se bite angle of five-membered metallocyclic ring at $82.2^{\circ}$ is somewhat smaller than found in the bidentate P-donor case $\left(86.7^{\circ}\right)$. The mean L-Pt-L bite angle of the five-membered chelate rings open with decreasing covalent radius of the donor ligand in the sequence: $82.2^{\circ}(\mathrm{Se}, 1.16 \AA)<86.7^{\circ}(\mathrm{P}, 1.06 \AA)<90.0^{\circ}(\mathrm{S}, 1.02 \AA)$.

One trans- $\mathrm{PtCl}_{2}\left(\eta^{2}-\mathrm{As}_{2} \mathrm{~L}\right)$ molecule has a slightly distorted square planar arrangement with two chlorine atoms and two As atoms from bidentate As donor ligand with a twelve-membered metallocyclic ring. The As-Pt-As bite angle is $174.1^{\circ}$. The mean Pt-As bond distance of $2.375 \AA$ is about $0.082 \AA$ longer than found in similar P-donor derivatives (2.293 $\AA$ ), in which a twelve-membered metallocyclic ring is also found with the P-Pt-P bite angle of $177.1^{\circ}$. The small differences reflect the relevant covalent radii of the donor atoms (As, 1.20; $\mathrm{P}, 1.06 \AA)$.

\subsection{7. $\mathrm{PtS}_{2} \mathrm{X}_{2}(\mathrm{X}=\mathrm{P}, \mathrm{Br}, \mathrm{I}$ or $\mathrm{As}), \mathrm{PtP}_{2} \mathrm{X}_{2}(\mathrm{X}=\mathrm{Br}, \mathrm{Se}, \mathrm{Si}, \mathrm{I}$ or $\mathrm{Te}), \mathrm{PtBr}_{2} \mathrm{Se}_{2}$ and $\mathrm{PtI}_{2} \mathrm{X}_{2}(\mathrm{X}=\mathrm{As}$ or $\mathrm{Te})$}

There are over sixty $\mathrm{PtS}_{2} \mathrm{X}_{2}(\mathrm{X}=\mathrm{P}(\mathrm{x} 56), \mathrm{Br}(\mathrm{x} 4), \mathrm{I}(\mathrm{x} 6)$, As (x2)) derivatives. They are predominantly yellow in color. The phosphorus containing derivatives are quite varied from a ligand point of view. Five derivatives (two cis- and three trans) have pairs of unidentate ligands creating a slightly distorted square planar environment about the Pt(II) atoms. Thirty two cis-derivatives have a bidentate-S,S' donor ligand and two unidentate P-donor ligands (predominantly $\mathrm{PPh}_{3}$ ) give a distorted square planar environment, with four-, five-, six- and sevenmembered metallocyclic rings. Another three derivatives have a pair of unidentate S-donors with a bidentate P-donor ligand to create the distorted square planar environment, with four- and five-membered metallocyclic rings. Bidentate S-donor and bidentate P-donor ligands are found in seven derivatives with distorted cis-square planar geometry. The chelates form four-S-Pt-S with five P-Pt-P membered; five S-Pt-S with five P-Pt-P membered, and six-S-Pt-S with four P-Pt-P membered metallocyclic rings.

Hetero (S,P) ligands are found in four examples with cis and trans square planar geometry. The size of the metallocyclic rings are five- and seven-membered. The remaining four examples have tetradentate $\left(\mathrm{S}_{2} \mathrm{P}_{2}\right)$ ligands forming distorted square planar environments about the Pt(II) atoms. Macrocyclic ligands form five-membered SPtS and PPtP rings; five SPtP, six SPS and PPtP rings; five SPtP and six SPtP rings; and six SPtP-membered rings.

The mean Pt-L (unidentate) bond distances, cis versus trans are 2.355 vs $2.30 \AA$ for S and 2.285 vs $2.33 \AA$ for P. The mean Pt-L (bidentate) bond distances for cis derivatives are $2.335 \AA$ for $\mathrm{S}$ and $2.29 \AA$ for P. In the series of bidentate chelating ligands the effect of both electronic and steric factors can be observed in the opening of the L-Pt-L bond angles for the metallocyclic rings. For example, in the four-membered rings the S-Pt-S angle opens in the sequence (mean values): $73.5^{\circ}$ (SCP) $<75.0^{\circ}$ (SCS) $<81.0^{\circ}(\mathrm{SSS})<91.7^{\circ}$ (SPS). In the five-membered rings the sequence is: $88.0^{\circ}\left(\mathrm{SC}_{2} \mathrm{~S}\right)<90.0^{\circ}$ (SSNS) $<90.0^{\circ}\left(\mathrm{SS}_{2} \mathrm{~S}\right)$. For the six-membered rings the sequence is: $87.0^{\circ}\left(\mathrm{SC}_{3} \mathrm{~S}\right)<92.5^{\circ}\left(\mathrm{SC}_{3} \mathrm{P}\right)<96.0^{\circ}$ (SPNPS).

There are three derivatives in which pair of unidentate S-donor ligands with two $\mathrm{Br}$ atoms is found $\left(\mathrm{PtS}_{2} \mathrm{Br}_{2}\right)$. In another one a chelate $\left(\mathrm{S}, \mathrm{S}^{\prime}\right)$ is found with two $\mathrm{Br}$ atoms. All have a distorted square planar geometry about the $\mathrm{Pt}(\mathrm{II})$ atom. The mean Pt-L bond distance elongated in the order: $2.25 \AA$ (bi-S) $<2.26 \AA$ (uni-S) $<2.43 \AA$ (Br).

In another five trans-derivatives a pair of unidentate S-donor ligands and two iodine atoms create square planar geometry $\left(\mathrm{PtS}_{2} \mathrm{I}_{2}\right)$. A cis-derivative has a bidentate S-donor ligand, forming a six membered metallocycle with S-Pt-S bite angle of $91.0^{\circ}$, plus two iodine atoms. The mean Pt-S and Pt-I bond distances in the trans deriv- 
atives are 2.30 and $2.61 \AA$, while in the cis-derivative the values are 2.265 and $2.60 \AA$, respectively.

In two trans-derivatives a pair of hetero (S,As) ligands create a slightly distorted square planar environment for Pt(II). The mean Pt-L bond distances are $2.30 \AA$ (S) and $2.366 \AA$ (As), with the mean five-membered S-Pt-As metallocyclic ring angle of $87.4^{\circ}$.

There are over thirty $\mathrm{Pt}(\mathrm{II})$ derivatives with the chromophores $\mathrm{PtP}_{2} \mathrm{X}_{2}(\mathrm{X}=\mathrm{Br}(\mathrm{x} 6)$, Se (x7), Si (x5), I (x11) or Te (x2)), $\mathrm{PtBr}_{2} \mathrm{Se}_{2}$ (x2), $\mathrm{PtAs}_{2} \mathrm{I}_{2}$ (x1) and $\mathrm{PtI}_{2} \mathrm{Te}_{2}$ (x1)). Six derivatives with the $\mathrm{PtP}_{2} \mathrm{Br}_{2}$ chromophore have a slightly distorted square planar geometry about each $\mathrm{Pt}(\mathrm{II})$ atom, utilizing a pair of monodentate $\mathrm{P}$-donor ligands (3 examples) and remaining three a bidentate P-donor ligand. In the former three cis-derivatives, the mean Pt-P (monodentate) and $\mathrm{Pt}-\mathrm{Br}$ bond distances are 2.300 and $2.446 \AA \AA$, respectively. In another two cis-derivatives the mean Pt-P (bidentate) and Pt-Br bond distances are 2.229 and $2.489 \AA$, respectively. The bidentate P-donor ligands create five-membered metallocyclic rings with the P-Pt-P bite angles of $86.3^{\circ}$. In one trans-derivative with the mean Pt-P (bidentate) and Pt-Br bond distances are 2.319 and $2.429 \AA$. The bidentate P-donor ligand forms a twelve-membered metallocycle with the P-Pt-P bite angle of $179.5^{\circ}$. The Pt-P as well as Pt-Br bond distances are somewhat shorter in the cis derivatives than in the trans. This suggests a greater trans influence of $\mathrm{P}$ compared to Br.

Seven species with the $\mathrm{PtP}_{2} \mathrm{Se}_{2}$ chromophore have two trans and five cis examples. Two unidentate P-donor ligands are found in one trans configurations, giving a slightly distorted square planar geometry about the $\mathrm{Pt}(\mathrm{II})$ atom. In another example a bidentate P-donor ligand with two unidentate PhSe ligands form a cis-configuration derivative with four-membered metallocycle P-Pt-P bite angle of 73.1 ${ }^{\circ}$. In cis- $\mathrm{Pt}\left(\mathrm{PPh}_{3}\right)_{2}\left(\eta^{2}-\mathrm{Se}_{2} \mathrm{CH}_{2}\right)$ derivative the bidentate Se ligand forms a four-membered metallocycle (Se-Pt-Se, $77.1^{\circ}$ ). Two other cis-derivatives have a pair of homobidentate P,P' and Se,Se'-donor ligands, with the mean P-Pt-P and Se-Pt-Se bite angles of $89.0^{\circ}$ and $90.0^{\circ}$. Remaining two derivatives, one cis and another one trans, contain a pair heterobidentate P,Se ligands with the mean P-Pt-Se bite angle of $90.3^{\circ}$. The mean Pt-P bond distances in the cis derivatives are about $0.002 \AA$ shorter, and the Pt-Se distances about $0.045 \AA$ longer than in the trans which strongly suggests a created trans influence for P than Se.

Here are five cis-derivatives of the chromophore $\mathrm{PtP}_{2} \mathrm{Si}_{2}$. In one derivative two unidentate $\mathrm{PPh}_{3}$ ligands with a bidentate Si-ligands created a distorted square planar geometry about the $\operatorname{Pt}(\mathrm{II})$ atom. In another one two unidentate Si-ligands with a bidentate P-ligand are found with the five-membered metallocycle (P-Pt-P, $84.8^{\circ}$ ). Two homobidentate ligands with five-membered ring (P-Pt-P, 84.5 ) and four-membered ring (Si-Pt-Si, 65. $0^{\circ}$ ) form a distorted square planar geometry about the Pt(II) atom. There is also example in which monodentate -P, monodentate -Si with heterobidentate -P,Si ligand form a distorted square planar geometry with P-Pt-Si bite angle of $70.7^{\circ}$ (four-membered). A pair of heterobidentate ligands gives a square planar environment in the last example with two five-membered metallocycles with the mean P-Pt-Sr bite angle of $83.3^{\circ}$.

There are eleven derivatives with the $\mathrm{PtP}_{2} \mathrm{I}_{2}$ chromophore. In eight of them cis ( 2 examples) and trans (6 examples), only unidentate ligands are involved. In the remaining three examples a bidentte $-\mathrm{P}$ donor ligand is involved, giving five-membered metallocycles with mean P-Pt-P bite angle of $85.4^{\circ}$. The mean Pt-L bond distances cis versus trans, are 2.235 vs $2.329 \AA$ for Pt-P and 2.658 vs $2.608 \AA$ for Pt-I. The Pt-P bond lengths in the cis derivatives are about $0.094 \AA$ shorter and the Pt-I bond lengths about $0.005 \AA$ longer than in the trans derivatives, indicating a greater trans influence for $\mathrm{P}$ than $\mathrm{I}$.

In cis- $\mathrm{Pt}\left(\mathrm{PPh}_{3}\right)_{2}\left(\eta^{2}-1,2-\mathrm{Te}_{2} \mathrm{C}_{6} \mathrm{H}_{4}\right)$ a homobidentate Te-ligand forms a five-membered metallocycle with the Te-Pt-Te bite angle of $88.4^{\circ}$. In another trans derivative a pair of heterobidentate -P,Te donor ligands form a five-membered metallocycle (mean P-Pt-Te, $88.5^{\circ}$ ).

There are cis- (1 example) and trans (1 example) with two Br ligands and two Se-atoms $\left(\mathrm{PtBr}_{2} \mathrm{Se}_{2}\right)$. In the cis derivative the Se atoms are part of a bidentate Se-donor ligand, while in the trans-derivative two 1,4-oxyselenate molecules are involved to give somewhat distorted square planar geometrics.

There is trans-derivative in which pair of iodine atoms with a pair of $\mathrm{AsPh}_{3}$ ligands forming a square planar geometry about the $\mathrm{Pt}(\mathrm{II})$ atom $\left(\mathrm{PtAs}_{2} \mathrm{I}_{2}\right)$. Finally, in another trans derivative a pair of iodine atoms and pair of methylphenyl telluride molecules give a slightly distorted square-planar geometry about the $\mathrm{Pt}(\mathrm{II})$ atom $\left(\mathrm{PtI}_{2} \mathrm{Te}_{2}\right)$.

The mean Pt-L bond distances in this 2.5.6 subgroup in the series of cis-derivatives elongated in the order: $2.25 \AA\left(\mathrm{L}=\eta^{2}-\mathrm{PL}\right)<2.295 \AA\left(\eta^{1}-\mathrm{PL}\right)<2.37 \AA\left(\eta^{1}-\mathrm{SiL}\right)<2.47 \AA\left(\eta^{1}-\mathrm{SeL}\right)<2.485 \AA(\mathrm{Br})<2.66 \AA$ (I). For the trans-derivatives the order is: $2.313 \AA\left(\eta^{2}\right.$-PL $)<2.325 \AA\left(\eta^{1}\right.$-PL $)<2.405 \AA\left(\eta^{1}\right.$-AsL $)<2.425 \AA\left(\eta^{1}\right.$-SeL $)<2.43$ $\AA(\mathrm{Br})<2.58 \AA\left(\eta^{1}-\mathrm{TeL}\right)<2.61 \AA$ (I). The mean Pt-P versus Pt-L (trans) are: 2.215 vs $2.49 \AA$ (Br); 2.24 vs 2.66 
$\AA$ (I); 2.24 vs $2.465 \AA$ (Se) and 2.33 vs $2.36 \AA$ (Si). The mean Pt-P bond distance in the cis-derivatives of 2.275

$\AA$ indicates that a trans influence is only significant in the case of $\mathrm{Si}$.

In this series of bidentate chelating ligands the effect of both electronic and steric effects can be seen in the opening of the L-Pt-L bite angles of the respective metallocycles. For example, in the four-membered metallocyclic rings the L-Pt-L angles open in the order: $65^{\circ}(\mathrm{SiCSi})<70.7^{\circ}(\mathrm{PCSi})<73.7^{\circ}(\mathrm{PCP})<77.0^{\circ}(\mathrm{SeCSe})<$ $85.3^{\circ}$ (SePSe). In the five-membered rings the order is: 83.5 $\left(\mathrm{PC}_{2} \mathrm{Si}\right)<85.5^{\circ}\left(\mathrm{PC}_{2} \mathrm{P}\right)<88.4^{\circ}\left(\mathrm{TeC}_{2} \mathrm{Te}\right)<88.5^{\circ}$ $\left(\mathrm{PC}_{2} \mathrm{Te}\right)<90.4^{\circ}$ (PNPSe).

Overall of the data in Chapter 2.5 cover almost eight hundred and twenty $\operatorname{Pt}(\mathrm{II})$ derivatives of the composition $\mathrm{PtA}_{2} \mathrm{~B}_{2}$. The mean Pt-L bond distance for monodentate ligands, elongated in the order: $1.65 \AA(\mathrm{H})<1.965 \AA$ $(\mathrm{CN})<1.99 \AA$ (NL, unsaturated) $<2.03 \AA(\mathrm{OL})<2.06 \AA(\mathrm{BL})<2.28 \AA(\mathrm{SL})<2.29 \AA(\mathrm{PL})<2.32 \AA(\mathrm{Cl})<$ $2.425 \AA(\mathrm{Br})<2.349 \AA(\mathrm{SeL})<2.59 \AA$ (I). For bidentate ligands the mean Pt-L bond distance elongated in the order: $2.02 \AA\left(\eta^{2}\right.$-NL, unsaturated $)<2.045 \AA\left(\eta^{2}\right.$-NL, saturated $)<2.29 \AA\left(\eta^{2}\right.$-SL $)<2.27 \AA\left(\eta^{2}\right.$-PL $)<2.39 \AA$ $\left(\eta^{2}\right.$-SeL $)<2.37 \AA\left(\eta^{2}-\mathrm{AsL}\right)<2.58 \AA\left(\eta^{2}-\mathrm{TeL}\right)<2.66 \AA\left(\eta^{2}-\mathrm{SiL}\right)$.

For heterobidentate ligands, the mean values are: $\mathrm{O}+\mathrm{N}, 2.02$ and $2.00 \AA$; $\mathrm{O}+\mathrm{S}, 2.00$ and $2.04 \AA ; \mathrm{N}+\mathrm{S}$, 1.98 and $2.29 \AA ; \mathrm{N}+\mathrm{P}, 2.06$ and $2.25 \AA ; \mathrm{S}+\mathrm{P}, 2.32$ and $2.305 \AA ; \mathrm{S}+\mathrm{As}, 2.308$ and $2.356 \AA ; \mathrm{P}+\mathrm{Te}, 2.306$ and $2.575 \AA$. For heterotridentate ligands, the mean values are: 20 + N, 1.995 and $2.02 \AA ; \mathrm{O}+2 \mathrm{P}, 2.15$ and $2.22 \AA$; $\mathrm{N}+2 \mathrm{~S}, 1.99$ and $2.29 \AA$; and for tetradentate, $2 \mathrm{~N}+2 \mathrm{~S}, 1.985$ and $2.265 \AA$.

There are rich variations of metallocyclic rings. The mean L-Pt-L bite angle open in the orders: $65.0^{\circ}$ (OCO) $<70.7^{\circ}(\mathrm{PCSi})<71.5^{\circ}(\mathrm{OPO})<72.4^{\circ}(\mathrm{PCP})<74.3^{\circ}(\mathrm{OSeO})<77.0^{\circ}(\mathrm{SCS}) ; 76.4^{\circ}\left(\mathrm{NN}_{2} \mathrm{~N}\right)<78.0^{\circ}\left(\mathrm{ON}_{2} \mathrm{O}\right)<$ $79.5^{\circ}\left(\mathrm{NC}_{2} \mathrm{~N}\right.$, unsaturated $)<79.7^{\circ}(\mathrm{NCPN})<80.6^{\circ}(\mathrm{OCNO})<81.5^{\circ}\left(\mathrm{OC}_{2} \mathrm{~N}\right)<82.2^{\circ}\left(\mathrm{OC}_{2} \mathrm{O}\right)<82.5^{\circ}(\mathrm{NNCS}$, $\mathrm{NCSN})<83.7^{\circ}\left(\mathrm{OC}_{2} \mathrm{P}\right)<83.8^{\circ}\left(\mathrm{NC}_{2} \mathrm{~N}\right.$, saturated $)<84.2^{\circ}\left(\mathrm{NC}_{2} \mathrm{~S}\right)<84.8^{\circ}\left(\mathrm{NC}_{2} \mathrm{P}\right)<85.0^{\circ}\left(\mathrm{NC}_{2} \mathrm{~S}\right)<86.3^{\circ}\left(\mathrm{PC}_{2} \mathrm{P}\right)$ $<86.7^{\circ}(\mathrm{OPNP})<87.7^{\circ}\left(\mathrm{SC}_{2} \mathrm{P}\right)<88.5^{\circ}\left(\mathrm{PC}_{2} \mathrm{Te}\right)<89.0^{\circ}\left(\mathrm{SC}_{2} \mathrm{~S}\right) ; 88.7^{\circ}(\mathrm{NSNSN})<89.0^{\circ}(\mathrm{NCPCN})<90.3^{\circ}$ $\left(\mathrm{PC}_{3} \mathrm{Se}\right)<91.5^{\circ}\left(\mathrm{NC}_{3} \mathrm{~N}\right)<93.0^{\circ}\left(\mathrm{OC}_{3} \mathrm{O}\right)<94.5^{\circ}\left(\mathrm{PC}_{3} \mathrm{P}\right) ; 88.5^{\circ}\left(\mathrm{NC}_{4} \mathrm{~N}\right.$, unsaturated $)<89.7^{\circ}\left(\mathrm{OC}_{4} \mathrm{O}\right)<98.8^{\circ}$ $\left(\mathrm{NC}_{4} \mathrm{~N}\right.$, saturated $)<100.7^{\circ}\left(\mathrm{PC}_{4} \mathrm{P}\right)$.

Some mean Pt-L bond distances are longer for the $\mathrm{PtA}_{3} \mathrm{~B}$ (Chapter 2.4) than in the $\mathrm{PtA}_{2} \mathrm{~B}_{2}$ (Chapter 2.5) types, especially for $\mathrm{H}, \mathrm{Cl}, \eta^{1}$-SL, $\eta^{2}$-SL, $\eta^{1}$-PL and $\mathrm{Br}$, probably because of the steric reasons. Some chelate rings in the $\mathrm{PtA}_{3} \mathrm{~B}$ type are a little more open than in the $\mathrm{PtA}_{2} \mathrm{~B}_{2}$ type, for example, $\mathrm{NC}_{2} \mathrm{~N}, \mathrm{OC}_{2} \mathrm{~N}$ and $\mathrm{NC}_{3} \mathrm{~N}$; but the reverse is true for the other examples, such as PCP, CSCS, $\mathrm{PC}_{2} \mathrm{P}, \mathrm{NC}_{2} \mathrm{~S}$ and $\mathrm{PC}_{3} \mathrm{P}$.

\subsubsection{PtA $\mathrm{A}_{2} \mathrm{XY}$ and PtABXY Derivatives}

There are over two hundred and seventy such derivatives in which each Pt(II) atom has a square planar environment with a different degree of distortion. These derivatives were detail characterized, classified and analyzed [4] and therefore here will be shortly summarized and discussed.

There are almost forty such derivatives; five of them have a $\mathrm{PtO}_{2} \mathrm{XY}$ chromophore. In cis- $\mathrm{PtO}_{2} \mathrm{NCl}$ a heterobidentate $-\mathrm{O}, \mathrm{N}$ ligand with water molecule and chlorine atom form a slightly distorted square planar geometry about the Pt(II) atom. The bidentate ligand creates a six-membered metallocycle with the O-Pt-N bite angle of 93. $7^{\circ}$. In trans $-\mathrm{PtO}_{2} \mathrm{NCl}$ a heterotridentate $-\mathrm{O}, \mathrm{O}^{\prime} \mathrm{N}$ ligand with chlorine atom created a distorted square planar geometry about the $\mathrm{Pt}(\mathrm{II})$ atom. The heterotridentate ligand forms two five-membered metallocycles with the mean O-Pt-N bite angles of $81.1^{\circ}$.

In trans- $\mathrm{PtO}_{2} \mathrm{NP}$ another heterotridentate $-\mathrm{O}, \mathrm{O}^{\prime}, \mathrm{N}$ ligand with $\mathrm{PPh}_{3}$ molecule form a distorted such geometry. The heteroligand forms one five- and another one six-membered metallocycles with the O-Pt-N bite angle values of $82.4^{\circ}$ and $94.8^{\circ}$, respectively. In another trans- $-\mathrm{PtO}_{2} \mathrm{NI}$ a heterotridentate $-\mathrm{O}, \mathrm{O}^{\prime}, \mathrm{N}$ ligand with iodine atom created a similar square-planar geometry like in trans $-\mathrm{PtO}_{2} \mathrm{NCl}$. The heterotridentate ligand forms a five-membered metallocycles with the O-Pt-N bite angles of $83.2^{\circ}$. In cis- $\mathrm{PtO}_{2} \mathrm{ClS}$ a bidentate -O,O' ligand with chlorine atom and dmso-S ligand form a square-planar geometry about the Pt(II) atom. The O-Pt-O bite angle is $89.9^{\circ}$ in the six-membered metallocycle.

There are six derivatives with $\mathrm{PtN}_{2} \mathrm{OCl}$ chromophore. In two trans-derivatives a bidentate $-\mathrm{O}, \mathrm{N}$ chelating prolinate ligand a chlorine and pyridine, or $\alpha$-methylbenzylamine create a distorted square planar geometry about the Pt(II) atom with the mean O-Pt-N bite angles of $83.3^{\circ}$ in the five-membered metallocycle. In cis-derivatives (4 examples) a tridentate, N,N',O-chelating ligand and a chlorine atom form such chromophore $\left(\mathrm{PtN}_{2} \mathrm{OCl}\right)$. In one derivative are two types of metallocycles five-membered rings, N-Pt-N and O-Pt-N with the bite angles of $84.3^{\circ}$ and $82.6^{\circ}$, respectively. In the remaining two cis derivatives only six-membered metallocycles are involved. The N-Pt-N and O-Pt-N bond angles are $93.6^{\circ}$ and $94.4^{\circ}$, respectively. 
There are five cis derivatives with the $\mathrm{PtN}_{2} \mathrm{OS}$ chromophore. In three of them a bidentate N,N'-chelating ligand, a unidentate $\mathrm{O}$ - and unidentate S-donor are involved. The chelating $\left(\mathrm{N}, \mathrm{N}^{\prime}\right)$ ligand forms five-membered metallocyclic rings with a mean N-Pt-N bite angle of $83.5^{\circ}$. The remaining two derivatives have a bidentate $\left(\mathrm{N}, \mathrm{N}^{\prime}\right)$ chelate and a bidentate $(\mathrm{O}, \mathrm{S})$ chelate. The chelating ligands form five-membered metallocyclic rings with N-Pt-N and O-Pt-S angles of $82.6^{\circ}$ and $85.4^{\circ}$, in one example, and in the other one a five-membered $\left(\mathrm{N}, \mathrm{N}^{\prime}\right)$ and six-membered $(\mathrm{O}, \mathrm{S})$ rings with values of $83.7^{\circ}$ and $95.3^{\circ}$.

Thirteen derivatives have the $\mathrm{PtN}_{2} \mathrm{ClS}$ chromophore. Two trans derivatives have unidentate ligands, two $\mathrm{NH}_{3}$ ligands, a chlorine atom and the $\mathrm{S}$ atom of dmso, with the mean N-Pt-N bond angles of $173.5^{\circ}$. Eight of the cis derivatives have a distorted square planar arrangement created by a N,N' chelate, a chlorine atom and a S-donor ligand. Structure of $c i s-\left[\mathrm{Pt}\left(\eta^{2}-\mathrm{mbda}\right)(\mathrm{Cl})(\mathrm{dmso})\right] \mathrm{Cl}$.EtOH is shows in Figure 8 [13] as an example. The structure showing the eight membered ring to have rigid elongated chain conformations, forcing one of the two bridging methylene hydrogen atoms (endo) in close proximity to the metal centre. The bidentate2,2'-methylene-bis(5(dimethylamino)aniline) ( $\left.\mathrm{N}, \mathrm{N}^{\prime}\right)$ ligand, with chlorine atom and unidentate $\mathrm{S}$ donor atom of dimethysuphoxide created a distorted square planar geometry about the Pt(II) atom. Five-membered chelate rings are found in the four derivatives with mean N-Pt-N bond angle of $82.2^{\circ}$. The one derivative has a six-membered metallocycle $\left(88.9^{\circ}\right)$, the other one a seven-membered (86.0) and one even an eight-membered $\left(89.5^{\circ}\right)$. A tridentate $\left(\mathrm{N}_{2} \mathrm{~S}\right)$ ligand and a chlorine atom forms the distorted square planar geometry in three other cis derivatives. In them the chelate ligand forms a five-membered $\left(\mathrm{N}, \mathrm{N}^{\prime}\right)$ ring $\left(80.6^{\circ}\right)$ and a six-membered $(\mathrm{N}, \mathrm{S})$ ring $\left(85.4^{\circ}\right)$.

Four cis-derivatives have a distorted square plane created by a bidentate $\left(\mathrm{N}, \mathrm{N}^{\prime}\right)$ chelate, a chlorine atom and a $\mathrm{P}$-donor ligand give the $\mathrm{PtN}_{2} \mathrm{ClP}$ chromophore. In two of them chelating $\left(\mathrm{N}, \mathrm{N}^{\prime}\right)$ ligand forms a five-membered rings (N-Pt-N, $81.3^{\circ}$ ) and in another two derivatives a six-membered rings (N-Pt-N, 88.8 $8^{\circ}$.

In cis-derivative a tridentate (N,N",S) dianion ligand with $\mathrm{PPh}_{3}$ to create a distorted square planar environment about $\mathrm{Pt}(\mathrm{II})$ to give the $\mathrm{PtN}_{2} \mathrm{SP}$ chromophore. The chelate forms two five-membered metallocycles with N-Pt-N and N-Pt-S bond angles of 78.5 and $81.6^{\circ}$, respectively. The structure of another cis-derivative is similar with a tridentate $\mathrm{N}, \mathrm{N}$,Se dianion ligand a $\mathrm{PPh}_{3}$ molecule with five-membered metallocycles N-Pt-N and N-PtSe bite angles of $78.7^{\circ}$ and $82.3^{\circ}$. In other cis-derivative two $\mathrm{CN}$ groups with a bidentate N,S-ligand forms a distorted square plane about the $\mathrm{Pt}(\mathrm{II})$ atom $\left(\mathrm{PtC}_{2} \mathrm{NS}\right)$.

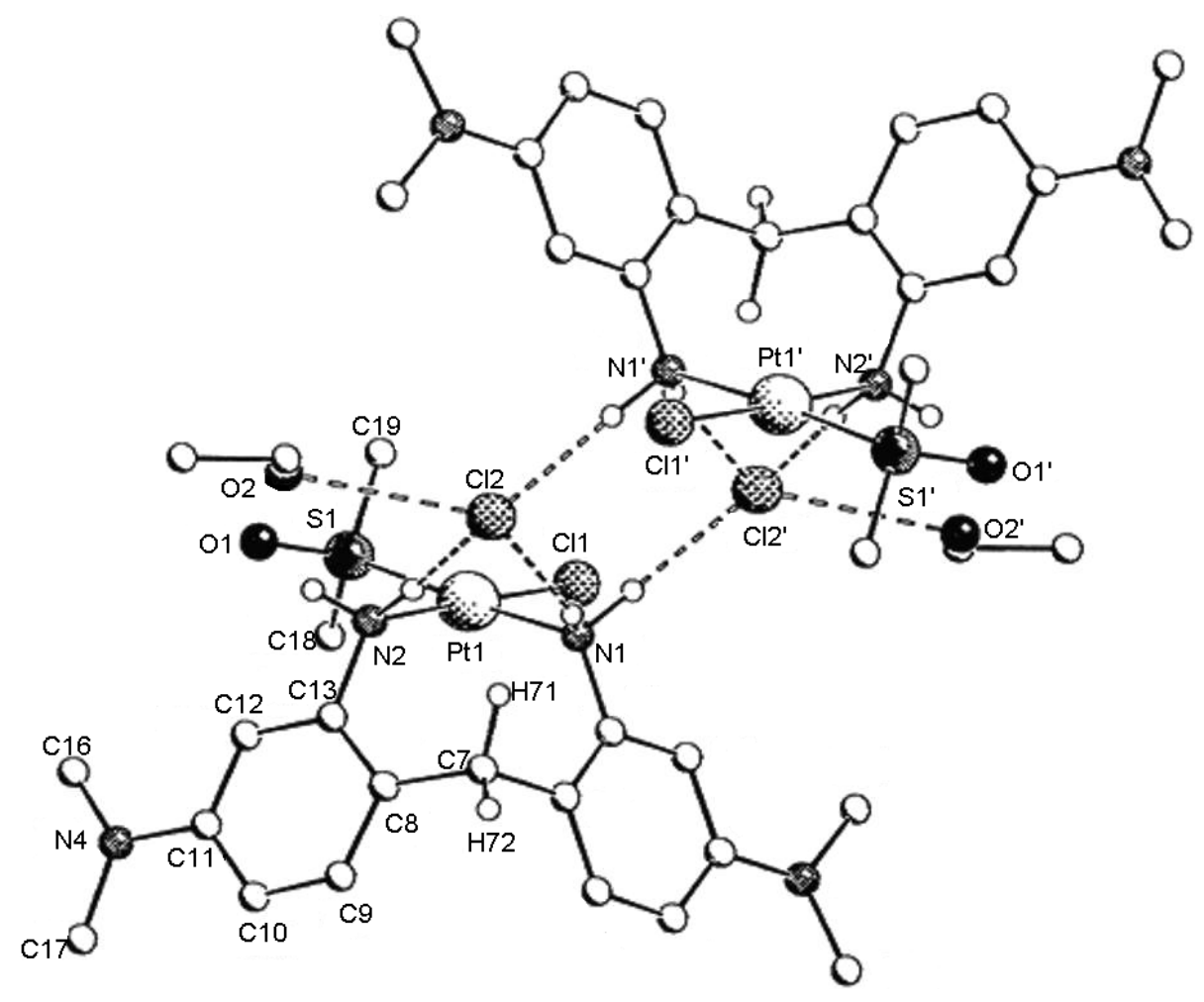

Figure 8. Structure of cis-[Pt( $\left.\left.\eta^{2}-\mathrm{mbda}\right)(\mathrm{Cl})(\mathrm{dmso})\right] \mathrm{Cl} . \mathrm{EtOH}[13]$. 
The data of $\mathrm{PtA}_{2} \mathrm{XY}(\mathrm{A}=\mathrm{O}, \mathrm{N}$ or $\mathrm{C}$ ) reveals homo, uni- and bidentate donor ligands. Of these only $\mathrm{Cl}$, uni-SL and uni-PL types are found in both cis- and trans positions with mean Pt-L bond distances of cis versus trans of 2.31 vs $2.295 \AA$ (Cl), 2.25 vs $2.26 \AA$ (PL) and 2.22 vs $2.20 \AA$ (SL). Unidentate O-donor ligands are found only in cis positions with the mean Pt-O bond length of $2.03 \AA$. Unidentate $\mathrm{N}$-donor ligands and iodine are found only in trans positions with mean Pt-L bond lengths of $2.06 \AA(\mathrm{N})$ and $2.583 \AA$ (I), respectively. Homobidentate $\left(\mathrm{O}, \mathrm{O}^{\prime}\right)$ and $\left(\mathrm{N}, \mathrm{N}^{\prime}\right)$ ligands occupy only cis positions with mean Pt-L bond lengths of $1.97 \AA(\mathrm{O})$ and $2.04 \AA(\mathrm{N})$, respectively. There are two types of heterobidetate ligands with $\mathrm{O}$ plus $\mathrm{N}$, or $\mathrm{O}$ plus $\mathrm{S}$ donor atoms. The former is found in both cis and trans positions with mean Pt-O and Pt-N bond lengths of 1.98 and $1.97 \AA$ (cis); 2.01 and $2.05 \AA$ (trans). There are four types of heterotridentate ligands: $2 \mathrm{O}$ plus N; O plus $2 \mathrm{~N}, \mathrm{~S}$ plus $2 \mathrm{~N}$, and Se plus $2 \mathrm{~N}$ sites, with the like atoms cis.

The effects of both electronic and steric hindrance of the coordinated atoms can be seen in the opening of the L-Pt-L bond angles of the respective metallocycles. For the five-membered rings the mean L-Pt-L intra-ligand angles are: $81.3^{\circ}(\mathrm{N}+\mathrm{N})<82.2^{\circ}(\mathrm{N}+\mathrm{O})<82.4^{\circ}(\mathrm{N}+\mathrm{Se})<83.5^{\circ}(\mathrm{N}+\mathrm{S})<85.5^{\circ}(\mathrm{O}+\mathrm{S})$. For the six-membered rings the mean L-Pt-L angles are: $90.0^{\circ}(\mathrm{O}+\mathrm{O})<90.5^{\circ}(\mathrm{N}+\mathrm{N})<94.3^{\circ}(\mathrm{O}+\mathrm{N})<95.3^{\circ}(\mathrm{O}+\mathrm{S})<99.3^{\circ}(\mathrm{N}+\mathrm{S})$.

There are over seventy $\mathrm{Pt}(\mathrm{II})$ derivative of $\mathrm{PtCl}_{2} \mathrm{XY}$ chromophores in which a $\mathrm{Pt}(\mathrm{II})$ atom are in a square planar environment with a different degrees of distortion. There are five derivatives, one trans- and four cis with $\mathrm{PtCl}_{2} \mathrm{ON}$ chromophore. The trans derivative is the only example in which only unidentate ligands are involved. In cis derivatives $\left(\mathrm{PtCl}_{2} \mathrm{ON}\right)$ a bidentate $\mathrm{O}, \mathrm{N}$ ligands form in three derivatives a five-membered metallocyclic rings (O-Pt-N, 83.6 $6^{\circ}$ and in the fourth one a six-membered metallocycle (O-Pt-N, 90.9 $)$. The mean Pt-Cl bond lengths are $2.303 \AA$ (cis) and $2.297 \AA$ (trans).

Two chlorine atoms plus water and dmso molecule form cis- $\mathrm{PtCl}_{2} \mathrm{OS}$. A slightly distorted square planar $\mathrm{PtCl}_{2} \mathrm{OP}$ chromophore uses water and a $\mathrm{PPh}_{3}$ molecule.

There are over thirty derivatives in which two chlorine atoms and $\mathrm{N}$ and $\mathrm{S}$ donor ligands are found in a $\mathrm{PtCl}_{2} \mathrm{NS}$ square planar array. In twenty of these (ten cis and ten trans) only unidentate ligands are involved. The remaining eleven are cis derivatives with bidentate $(\mathrm{N}, \mathrm{S})$ chelating ligands. In four of these a chelating ligands forms a five-membered metllocyclic ring with mean N-Pt-S bite angle of $87.3^{\circ}$, and in seven derivatives a sixmembered metallocycle is found with mean N-Pt-S bite angle of $94.8^{\circ}$. The mean cis versus trans Pt-L bond lengths are: 2.03 vs $2.055 \AA$ (NL) $<2.21$ vs $2.22 \AA$ (SL) $<2.305$ vs $2.295 \AA(\mathrm{Cl})$. The mean Pt-N and Pt-S bond lengths for heterobidentate ligands are: 2.06 and $2.215 \AA$, respectively.

Twenty five species have a distorted square planar arrangement about the $\mathrm{Pt}(\mathrm{II})$ atom with the $\mathrm{PtCl}_{2} \mathrm{NP}$ chromophore. Two cis and twenty trans contain only unidentate ligands. The remaining three are cis derivatives with bidentate $(\mathrm{N}, \mathrm{P})$ chelating ligands. In two the chelating ligand forms five-membered metallocyclic ring with mean N-Pt-P bite angle of $87.3^{\circ}$, and the third forms a six-membered metallocycle with bite angle of $95.7^{\circ}$. The mean Pt-L bond distances cis vs trans, elongated in the order: 2.03 vs $2.13 \AA(\mathrm{NL})<2.225$ vs $2.230 \AA(\mathrm{PL})<$ 2.335 vs $2.295 \AA(\mathrm{Cl})$.

In cis derivative two chlorine atoms with a bidentate $\mathrm{N}$,Se ligand forms $\mathrm{PtCl}_{2} \mathrm{NSe}$ chromophore and the $\mathrm{N}$-Pt-Se bite angle is $90.3^{\circ}$. In another two derivatives, two chlorine atoms, a unidentate N-donor and $\mathrm{AsEt}_{3} \mathrm{li}_{-}$ gand forms $\mathrm{PtCl}_{2} \mathrm{NAs}$ chromophore. In cis- $\mathrm{PtCl}_{2} \mathrm{NTe}$ derivative a bidentate $-\mathrm{N}, \mathrm{Te}$ ligand forms six-membered metallocycle with N-Pt-Te bite angle of $89.9^{\circ}$. The Pt-Cl bond length of $2.351 \AA$ opposite the Te atom is about 0.058 A longer than the Pt-Cl distance opposite to the $\mathrm{N}$ atom indicating the larger trans influence of Te over $\mathrm{N}$.

In six cis-derivatives a slightly distorted square planar arrangement has the $\mathrm{PtCl}_{2} \mathrm{SP}$ chromophore. In three of those, only unidentate ligands are involved. The other three involve bidentate $(\mathrm{S}, \mathrm{P})$ chelating ligands all of which form five-membered metallocyclic rings with mean S-Pt-P bite angle of $88.1^{\circ}$. The mean Pt-Cl bond lengths trans to the $\mathrm{P}$ atom at $2.360 \AA$ are about $0.045 \AA$ longer than that trans to $\mathrm{S}$, which suggests a greater trans effect of $\mathrm{P}$ over $\mathrm{S}$.

A finally, there is derivative in which two chlorine atoms and a bidentate $(\mathrm{S}, \mathrm{Te})$ chelating ligand to give the square planar $\mathrm{PtCl}_{2} \mathrm{STe}$ chromophore. The chelating ligand forms a five-membered metallocycle with S-Pt-Te bite angle of $91.5^{\circ}$.

The data in this section (2.6.2) reveal the mean Pt-L (unidentate) bond distances for cis derivatives to elongated in the order: $2.00 \AA(\mathrm{NL})<2.08 \AA(\mathrm{OL})<2.24 \AA(\mathrm{PL})<2.315 \AA(\mathrm{Cl})<2.375 \AA(\mathrm{SL})$. The mean Pt-O vs Pt-L (trans) bond lengths are: 2.05 vs $2.01 \AA(\mathrm{N})$ and 2.12 vs $2.245 \AA(\mathrm{P})$, suggesting a somewhat stronger trans effects in the order $\mathrm{N}<\mathrm{O}<\mathrm{P}$. The mean Pt-N vs Pt-L (trans) bond lengths are 2.055 vs $2.220 \AA$ (S) $<2.13$ vs $2.345 \AA$ (As) $<2.135$ vs $2.230 \AA$ (P) indicating a greater trans influence of P over As. The mean Pt-Cl bond 
lengths (trans to L) elongated in the order: $2.29 \AA(\mathrm{L}=\mathrm{O})<2.30 \AA(\mathrm{N})<2.315 \AA(\mathrm{S})<2.32 \AA(\mathrm{Se})<2.345 \AA$ $(\mathrm{Te})<2.36 \AA(\mathrm{P})$. These results suggest a trans influence in the order of $\mathrm{Se}<\mathrm{Te}<\mathrm{P}$. For comparison, the mean $\mathrm{Pt}-\mathrm{Cl}$ bond length in the cis geometry is $2.315 \AA$.

There are a series of heterobidentate ligands $\mathrm{O} / \mathrm{N}, \mathrm{N} / \mathrm{S}, \mathrm{N} / \mathrm{P}, \mathrm{N} / \mathrm{Se}, \mathrm{N} / \mathrm{Te}, \mathrm{S} / \mathrm{P}$ and S/Te. These chelates form metallocyclic rings in which the effects of both steric and electronic factors can be seen in the opening of the L-Pt-L bond angles. For the five-membered metallocyclic rings the mean L-Pt-L bite angles are: $83.5^{\circ}(\mathrm{O} / \mathrm{N})<$ $87.3^{\circ}(\mathrm{N} / \mathrm{S})$ and $(\mathrm{N} / \mathrm{P})<87.6^{\circ}(\mathrm{S} / \mathrm{P})<90^{\circ}(\mathrm{N} / \mathrm{Te})<90.3^{\circ}(\mathrm{N} / \mathrm{Se})<90.5^{\circ}(\mathrm{SPNP})<91.50^{\circ}(\mathrm{S} / \mathrm{Te})$. For the sixmembered rings the respective values are: $91^{\circ}(\mathrm{O} / \mathrm{N})<94.8^{\circ}(\mathrm{N} / \mathrm{S})<95.7^{\circ}(\mathrm{N} / \mathrm{P})$.

There are ten species with chromophores of the $\mathrm{PtS}_{2} \mathrm{XY}$ type a trans configuration about $\mathrm{Pt}(\mathrm{II})$ is created by a terdentate $\left(\mathrm{S}, \mathrm{S}^{\prime}, \mathrm{N}\right)$ ligand plus a chlorine atom $\left(\mathrm{PtS}_{2} \mathrm{NCl}\right)$ and it is only example with such chromophore. The ligand forms two five-membered metallocycles with mean N-Pt-S angle of $87.2^{\circ}$. A similar structure has tran$\mathrm{PtS}_{2} \mathrm{NBr}$ derivative, here a terdentate (S,S,N) ligand also forms two five-membered metallocycles (N-Pt-S, $85.7^{\circ}$ ). In another two trans derivatives a distorted square planar environment about the $\mathrm{Pt}(\mathrm{II})$ atom is formed by a bidentate $(\mathrm{S}, \mathrm{N})$ chelate with a unidentate $\mathrm{S}$-donor ligand and a $\mathrm{PPh}_{3}$ molecule $\left(\mathrm{PtS}_{2} \mathrm{NP}\right)$. The chelating ligand forms a four- in one example and five- in another one, membered metallocycle with N-Pt-S angles of $78.3^{\circ}$ and $84.9^{\circ}$, respectively. Therefore the former is more distorted than the latter.

There are three cis $\mathrm{PtS}_{2} \mathrm{XY}$ derivatives in which both $\mathrm{X}$ and $\mathrm{Y}$ are halogen atoms $(\mathrm{Cl}+\mathrm{I}, \mathrm{Br}+\mathrm{I})$. The chelating (S,S") ligand forms a five-membered metallocycle with the $\mathrm{Pt}(\mathrm{II})$ atom in each case at a mean S-Pt-S angle of $91.0^{\circ}$.

There are six trans derivatives with the $\mathrm{PtP}_{2} \mathrm{HO}$ chromophore, created by two unidentate P-donor ligands, a hydrogen atom and a unidentate O-donor ligand. The trans P-Pt-P angle ranges from $166.1^{\circ}$ to $170.7^{\circ}$. Another nine derivatives have the $\mathrm{PtP}_{2} \mathrm{HM}$ chromophore involving also only unidentate ligands. The trans P-Pt-P angles range from $161.4^{\circ}$ to $170.9^{\circ}$ with a mean value of $166.8^{\circ}$ which is about $1.0^{\circ}$ smaller than the O-donor analogues.

Another seven trans derivatives contain the $\mathrm{PtP}_{2} \mathrm{HCl}$ chromophore with P-Pt-Pt angles ranging from $165.7^{\circ}$ to $176.2^{\circ}$, mean value $170.5^{\circ}$. Two trans derivatives also with unidentate ligands have the $\mathrm{PtP}_{2} \mathrm{HS}$ chromophore. Here the P-Pt-P angles are $161.1^{\circ}$ and $162.6^{\circ}$, respectively. A $\mathrm{PtP}_{2} \mathrm{HBr}$ chromophore with unidentate ligand is found in two examples with P-Pt-P angle of $163.9^{\circ}$.

There are six derivatives with the $\mathrm{PtP}_{2} \mathrm{HSi}$ chromophore, both trans (2 examples) and cis (4 examples). The trans derivatives have unidentate ligands with trans P-Pt-P angle of $166.2^{\circ}$. Two of the cis derivatives have only unidentate ligands and the remainders have a bidentate (P,P') ligand with an $\mathrm{H}$ atom and a S-donor ligand. The chelating ligand forms a seven-membered metallocycle with cis-P-Pt-P bond angles of $102.3^{\circ}$ and $103.5^{\circ}$, respectively. Two $\mathrm{PPr}_{3}^{\mathrm{i}}$ molecules in trans positions, a $\mathrm{H}$ atom and a phenyl iodide ligand form a distorted square plane about $\mathrm{Pt}(\mathrm{II})\left(\mathrm{PtP}_{2} \mathrm{HI}\right)$ with a trans $\mathrm{P}-\mathrm{Pt}-\mathrm{Pt}$ angle of $163.7^{\circ}$.

In the trans derivatives with the $\mathrm{PtS}_{2} \mathrm{HY}$ chromophore there is a relationship between the trans P-Pt-Pt angle and the cis-X-Pt-Y angles, the former opening as the trans closes, in the order: $161.8^{\circ}$ vs $98.8^{\circ}(\mathrm{Y}=\mathrm{S}) ; 163.7^{\circ}$ vs $98.7^{\circ}(\mathrm{I}) ; 163.9^{\circ}$ vs $98.0^{\circ}(\mathrm{Br}) ; 166.2^{\circ}$ vs $96.7^{\circ}(\mathrm{Si}) ; 166.8^{\circ}$ vs $96.1^{\circ}(\mathrm{N}) ; 167.8^{\circ}$ vs $95.8^{\circ}(\mathrm{O}) ; 170.5^{\circ}$ vs $94.7^{\circ}$ (Cl). The mean Pt-Y (trans to H) distance elongated in the order: $2.11 \AA(\mathrm{Y}-\mathrm{N})<2.165 \AA(\mathrm{O})<2.355 \AA(\mathrm{Si})<$ $2.385 \AA(\mathrm{S})<2.400 \AA(\mathrm{Cl})<2.572 \AA(\mathrm{Br})<2.696 \AA$ (I). The mean Pt-H and Pt-P bond lengths found in the trans derivatives are $1.50( \pm 0.02) \AA$ and $2.290( \pm 0.03) \AA$, respectively.

There are over twenty species with the $\mathrm{PtP}_{2} \mathrm{OY}$ chromophore. Ten of them are cis with $\mathrm{Y}=\mathrm{N}$. In eight of these there is a hetero-bidentate $(\mathrm{O}, \mathrm{N})$ divalent anionic ligand with two $\mathrm{PPh}_{3}$ molecules. In seven of these the chelate forms a five-membered metallocycle with mean O-Pt-N angle of $79.3^{\circ}$. In the other case, there is a sixmembered metallocycle with angle of $87.1^{\circ}$. In the other two derivatives of cis- $\mathrm{PtP}_{2} \mathrm{ON}$ type there are two chelate ligands, one homo-bidentate $\left(\mathrm{P}, \mathrm{P}^{\prime}\right)$ and the other hetero-bidentate $(\mathrm{O}, \mathrm{N})$. Five-membered metallocyclic rings are found with P-Pt-P and O-Pt-N angles of $86.4^{\circ}$ and $80.2^{\circ}$. The mean Pt-P (trans to O) and Pt-P (trans to N) distance are 2.25 and $2.28 \AA$, respectively.

Four examples have a $\mathrm{PtP}_{2} \mathrm{OCl}$ chromophore formed by a hetero-bidentate $(\mathrm{O}, \mathrm{P})$ ligand a $\mathrm{Cl}$ atom and a $\mathrm{P}$ donor ligand. Each chelate ligand forms a five-membered metallocycle with the mean O-Pt-P angle of $84.8^{\circ}$ $(\mathrm{OPNP})$ and $84.2^{\circ}\left(\mathrm{OC}_{2} \mathrm{P}\right)$. The mean Pt-Cl (trans to O) and Pt-P (trans to P) bond lengths are 2.295 and 2.350 $\AA$, respectively, suggesting a larger trans effect for $\mathrm{P}$ than $\mathrm{O}$.

Five cis-derivatives contain the $\mathrm{PtP}_{2} \mathrm{OS}$ chromophore created by a hetero-bidentate $(\mathrm{O}, \mathrm{S})$ ligand with two $\mathrm{PPh}_{3}$ molecules. In four derivatives there are heterobidentate $(\mathrm{O}, \mathrm{S})$ chelating ligands, three with five-membered 
metallocyclic rings with angles $82.7^{\circ}$ (OCNS), and $84.2^{\circ}\left(\mathrm{OC}_{2} \mathrm{~S}\right)$. In the fourth case the 1,2-SC $\mathrm{H}_{4} \mathrm{COO}$ divalent anion forms a six-membered metallocycle with O-Pt-S angle of $84.7^{\circ}$. The mean Pt-P (trans to O) and Pt-P (trans to S) bond lengths are 2.247 and $2.302 \AA$, respectively. In another derivative a hetero-bidentate (O,P) ligand, a unidentate P-donor and a bromine atom form a cis- $\mathrm{PtP}_{2} \mathrm{OBr}$ chromophore. The O-Pt-P angle of a fivemembered metallocycle is $83.11^{\circ}$. cis- $\mathrm{PtP}_{2} \mathrm{OSi}$ chromophore in other derivative is created by a bidentate $\left(\mathrm{P}, \mathrm{P}^{\prime}\right)$ ligand, a unidentate O-donor ligand and a unidentate Si-ligand.

The mean Pt-P (trans to Y) and Pt-P (trans to P) bond length change in the order: 2.22 and $2.09 \AA(\mathrm{Y}=\mathrm{O})<$ 2.24 and $2.35 \AA(\mathrm{Cl})<2.255$ and $2.04 \AA(\mathrm{N}) \sim 2.25$ and $2.455 \AA(\mathrm{Br})<2.302$ and $2.31 \AA(\mathrm{S})<2.38$ and $2.40 \AA$ (Si). In the five-membered metallocyclic rings the O-Pt-L angle opens in the sequence (mean values): $79.5^{\circ}$ $\left(\mathrm{OC}_{2} \mathrm{~N}\right)<81.8^{\circ}(\mathrm{OCNS})<83.6^{\circ}(\mathrm{ONCS})<83.8^{\circ}\left(\mathrm{OC}_{2} \mathrm{P}\right)<84.5^{\circ}(\mathrm{OPNP})$.

The most common $\mathrm{Pt}(\mathrm{II})$ derivatives are those with the general inner coordination sphere of $\mathrm{PtP}_{2} \mathrm{NY}$, with 30 $(\mathrm{Y}=\mathrm{Cl}), 22(\mathrm{~S}), 2(\mathrm{Br}), 5(\mathrm{Se})$ and $1(\mathrm{I})$. In the $\mathrm{Cl}$ derivatives fourteen are cis and four trans with only unidentate ligands using $\mathrm{PPh}_{3}$ or $\mathrm{PEt}_{3}$. In another nine cis derivatives there are hetero-bidentate $(\mathrm{N}, \mathrm{P})$ ligands with a $\mathrm{PMe}_{3}, \mathrm{PEt}_{3}$ or $\mathrm{PPh}_{3}$ ligand and the $\mathrm{Cl}$ atom, forming metallocyclic rings with varying numbers of ring atoms, four-N-Pt-P angle $70.8^{\circ}(\mathrm{NCP})$; five-80.1 $1^{\circ}(\mathrm{NCNP})$ and $84.2^{\circ}\left(\mathrm{NC}_{2} \mathrm{P}\right)$; six-89.4 $4^{\circ}\left(\mathrm{NCN}_{2} \mathrm{P}\right)$ and $94.5^{\circ}\left(\mathrm{NC}_{2} \mathrm{NP}\right)$. There are three $\mathrm{PtP}_{2} \mathrm{NCl}$ derivatives in which hetero-tridentate $\left(\mathrm{P}, \mathrm{P}^{\prime}, \mathrm{N}\right)$ ligand with a $\mathrm{Cl}$ atom forms a such chromophore. In one of these (trans) a heterotridentate ligand forms two almost equal five-membered metallocycles with N-Pt-P angles of $84.2^{\circ}$ and $84.9^{\circ}$. In another trans derivative, the hetero-tridentate ligand forms a five-(N-Pt-P) and six-(N-Pt-P) metallocycles with angle of $80.7^{\circ}$ and $91.3^{\circ}$, respectively. In the third one (cis) the respective ligand created a five-(N-Pt-P) and six-(P-Pt-P) membered rings for which the data are not available.

In the derivatives $\left(\mathrm{PtP}_{2} \mathrm{NCl}\right.$ ) with unidentate ligands, the mean values of the Pt-P (trans to $\mathrm{N}$ ) and $\mathrm{Pt}-\mathrm{N}$ (trans to $\mathrm{P}$ ) bond lengths are 2.265 and $2.07 \AA$. The Pt-P (trans to $\mathrm{Cl}$ ) and Pt-Cl (trans to $\mathrm{P}$ ) bond lengths are 2.250 and $2.350 \AA$. When heterobidentate (N,P) ligands are involved the mean Pt-P and Pt-N (mutually trans) bond lengths are at 2.255 and $2.120 \AA$, and the Pt-P and Pt-Cl (mutually trans) are 2.205 and $2.360 \AA$. When hetero-tridentate $\left(\mathrm{P}, \mathrm{P}^{\prime}, \mathrm{N}\right)$ ligand are involved, the Pt-P and Pt-N (mutually trans) bond lengths are 2.298 and $2.165 \AA$, while the mutually trans Pt-P and Pt-Cl values are 2.245 and $2.393 \AA$, and the mutually trans Pt-N and Pt-Cl values are 2.03 and $2.307 \AA$.

The effects of both electronic and steric factors can be seen in the opening of the L-Pt-L bond angles of the respective metallocyclic rings. The five-membered metallocycles open in the sequence: $80.1^{\circ}(\mathrm{NCNP})<83.5^{\circ}$ $\left(\mathrm{NC}_{2} \mathrm{P}\right)$. For the six-membered rings the sequence is: $86.4^{\circ}\left(\mathrm{NC}_{2} \mathrm{NP}\right)<89.4^{\circ}\left(\mathrm{NCN}_{2} \mathrm{P}\right)<91.2^{\circ}\left(\mathrm{NNC}_{2} \mathrm{P}\right)<94.5^{\circ}$ $\left(\mathrm{NC}_{2} \mathrm{OP}\right)$.

There are twenty two derivatives with the $\mathrm{PtP}_{2} \mathrm{NS}$ inner coordination sphere, one is trans and remainders are cis. In the trans and two cis-derivatives only unidentate ligands are involved. In eighteen cis-derivatives a heterobidentate $(\mathrm{N}, \mathrm{S})$ chelating ligand and two unidentate P-donor ligands create the distorted square planar arrangement around the $\mathrm{Pt}(\mathrm{II})$ atom $\left(\mathrm{PtP}_{2} \mathrm{NS}\right)$. Four-membered (3 derivatives), five-membered (13 derivatives), and six-membered (2 derivatives) metallocycles are involved for which the mean N-Pt-S bond angles are: $70.0^{\circ}$ (NCS), $84.8^{\circ}$ (NSNS), $88.4^{\circ}\left(\mathrm{NC}_{2} \mathrm{NS}\right)$ and $93.3^{\circ}$ (NCNCS), respectively. In remaining cis-derivative the $\mathrm{PtP}_{2} \mathrm{NS}^{\circ}$ chromophore is created by hetero-terdentate $(\mathrm{P}, \mathrm{N}, \mathrm{S})$ ligand and $\mathrm{PPh}_{3}$ molecule. The terdentate ligand forms two metallocyclic rings four-(N-Pt-S) and five-(N-Pt-P) membered rings with the bond angles of $69.5^{\circ}$ and $83.5^{\circ}$, respectively.

The data for the $\mathrm{PtP}_{2} \mathrm{NS}$ derivatives with unidentate ligands shows the mean Pt-P (trans to $\mathrm{N}$ ) and $\mathrm{Pt}-\mathrm{N}$ (trans to P) lengths are 2.255 and $2.05 \AA$, respectively. The mutually trans Pt-P and Pt-S values are 2.285 and $2.365 \AA$. The bidentate $(\mathrm{N}, \mathrm{S})$ ligands the mutually trans Pt-P and Pt-N values are 2.264 and $2.05 \AA$, and the Pt-P and Pt-S values are 2.300 and $2.297 \AA$.

There are two cis-derivatives with $\mathrm{PtP}_{2} \mathrm{NBr}$ inner coordination sphere, one with unidentate ligands and the other with a hetero-bidentate (N,P) ligand plus a $\mathrm{PPh}_{3}$ molecule and bromine atom. In the latter there is a threemembered metallocyclic ring with N-Pt-N bite angle of $51.0^{\circ}$.

In five cis-derivatives the inner coordination sphere about the $\mathrm{Pt}(\mathrm{II})$ atom contains a hetero-bidentate $(\mathrm{N}, \mathrm{Se})$ ligand with a pair of unidentate P-donor ligands (4 derivatives), or two bidentate ligands (P,P' and N,Se) (1 derivative). In three derivatives a bidentate ligand forms a five-membered with a N-Pt-Se angle of 87.1 (NSeNSe) ( 2 derivatives) and $85.8^{\circ}$ (NSNSe) (1 derivative). A six-membered ring with angle $93.9^{\circ}\left(\mathrm{NC}_{2} \mathrm{NSe}\right.$ ) is found in one derivative. Two bidentate ligands in the last example form two five-membered metallocycles with P-Pt-P 
and N-Pt-Se angles of $84.8^{\circ}$ and $83.8^{\circ}$ (NCNSe).

One trans-derivative has an inner coordination sphere with a hetero-terdentate $\left(\mathrm{P}, \mathrm{N}, \mathrm{P}^{\prime}\right)$ ligand and an iodine atom $\left(\mathrm{PtP}_{2} \mathrm{NI}\right)$. The terdentate ligand forms two metallocycles, five-membered (N-Pt-P) $83.3^{\circ}$ and six-membered (P-Pt-P) $89.2^{\circ}$. In cis-derivative two $\mathrm{PMe}_{2} \mathrm{Ph}$ molecules and a hetero-bidentate $(\mathrm{N}, \mathrm{Te})$ form a distorted square plane $\left(\mathrm{PtP}_{2} \mathrm{NTe}\right)$. The bidentate ligand forms a five-membered metallocycle with $\mathrm{N}-\mathrm{Pt}-\mathrm{Te}$ angle of $84.9^{\circ}$.

In the $\mathrm{PtP}_{2} \mathrm{NY}$ derivatives the mean Pt-P (trans to $\mathrm{P}$ ) and $\mathrm{Pt}-\mathrm{Y}$ (trans to $\mathrm{P}$ ) bond lengths are 2.254 and $2.07 \AA$ $(\mathrm{Y}=\mathrm{N}) ; 2.242$ and $2.505 \AA$ (Br); 2.285 and $2.399 \AA$ (Se), and 2.131 and $2.552 \AA$ (Te). The mutually trans Pt-N and Pt-I bond lengths are 2.062 and $2.609 \AA$. The N-Pt-Y angles open in the order: $51.0^{\circ}(\mathrm{NCP})<83.3^{\circ}\left(\mathrm{NC}_{2} \mathrm{P}\right)$ $<83.8^{\circ}(\mathrm{NCNSe})<84.9^{\circ}(\mathrm{NSNTe})<85.5^{\circ}(\mathrm{NSNSe})<87.2^{\circ}\left(\mathrm{NC}_{2} \mathrm{Se}\right)<89.2^{\circ}\left(\mathrm{NC}_{3} \mathrm{P}\right)<93.9^{\circ}\left(\mathrm{NC}_{2} \mathrm{NSe}\right)$.

Two derivatives trans- and cis, contain the $\mathrm{PtP}_{2} \mathrm{BCl}$ inner coordination sphere. While the cis-derivative has only unidentate ligands, the trans derivative has a hetero-bidentate $(\mathrm{P}, \mathrm{B})$ ligand a unidentate $\mathrm{P}$-donor ligand and a chlorine atom. Bidentate ligand forms a four-membered metallocycle (Pt pB) with P-Pt-B angle of $73.6^{\circ}$.

Four species have an inner coordination sphere $\mathrm{PtP}_{2} \mathrm{ClS}$. One cis- and one trans-derivative contain only unidentate ligands. In another two trans-derivatives a hetero-bidentate $(\mathrm{P}, \mathrm{S})$ or a hetero-terdentate ligand are involved. In the former, heterobidentate ligand forms a five-membered metallocycle with P-Pt-S angle of $91.0^{\circ}$ (PCPS), and in the latter, hetero-terdentate ligand forms two five-membered metallocycles for which data are not available.

There are five derivatives with the $\mathrm{PtP}_{2} \mathrm{ClSi}$ inner coordination sphere, four trans- and one cis. In three of trans, only unidentate ligands are involved. The fourth trans-derivative has a hetero-terdentate (P, $\left.\mathrm{P}^{\prime}, \mathrm{Si}\right)$ ligand and a chlorine atom to form the distorted square plane. There are two five-membered metallocycles with P-Pt$\mathrm{Si}$ angles of $89.4^{\circ}$ and $89.9^{\circ}$, respectively. The trans- $\mathrm{Pt}\left(\mathrm{PEt}_{3}\right)_{2}(\mathrm{Br})\left(\mathrm{SiMe}_{3}\right)$ has an inner coordination sphere of $\mathrm{PtP}_{2} \mathrm{BrSi}$ another trans-derivative $\mathrm{PtP}_{2} \mathrm{SiTe}$.

The data for the derivatives with $\mathrm{PtP}_{2} \mathrm{BCl}, \mathrm{PtP}_{2} \mathrm{ClS}, \mathrm{PtP}_{2} \mathrm{ClSi}, \mathrm{PtP}_{2} \mathrm{BrSi}$ and $\mathrm{Pt}_{2} \mathrm{SiTe}$ show the mean variation in trans influenced Pt-L bond lengths are: $2.235 \AA(\mathrm{L}=\mathrm{P})$ vs $2.382 \AA(\mathrm{Cl}) ; 2.286 \AA(\mathrm{P})$ vs $2.320 \AA(\mathrm{S}) ; 2.326 \AA$ $(\mathrm{P})$ vs $2.423 \AA(\mathrm{Si}) ; 2.330 \AA(\mathrm{Cl})$ vs $2.233 \AA(\mathrm{S}) ; 2.430 \AA(\mathrm{Cl})$ vs $2.08 \AA(\mathrm{B}) ; 2.605 \AA(\mathrm{Br})$ vs $2.33 \AA$ ( $\mathrm{Si})$, and $2.35 \AA$ (Si) vs $2.764 \AA$ (Te).

In cis $\mathrm{PtBr}_{2}(\mathrm{MeCN})(\mathrm{dmso})$ an unidentate ligands created a slightly distorted square planar arrangement about the $\mathrm{Pt}(\mathrm{II})$ atom $\left(\mathrm{PtBr}_{2} \mathrm{NS}\right)$. In trans- $\mathrm{PtBr}_{2} \mathrm{Cl}\left(\mathrm{PPh}_{3}\right)$ also unidentate ligands created a somewhat distorted square plane about the $\mathrm{Pt}(\mathrm{II})$ atom $\left(\mathrm{PtBr}_{2} \mathrm{ClP}\right)$. Another trans-derivative has the $\mathrm{PtSe}_{2} \mathrm{NP}$ chromophore made up from a hetero-bidentate $(\mathrm{N}, \mathrm{Se})$ ligand, a unidentate Se-ligand and a $\mathrm{PPh}_{3}$ molecule. The N-Pt-Se angle of the fourmembered metallocycle is $78.2^{\circ}$. Another trans-derivative has a hetero-terdentate $\left(\mathrm{As}_{2} \mathrm{~S}\right)$ ligand and a chlorine atom giving the $\mathrm{PtAs}_{2} \mathrm{ClS}$ chromophore. The hetero-terdentate ligand forms two six-membered metallocycles with mean S-Pt-As angle of $93.0^{\circ}$.

Trans-PtI 2 (3,5-Me $2 \mathrm{py}$ )(dmso) has only unidentate ligands giving a slightly distorted square planar environment $\left(\mathrm{PtI}_{2} \mathrm{NS}\right)$. There are two derivatives with $\mathrm{PtI}_{2} \mathrm{NP}$ chromophore, one cis and one trans. The cis derivative has two iodine atoms and a hetero-bidentate (N,P) ligand with a N-Pt-P angle of $88.3^{\circ}$. The trans derivative involves only unidentate ligands. In cis-derivative the $\mathrm{PtI}_{2} \mathrm{SP}$ chromophore is build up by two iodine atoms and a hetero-bidentate (S,P) ligand with S-Pt-P angle of $86.9^{\circ}$.

The Pt-N (trans to Y) versus Pt-Y (trans to N) bond lengths have the values: 1.985 vs $2.395 \AA$ (mean) ( $\mathrm{Y}=$ $\mathrm{Br}$ ), 2.05 vs $2.306 \AA$ (Cl); 2.054 vs $2.586 \AA$ (I); 2.08 vs $2.233 \AA$ (S); and 2.168 vs $2.232 \AA$ (P). The Pt-Cl (trans to $\mathrm{Y}$ ) vs Pt-Y (trans to $\mathrm{Cl}$ ) bond lengths have the values 2.231 vs $2.438 \AA$ (mean) ( $\mathrm{Y}=\mathrm{S}$ ), 2.168 vs $2.232 \AA$ (P). The Pt-S (trans to Y) vs Pt-Y (trans to S) bond lengths the values are: 2.314 vs $2.428 \AA$ (mean) $(\mathrm{Y}=\mathrm{Br}$ ) and 2.280 vs $2.598 \AA$ (I). The mean Pt-P (trans to I) vs Pt-I (trans to I) the values are: 2.230 vs $2.657 \AA$. In the $\mathrm{PtP}_{2} \mathrm{XY}$ derivatives with bidentate or terdentate ligands the L-Pt-L angles open in the order: $78.1^{\circ}(\mathrm{NPSe})<$ $86.9^{\circ}\left(\mathrm{SC}_{2} \mathrm{P}\right)<88.3^{\circ}\left(\mathrm{NC}_{3} \mathrm{P}\right)<88.5^{\circ}$ (mean) $\left(\mathrm{NC}_{2} \mathrm{Te}\right)<93.0^{\circ}\left(\mathrm{SC}_{3} \mathrm{As}\right)$.

There are thirteen derivatives with the chromophore PtABXY in a distorted square planar geometry. Five species have the inner coordination sphere of PtONClS. All have a hetero-bidentate $(\mathrm{O}, \mathrm{N})$ ligand, a chlorine atom and dimethylsulphoxide molecule. Four derivatives have a five-membered metallocyclic ring and one has a six membered with the mean O-Pt-N angles of $81.5^{\circ}$ and $90.8^{\circ}$, respectively.

Four derivatives have the PtONClP chromophore. Three of these contain a heterobidentate $(\mathrm{O}, \mathrm{N})$ ligand, a chlorine atom and $\mathrm{PR}_{3}$ molecule. A five-membered metallocycles have the mean O-Pt-N angle of $80.3^{\circ}$. There is example, in which hetero-terdentate (O,N,P) with a chlorine atom forms a distorted square plane (PtONClP). This ligand forms two six-membered metallocycles with values of the O-Pt-N and N-Pt-P angles of $93.3^{\circ}$ and 


\section{$94.2^{\circ}$ respectively.}

In another Pt(II) derivative a hetero-terdentate (N,S,P) and a chlorine atom forms PtNClSP chromophore. The terdentate ligand forms five- (NNCS) and six $\left(\mathrm{NC}_{3} \mathrm{P}\right)$ membered metallocycles with the N-Pt-S and N-Pt-P angles of $84.9^{\circ}$ and $95.8^{\circ}$.

Another two derivatives contain a hetero-bidentate $(\mathrm{N}, \mathrm{S})$ ligand, plus $\mathrm{PMe}_{2} \mathrm{Ph}$ molecule and a bromine or iodine atom. The chelating ligand forms a five-membered metallocycle with N-Pt-S angle of $85.4^{\circ}$ (PtNSPBr) and $85.5^{\circ}$ (PtNSPI). Another derivative with PtNSPI chromophore has a hetero-terdentate (N,S,P) ligand and iodine atom. The chelating ligand forms two six-membered metallocycles N-Pt-S and N-Pt-P angles of $93.2^{\circ}$ and $89.1^{\circ}$, respectively.

In the PtABXY derivatives the mean Pt-O (trans to Y) vs Pt-Y (trans to O) bond lengths are: 1.995 vs 2.287 $\AA(\mathrm{Y}=\mathrm{Cl}) ; 2.017$ vs $2.185 \AA(\mathrm{S})$; and 2.14 vs $2.206 \AA(\mathrm{P})$. The Pt-N (trans to $\mathrm{Y}$ ) vs Pt-Y (trans to $\mathrm{N}$ ) bond lengths are: 2.00 vs $2.313 \AA$ ( $\mathrm{Y}=\mathrm{Cl}) ; 2.05$ vs $2.238 \AA$ (P); and 2.055 vs $2.520 \AA$ (I). The Pt-S (trans to $\mathrm{Y}$ ) vs Pt-Y (trans to S) are 2.222 vs $2.475 \AA(\mathrm{Y}=\mathrm{Br}) ; 2.228$ vs $2.635 \AA$ (I); and 2.331 vs $2.247 \AA$ (P).

\subsection{Pt(II) Complexes-Five Coordinated}

Detail analyzed of the structures of penta coordinated Pt(II) complexes was done [4]. Therefore, only briefly view of the structures will be outline here. There are only seven such derivatives and in all each Pt(II) atom has a trigonal bipyramidal arrangement. In three of them a tetradentate- $\mathrm{P}_{4}$ ligand with hydride forms such arrangement. The trigonal plane is build up by three $\mathrm{P}$ atoms of the respective tetradentate ligand and the fourth $\mathrm{P}$-atom occupied with hydride atom an axial positions. The mean Pt-P $\mathrm{P}_{\mathrm{eq}}$ bond distance of $2.315 \AA$ is somewhat longer than the mean Pt- $\mathrm{P}_{\mathrm{ax}}$ bond $(2.210 \AA)$. The Pt- $\mathrm{H}_{\mathrm{ax}}$ bond distances are not available. The terdentate $\mathrm{P}_{4}$ ligand forms three five-membered metallocycle with the mean P-Pt-P angles of $85.6^{\circ}$. In another derivative, a tetradentate $\mathrm{P}_{4}$ ligand with a unidentate $\mathrm{P}$-donor ligand created a trigonal-bipyramidal arrangement about the $\mathrm{Pt}(\mathrm{II})$ atom $\left(\mathrm{PtP}_{5}\right)$. In this case also three $\mathrm{P}$ atoms of the chelating ligand created trigonal plane and the fourth $\mathrm{P}$ atom with a unidentate P-atom occupied an axial positions. The mean Pt- $\mathrm{P}_{\mathrm{eq}}$ bond distances of $2.372 \AA$ are longer than remaining two Pt- $\mathrm{P}_{\mathrm{ax}}$ bond distances $(2.298 \AA$ ). The tetradentate ligand created three five-membered metallocycles with the mean P-Pt-P angles of $83.4^{\circ}$.

There is an example in which hetero-tetradentate $\left(\mathrm{P}_{3} \mathrm{~N}\right)$ ligand with an unidentate $\mathrm{PHEt}_{2}$ ligand build up a trigonal-bipyramidal environment about the $\mathrm{Pt}(\mathrm{II})$ atom. An equatorial plane is occupied by three $\mathrm{P}$ atoms of the chelating ligand and an $\mathrm{N}$ atom of the respective ligand with $\mathrm{PHEt}_{2}$ ligand occupied an axial positions. The mean P-Pt-N "bite" angles are 84.2 ${ }^{\circ}$. The Pt-L bond distance elongated in the order: $2.196 \AA\left(\mathrm{Pt}-\mathrm{N}_{\mathrm{ax}}\right)<2.256 \AA$ $\left(\mathrm{Pt}-\mathrm{P}_{\mathrm{ax}}\right)<2.695 \AA\left(\mathrm{Pt}-\mathrm{P}_{\mathrm{eq}}\right)$. In other derivative a tetradentate $\left(\mathrm{P}_{3} \mathrm{~N}\right)$ ligand with an unidentate $\mathrm{AsPh}_{2}$ ligand forms a trigonal-bipyramid about the $\mathrm{Pt}(\mathrm{II})$ atom. Three $\mathrm{P}$ atoms of the chelating ligand created a trigonal plane and axial positions are occupied by $\mathrm{N}$ atom and As atom. The Pt-L bond distance elongated in the order: $2.276 \AA$ $\left(\mathrm{Pt}-\mathrm{N}_{\mathrm{ax}}\right)<2.350 \AA\left(\mathrm{Pt}-\mathrm{P}_{\mathrm{eq}}\right)<2.457 \AA\left(\mathrm{Pt}^{-} \mathrm{As}_{\mathrm{ax}}\right)$. The mean N-Pt-P "bite" angle is $84.0^{\circ}$. Finally, there is a derivative in which a tetradentate- $\mathrm{As}_{4}$ ligand with iodine atom created a trigonal-bipyramid about the $\mathrm{Pt}(\mathrm{II})$ atom. Unfortunately, the crystal data are not available.

\section{Pt(III) Complexes}

Detail analyzed of crystallographic and structural data of Pt(III) complexes are in [5]. Therefore, in this part will be given only a briefly view on the structures. There are fifteen $\mathrm{Pt}(\mathrm{III})$ derivatives for which structural data are available. A pair of diphenylglyoximate-N,N' chelating anion create a distorted square-planar geometry about the $\mathrm{Pt}(\mathrm{III})$ atom with $\mathrm{PtN}_{4}$ chromophore and it is only one such example. Each of the chelating ligand forms five-membered metallocycle with the N-Pt-N bond angle of $77.0^{\circ}$. The mean Pt-N bond distance is $1.95 \AA$. The next twelve Pt(III) derivatives have a pair of bidentate-S,S' donor chelating ligands to make a square-planar geometry about $\mathrm{Pt}(\mathrm{III})$ atom $\left(\mathrm{PtS}_{4}\right)$. The Pt-S bond distances range from 2.25 to $2.30 \AA$ (ave $2.27 \AA$ ). The fivemembered metallocycles with S-Pt-S bite angles range from $88.5^{\circ}$ to $91.5^{\circ}$ (ave $89.5^{\circ}$ ).

There is also example, in which a pair of chelating-Se,Se' ligands form a square-planar geometry about the $\mathrm{Pt}(\mathrm{III})$ atom $\left(\mathrm{PtSe}_{4}\right)$. The mean Pt-Se bond distance is $2.367 \AA$. Each of the chelating ligand forms a five-membered metallocycle with the Se-Pt-Se bite angle of $90.3^{\circ}$.

In $\mathrm{PtCl}_{3}\left(\eta^{2}\right.$-en) complex the $\mathrm{Pt}(\mathrm{III})$ atom has a square-pyramidal geometry $\left(\mathrm{PtCl}_{3} \mathrm{~N}_{2}\right)$. The two chlorine atoms 
with two $\mathrm{N}$ atoms of chelating ethylenediamine created square plane and remaining chlorine atom occupied an axial position. The Pt-L bond distance elongated in the order $2.04 \AA\left(\mathrm{Pt}-\mathrm{N}_{\mathrm{eq}}\right)<2.313 \AA$ (mean) $\left(\mathrm{Pt}-\mathrm{Cl}_{\mathrm{eq}}\right)<2.376$ $\AA$ ( $\left.\mathrm{Pt}-\mathrm{Cl}_{\mathrm{ap}}\right)$. The N-Pt-N bite angle is $84.6^{\circ}$.

A pair of bidentate maleonitriledithiolate dianion-S,S' chelating ligands in the respective complex anion form a distorted square-planar geometry about $\mathrm{Pt}(\mathrm{III})$ atom $\left(\mathrm{PtS}_{4}\right)$. The mean Pt-S bond distance is $2.269 \AA$ and the mean S-Pt-S bite angle is $90.3^{\circ}$.

\section{Pt(IV) Complexes}

\section{1. $\mathrm{PtA}_{4}(\mathrm{~A}=\mathrm{N}$ or $\mathrm{S}), \mathrm{PtA}_{6}(\mathrm{~A}=\mathrm{O}, \mathrm{N}, \mathrm{Cl}, \mathrm{S}, \mathrm{P}, \mathrm{Se}$ or $\mathrm{I})$}

There are only three derivatives in which $\mathrm{Pt}(\mathrm{IV})$ atoms are in a square-planar environment with $\mathrm{PtN}_{4}$ (2 examples) and $\mathrm{PtS}_{4}$ (1 example). In one $\mathrm{PtN}_{4}$ four unidentate $\mathrm{N}$-donor ligands and another $\mathrm{PtN}_{4}$ chromophore is created by terdentate ligand and a unidentate ligand. In the former the mean Pt-N bond distance is $2.036 \AA$. For the latter derivative only unit cell dimensions are available. In the third example a pair of bidentate-S,S' ligand forms a square-planar geometry about the Pt(IV) atom $\left(\mathrm{PtS}_{4}\right)$. The mean Pt-S bond distance is $2.241 \AA$. Each of the chelating ligand forms a five-membered metallocycle with the S-Pt-S bite angle of $88.0^{\circ}$.

There are over sixty Pt(IV) derivatives, where each Pt(IV) atom is, six-coordinated by equivalent donor atoms. Two derivatives contain a $\mathrm{PtO}_{6}$ inner coordination sphere. One has a centrosymmetric trans- $\left[\mathrm{Pt}\left(\eta^{2}-\mathrm{ox}\right)_{2}(\mathrm{OH})_{2}\right]^{2-}$ anion connected via hydrogen bonds from its $\mathrm{OH}$ groups to the aqua ligands of two protonated complex anions trans- $\left[\mathrm{Pt}\left(\eta^{2}-\mathrm{Ox}\right)_{2}(\mathrm{OH})\left(\mathrm{H}_{2} \mathrm{O}\right)\right]^{-}$. While the divalent anion has six almost equal Pt-O bond lengths (four at 1.993 and two at $1.994 \AA$ ) the monovalent anion has four distances at $1.992 \AA$ and the other two are 1.958 and $2.034 \AA$. This indicates a higher degree of distortion with 4:1:1 arrangement in the monovalent anion. In another Pt(IV) derivative a pentadentate oxygen donor ligand plus a hydroxide group form a distorted octahedral geometry about the Pt(IV) atom. The pentadentate ligand forms four six-membered metallocycles with a mean O-Pt-O bite angle of $95.5^{\circ}$. The Pt-OH bond distance of $2.039 \AA$ is somewhat longer than the mean Pt-O bond distance (2.006 $\AA$ ).

Six derivatives have the $\mathrm{PtN}_{6}$ chromophore. In two of them a pair of bidentate chelating ligands plus two $\mathrm{NH}_{3}$ molecules forms the coordination sphere. In one derivative the 1-methylcytosinate ligands form a four-membered metallocycles with the N-Pt-N bite angles of $63.9^{\circ}$. In another one a pair of 2,4-pentanediiminate ligands form a six-membered metallocycles with the N-Pt-N bite angles of $90.3^{\circ}$. In both derivatives a pair of the chelating ligands create the plane while $\mathrm{NH}_{3}$ molecules occupy the axial sites, to give a somewhat elongated tetragonal bipyramidal geometry about the $\mathrm{Pt}(\mathrm{IV})$ atom. Another $\mathrm{PtN}_{6}$ derivative has a terdentate anion with two unidentate $\mathrm{NO}_{2}^{-}$anions and a pyridine to give somewhat elongated tetragonal bipyramidal geometry. The $\mathrm{NO}_{2}^{-}$anions occupy axial positions, and the terdentate divalent anion forms two five-membered metallocycles with mean $\mathrm{N}$-Pt-N bite angle of $82.7^{\circ}$. In the remaining the $\mathrm{PN}_{6}$ species a hexadentate ligand is involved. The ligands make both five- and six-membered metallocycles with mean N-Pt-N bite angles of $84.5^{\circ}$ and $92.2^{\circ}$, respectively. The mean Pt-N bond distance elongated in the order $2.02 \AA$ (bidentate) $<2.035 \AA$ (ter-) $<2.07 \AA$ (uni-) $<2.075 \AA$ (tetradentate). The mean N-Pt-N bite angle opens in with increasing number of atoms as expected: $64^{\circ}(\mathrm{NCN})<$ $92^{\circ}\left(\mathrm{NC}_{2} \mathrm{~N}\right)<94^{\circ}\left(\mathrm{NC}_{3} \mathrm{~N}\right)$.

There are forty examples with the $\mathrm{PtCl}_{6}$ chromophore. The geometry in each case is octahedral with varying degrees of distortion. The Pt-Cl (equatorial) distances range from 2.21 to $2.34 \AA$ (ave. $2.31 \AA$ ) which is only slightly shorter than that of the Pt-Cl (axial) range from 2.29 to $2.35 \AA$ (ave. $2.32 \AA$ ).

Six derivatives contain a $\mathrm{PtS}_{6}$ inner coordination sphere. In three of them, six thiocyanate groups form a pseudo-octahedral environment about Pt(IV). The Pt-S bond distances range from 2.355 to $2.396 \AA$ (ave. 2.375 $\AA)$. Another two contain $\left[\mathrm{Pt}\left(\eta^{2}-\mathrm{S}_{5}\right)_{3}\right]^{-2}$ anion. The $\mathrm{S}_{5}^{-2}$ ligands are coordinated to $\mathrm{Pt}(\mathrm{IV})$ in a bidentate fashion, forming three six-membered rings around it. The bonding parameters of the anions in both compounds are very similar. The mean S-Pt-S bite angle is $91.2^{\circ}$ (range $90.5^{\circ}-92.1^{\circ}$ ). In another derivative the inner coordination sphere consists of three $\mathrm{S}_{6}^{-2}$ ligands, which form three seven-membered metallocycles with mean S-Pt-S bite angle of $99.9^{\circ}$. The mean Pt-S bond length of $2.376 \AA$ is about $0.021 \AA$ shorter than in the $\left.\mathrm{Pt}\left(\eta^{2}-\mathrm{S}_{5}\right)_{3}\right]^{-2}$.

Structure of $\left[\mathrm{Pt}\left(\eta^{3}-\mathrm{P}_{3}\right)\left(\eta^{3} \text {-triphos) }\right]^{+}\right.$is shown in Figure 9 [14]. The $\mathrm{Pt}(\mathrm{IV})$ atom is six-coordinated by the cyclo- $\mathrm{P}_{3}$ group and the triphos $\mathrm{P}$ atoms, giving a distorted octahedral environment. The mean Pt-P bond distances are $2.435 \AA\left(\mathrm{P}_{3}\right)$ and $2.339 \AA$ (triphos). There are two type of metallocycle, one three- $\left(\mathrm{P}_{3}\right)$ and one six(triphos) membered with P-Pt-P bite angles of $52.6^{\circ}$ and $90.0^{\circ}$, respectively. 


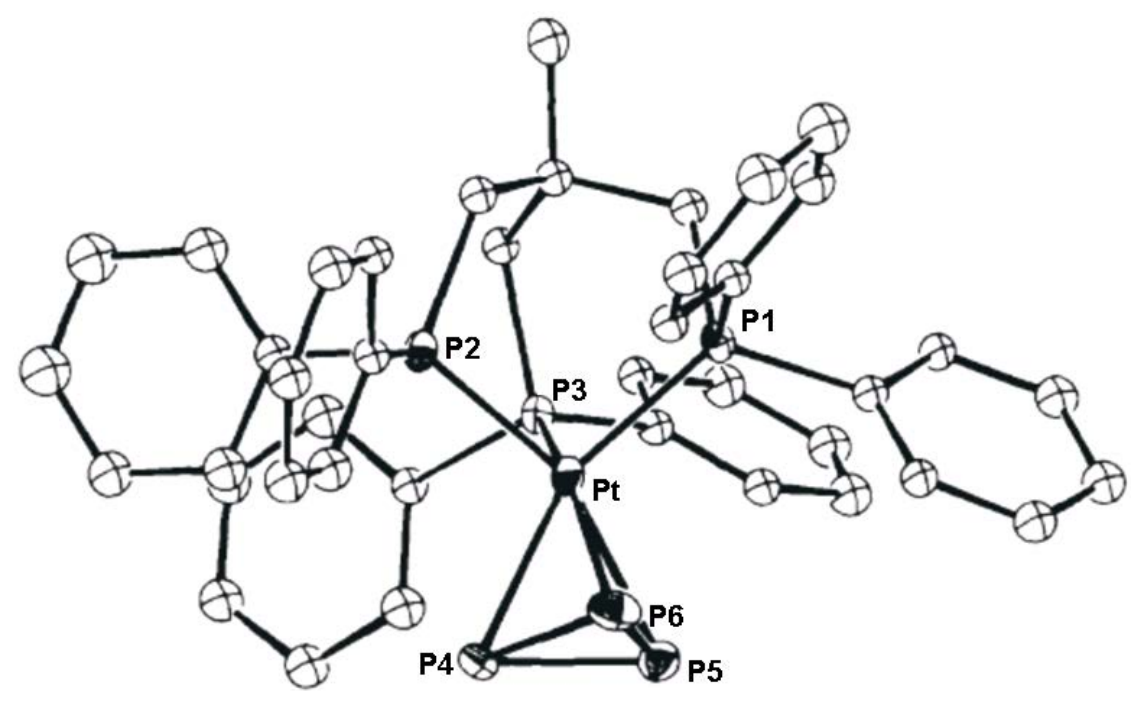

Figure 9. Structure of $\left[\mathrm{Pt}\left(\eta^{2}-\mathrm{P}_{3}\right)\left(\eta^{2} \text {-tripos }\right)\right]^{+}[14]$.

Six bromine atoms form an octahedral geometry about the $\mathrm{Pt}(\mathrm{IV})$ in another derivative $\left(\mathrm{PtBr}_{6}\right)$ with the mean $\mathrm{Pt}-\mathrm{Br}$ bond length of $2.456 \AA$. Three derivatives contain a $\left[\mathrm{Pt}\left(\eta^{2}-\mathrm{Se}_{4}\right)_{3}\right]^{-2}$ complex anion. The $\mathrm{S}_{4}^{-2}$ ligands are coordinated to $\mathrm{Pt}(\mathrm{IV})$ atom in a bidentate fashion forming three five-membered metallocycles. The mean Pt-Se bond distance is $2.486 \AA$ and Se-Pt-Se bite angle is $99.4^{\circ}$. Six iodine atoms form an octahedral arrangement about Pt(IV) atom with mean Pt-I bond distance of $2.665 \AA$ which is about 0.210 and $0.352 \AA$ longer than those for Pt-Br and Pt-Cl.

\subsection{PtA $\mathrm{X}_{3}, \mathrm{PtA}_{4} \mathrm{X}_{2}, \mathrm{PtA}_{3} \mathrm{X}_{3}, \mathrm{PtA}_{4} \mathrm{XY}$}

There are seventeen examples of $\mathrm{PtA}_{5} \mathrm{X}$ type. In one derivative the five fluorine atoms and one chlorine atom form an unsymetrical tetragonal bipyramid about the $\mathrm{Pt}(\mathrm{IV})$ atom $\left(\mathrm{PtF}_{5} \mathrm{Cl}\right)$. Four of the $\mathrm{F}$ atoms, with a mean Pt-F bond distance of $1.929 \AA$ (1.926 - $1.932 \AA$ ), are in one plane, while the fifth $\mathrm{F}$ atom occupies and axial position (Pt-F $1.957 \AA$ ) and the $\mathrm{Cl}$ atom occupies the other (Pt-Cl $2.258 \AA$ ). As noted, the Pt-F (axial) distance is about $0.028 \AA$ longer than the Pt-F (equatorial) which is a result of the $\mathrm{Cl}$ atom trans effect.

In two divalent anions $\left[\mathrm{Pt}\left(\mathrm{NH}_{3}\right)_{2}\left(\eta^{2} \text {-mec }\right)(\eta \text {-mec })(\mathrm{OH})\right]^{-2}$ and $\left[\mathrm{Pt}\left(\eta^{2} \text {-bpy) }\left(\eta^{3} \text {-tachH } \mathrm{H}_{2}\right) .\left(\mathrm{H}_{2} \mathrm{O}\right)\right]^{-2}\right.$, the $\mathrm{Pt}(\mathrm{IV})$ atoms have five $\mathrm{N}$ atoms and one $\mathrm{O}$ atom as donors. In the first anion three unidentate ligands and one bidentate group donate $\mathrm{N}$ atoms, and together with a hydroxide group form a pseudo-octahedral environment about the $\mathrm{Pt}(\mathrm{IV})$ atom $\left(\mathrm{PtN}_{5} \mathrm{O}\right)$. The chelating ligand forms a four-membered metallocyclic ring with the N-Pt-N bite angle of $65.0^{\circ}$. The other anion has ter- and bidentate $\mathrm{N}$ donor ligands, which together with a water molecule form a pseudo-octahedron $\left(\mathrm{PtN}_{5} \mathrm{O}\right)$.

There are four derivatives in which inner coordination sphere about the $\operatorname{Pt}(\mathrm{IV})$ centre consists of five $\mathrm{N}$ atoms and one chlorine atom $\left(\mathrm{PtN}_{5} \mathrm{Cl}\right)$. In two of these, three unidentate $\mathrm{N}$ donor ligands with one bidentate $\mathrm{N}$ donor and together with $\mathrm{Cl}$ atom create a distorted octahedral environment. In a third example two bidentate $\mathrm{N}$-donor ligands are found, and in the fourth terdentate and unidentate ligands provide the $\mathrm{N}$ atoms. Together with the $\mathrm{Cl}$ atom in each case a similar geometry is found with mean Pt-N bond length of $2.09 \AA$ and mean Pt-Cl bond length of $2.34 \AA$. The bi- and terdentate ligands form five-membered metallocycles with mean N-Pt-N bite angle of $81.0^{\circ}$ (range $77.8-84.0$ ).

Five chlorine atoms plus a $\mathrm{O}$ donor ligand form an octahedral environment around $\mathrm{Pt}(\mathrm{IV})$ in three derivatives. The mean Pt-Cl (equatorial) bond distance of $2.315 \AA$ (range $2.30-2.33 \AA$ ) is about 0.035 longer than the Pt-Cl (axial) distance (2.280 $\AA$ ), which is trans to the $\mathrm{O}$ atom, and the Pt-O (axial) distance range from 2.06 to 2.084 $\AA$ (ave. $2.07 \AA$ ).

There are three derivatives which have five chlorine atoms and one $\mathrm{N}$ atom in the inner coordination sphere $\left(\mathrm{PtCl}_{5} \mathrm{~N}\right)$. The mean Pt-Cl (equatorial) distance of $2.315 \AA$ is only about $0.001 \AA$ longer than the Pt-Cl (axial) distance, which is trans to a N atom, and the Pt-N bond distances have the mean value of $2.045 \AA$.

Two other derivatives have five chlorine atoms with an $\mathrm{S}$ atom giving an octahedral environment $\left(\mathrm{PtCl}_{5} \mathrm{~S}\right)$. 
The mean Pt-Cl (axial) distance trans to the $\mathrm{S}$ atom is $2.340 \AA$, and is about $0.025 \AA$ longer than the Pt-Cl (equatorial) distance. The mean Pt-S (axial) distance is $2.335 \AA$.

In $\left[\mathrm{PtCl}_{5}\left(\mathrm{PEt}_{3}\right)\right]^{-}$complex anion the mean Pt-Cl (axial) bond distance (trans to the $\mathrm{P}$ atom) is $2.425 \AA$ which is about $0.110^{\circ}$ longer than the Pt-Cl (equatorial) mean value of $2.315 \AA$. The Pt-P (axial) length is $2.307 \AA$. In $\left[\mathrm{PtBr}_{5}\left(\mathrm{PPh}_{3}\right)^{-}\right.$complex anion the mean Pt-Br (equatorial) distance of $2.468 \AA$ which is about $0.065 \AA$ shorter than the Pt- $\mathrm{Br}$ (axial) value trans to the $\mathrm{P}$ atom. The Pt-P (axial) bond distance is $2.364 \AA$.

The data in $\mathrm{PtA}_{5} \mathrm{X}$ derivatives show the Pt-Cl (trans to $\mathrm{Y}$ ) distance increasing in the order: $2.26 \AA(\mathrm{Y}=\mathrm{F})<$ $2.28 \AA(\mathrm{OL})<2.325 \AA(\mathrm{NL})<2.340 \AA(\mathrm{SL})<2.425 \AA(\mathrm{PL})$. This follows the trans effect of the donor atom $\mathrm{Y}$. The mean Pt-X (equatorial) versus Pt-X (axial) elongated in the order: 1.93 vs $1.96 \AA$ (F, $0.72 \AA$ ) $<2.315$ vs $2.333 \AA(\mathrm{Cl}, 0.99 \AA)<2.468$ vs $2.533 \AA(\mathrm{Br}, 1.14 \AA)$. The hetero-trans X-Pt-Y angles range from 164.9 to $179.8^{\circ}$ (ave. $\left.176.6^{\circ}\right)$.

There are ninety examples with PtA $\mathrm{X}_{4}$ type. Two derivatives contain $\left[\mathrm{PtF}_{4} \mathrm{Cl}_{2}\right]^{-2}$ anions, one cis and the other trans with the sum of all six Pt-X bond distances of 12.31 and $12.37 \AA$, respectively, indicating a trans influence of the $\mathrm{Cl}$ atom on the Pt-F distance. The mean Pt-F vs Pt-Cl (trans) bond distances of 1.96 and $2.26 \AA$ differ from the latter longer $(2.30 \AA)$. This indicates that $\mathrm{Cl}$ has the larger trans effect over $\mathrm{F}$.

Eleven derivatives have an inner coordination sphere of $\mathrm{PtO}_{4} \mathrm{~N}_{2}$. In two of these four unidentate $\mathrm{OH}^{-}$or $\mathrm{CH}_{3} \mathrm{COO}^{-}$groups with a bidentate-N,N' donor ligand form a distorted octahedron about the Pt(IV) atom. The chelating ligand form a five-membered metallocycle with mean N-Pt-N bite angle of $84.5^{\circ}$. In another example a pair of heterobidentate $(\mathrm{O}, \mathrm{N})$ ligands and two $\mathrm{OH}^{-}$units form the distorted octahedron with two five-membered metallocycles with mean O-Pt-N bite angle of $84.5^{\circ}$. Two more derivatives have a pairs of $\mathrm{OH}^{-}$and $\mathrm{NH}_{3}$ ligands with a bidentate- $\mathrm{O}, \mathrm{O}^{\prime}$ ligand, or a pairs of $\mathrm{CH}_{3} \mathrm{COO}^{-}$and $\mathrm{NH}_{3}$ ligands with a bidentate-O,O' ligand.. Each chelating ligand forms a six-membered metallocycle with O-Pt-O bite angles of $94.3^{\circ}$ and $91.3^{\circ}$, respectively.

The remaining six examples use a pair of $\mathrm{OH}^{-}$groups or $\mathrm{CH}_{3} \mathrm{COO}^{-}$groups plus two bidentate ligand one $\mathrm{O}, \mathrm{O}^{\prime}$ and the other $\mathrm{N}, \mathrm{N}^{\prime}$ donor, to give $\mathrm{PtO}_{4} \mathrm{~N}_{2}$ chromophore. The chelating-O,O' ligands created a six-membered metallocycle with the mean O-Pt-O bite angle of $92.3^{\circ}$ and chelating $\mathrm{N}, \mathrm{N}^{\prime}$ ligands a five-membered with the mean N-Pt-N bite angle of $84.5^{\circ}$. The mean Pt-O vs Pt-N (trans) bond lengths 2.01 and $2.02 \AA$, respectively. The values for both homo-trans situations are 2.00 and $2.05 \AA$, respectively.

A pair of oxalate or acetylacetonate groups form a plane about the Pt(IV) with two chlorine atoms (in axial) positions to give tetragonal bipyramidal environment $\left(\mathrm{PtO}_{4} \mathrm{Cl}_{2}\right)$. The chelating ligands form five-membered metallocycles in the former with the mean O-Pt-O bite angle of $83.2^{\circ}$ and in the latter a six-membered (O-Pt-O) 95.9 $9^{\circ}$. A similar structure is found with two bidentate acetylacetonate ligands forming a $\mathrm{PtO}_{4}$ plane with two CNS groups in axial positions $\left(\mathrm{PtO}_{4} \mathrm{~S}_{2}\right)$ with equivalent O-Pt-O bite angles of $96.3^{\circ}$.

Two derivatives $\operatorname{Pt}\left(\eta^{2}-\mathrm{ox}\right)_{2} \mathrm{Br}_{2}$ and $\mathrm{Pt}\left(\eta^{2} \text {-acac }\right)_{2} \mathrm{Br}_{2}$ are isostructural with their chloro analogues. The mean Pt-Br (axial) lengths of $2.453 \AA$ are longer than the Pt-Cl (axial) lengths by about $0.138 \AA$, as would be expected from the covalent radii of $\mathrm{Br}$ and $\mathrm{Cl}$. Another two derivative $\operatorname{Pt}\left(\eta^{2}-\mathrm{ox}\right)_{2} \mathrm{I}_{2}$ and $\operatorname{Pt}\left(\eta^{2} \text {-acac }\right)_{2} \mathrm{I}_{2}$ are isostructural with $\mathrm{Br}$ and $\mathrm{Cl}$ analogues. The mean Pt-I (axial) bond lengths is $2.661 \AA$. This again is longer than the Pt-Br length, as expected. The trans-Pt(py $)_{4} \mathrm{~F}_{2}$ has a $\mathrm{Pt}(\mathrm{IV})$ atom in a squashed tetragonal bipyramidal environment, with four equal in plane Pt-N(py) distances $(2.008 \AA$ ) and Pt-F (axial) at $1.941 \AA$.

Another seven derivatives have $\mathrm{PtN}_{4} \mathrm{O}_{2}$ inner coordination sphere. Six of these have a trans-configuration of which five have only unidentate ligands. The other one has a terdentate $\left(\mathrm{N}, \mathrm{N}^{\prime}, \mathrm{N}^{\prime \prime}\right)$ ligand, one unidentate $\mathrm{N}$ donor ligand and two $\mathrm{OH}^{-}$groups. The cis-derivative has four unidentate $\mathrm{N}$-donor ligands plus $\mathrm{OH}^{-}$and water.

Nineteen derivatives have $\mathrm{PtN}_{4} \mathrm{Cl}_{2}$ inner coordination sphere. In four of them only unidentated ligands are involved. In another three derivatives one bidentate- $\mathrm{N}, \mathrm{N}$ ' ligand with unidentate ligands. The chelating ligands form a five-membered metallocycle with mean N-Pt-N bite angle of $83^{\circ}$. In another two derivatives a bidentate$\mathrm{N}, \mathrm{N}^{\prime}$ ligand forms a six-membered metallocycles or two bidentate- $\mathrm{N}, \mathrm{N}^{\prime}$ ligand each forming a six-membered metallocycle. In the remaining six derivatives, tetradentate $\mathrm{N}$-donor ligands are involved. The mean Pt-L bond distances in the $\mathrm{PtN}_{4} \mathrm{Cl}_{2}$ derivatives elongated in the order: $2.05 \AA$ (tetra-NL) $<2.06 \AA$ (uni-NL) $<2.065 \AA$ (bi-NL) $<2.305 \AA(\mathrm{Cl})$. It is noted that the mean Pt-N vs Pt-Cl (trans) and hetero-trans bond distances are the same at 2.06 and $2.31 \AA$, respectively. The mean N-Pt-N bite angles are $83.5^{\circ}$ (five-) and $95.4^{\circ}$ (six-membered).

There are four derivatives with four $\mathrm{N}$ atoms in plane and two bromine atoms in axial positions to give a tetragonal bipyramidal geometry about the Pt(IV) atom $\left(\mathrm{PtN}_{4} \mathrm{Br}_{2}\right)$. Six derivatives have a similar geometry with iodine atoms in axial positions $\left(\mathrm{PtN}_{4} \mathrm{I}_{2}\right)$. Tetragonal bipyramidal geometry is also formed by four in-plane $\mathrm{CN}^{-}$ groups with two $\mathrm{NH}_{3}$ ligands in axial positions $\left(\mathrm{PtC}_{4} \mathrm{~N}_{2}\right)$. In another derivative four $\mathrm{Cl}$ atoms and two $\mathrm{O}$ donor 
ligands form a pseudo-octahedron $\left(\mathrm{PtCl}_{4} \mathrm{O}_{2}\right)$. Sixteen derivatives have four $\mathrm{Cl}$ atoms and two $\mathrm{N}$-donor ligands $\left(\mathrm{PtCl}_{4} \mathrm{~N}_{2}\right)$. There are eleven of those with trans-configurations and four with cis, using only unidentate ligands. The remaining five have bidentate ( $\left.N, N^{\prime}\right)$ ligands which form five- (3 examples), six- (1 example) and seven- (1 example)-membered metallocycles with mean bite angles of $83^{\circ}, 92^{\circ}$ and $98.5^{\circ}$, respectively. The mean Pt-N vs Pt-Cl (trans) bond lengths are 2.05 and $2.31 \AA$, respectively, which are almost the same as for homo-trans situation at 2.05 and $2.315 \AA$, respectively.

There are one cis- and three trans-derivatives, involving only unidentate ligands forming a $\mathrm{PtCl}_{4} \mathrm{~S}_{2}$ chromophore. The mean Pt-Cl vs Pt-S (trans) bond lengths at 2.315 and $2.365 \AA$, respectively, differ from hetero-trans values of 2.360 and $2.340 \AA$, suggesting a greater trans influence of $\mathrm{S}$ over $\mathrm{Cl}$. In cis- $\mathrm{PtCl}_{4}\left(\mathrm{PEt}_{3}\right)_{2}$ the mean $\mathrm{Pt}-\mathrm{Cl}$ vs Pt-P (trans) bond lengths are 2.394 and $2.335 \AA$, respectively. The former is about $0.073 \AA$ longer than that for the homo-trans value of $2.321 \AA$, indicating a greater trans effect of $\mathrm{P}$ over $\mathrm{S}$, as expected. In another derivative a bidentate-Se,Se' ligand with four chlorine atoms form a pseudo octahedral geometry about the $\mathrm{Pt}(\mathrm{IV})$ atom $\left(\mathrm{PtCl}_{4} \mathrm{Se}_{2}\right)$. The chelating ligand forms a five-membered metallocycle (Se-Pt-Se, $\left.87.6^{\circ}\right)$. The mean Pt-Cl vs PtSe (trans) bond lengths are 2.343 and $2.437 \AA$, the former being shorter in the homo-trans situation at $2.315 \AA$ indicating a greater trans influence of the Se over $\mathrm{Cl}$. In $\left[\mathrm{Pt}\left(\eta^{3}-\mathrm{As}_{2} \mathrm{~S}_{5}\right)_{2}\right]^{2-}$ anion the $\mathrm{Pt}(\mathrm{IV})$ atom has $\mathrm{PtS}_{4} \mathrm{As}_{2}$ chromophore (Figure 10) [15]. There are two types of metallocycles, a pair of five-membered (SAsSAs) rings and a pair of six-membered (SAsSAsS) rings with mean S-Pt-As and S-Pt-S bite angles of $91.4^{\circ}$ and $99.1^{\circ}$. There are also two types of Pt-S bond distance with mean values of $2.428 \AA$ (trans to As) and $2.355 \AA$ otherwise. This indicates a greater trans effect for As over S. The trans Pt-As bond length is $2.454 \AA$.

In cis-derivative a pair of bidentate-S,S' ligands with two iodine atoms form a tetragonal bipyramidal geometry about the Pt(IV) atom $\left(\mathrm{PtS}_{4} \mathrm{I}_{2}\right)$. The chelating ligands form four-membered metallocycles (S-Pt-S, $73.5^{\circ}$ ). There are two types of Pt-S bond distance, $2.34 \AA$ (trans to I) and $2.355 \AA$ (trans to S). The mean Pt-I bond distance is $2.659 \AA$.

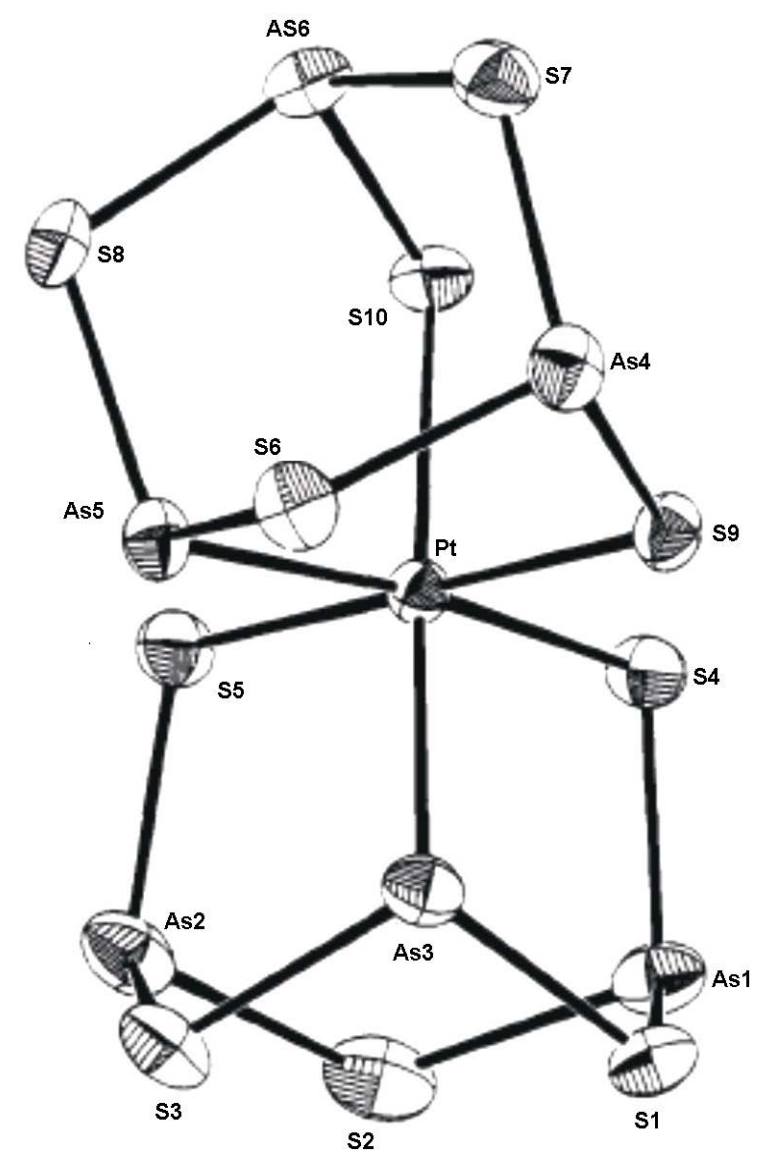

Figure 10. Structure of $\left[\mathrm{Pt}\left(\eta^{3}-\mathrm{As}_{2} \mathrm{~S}_{5}\right)_{2}\right]^{2-}[15]$. 
Two cis-derivatives $\mathrm{PtBr}_{4}\left(\eta^{2}\right.$-en) and $\mathrm{PtBr}_{4}\left(\eta^{2}\right.$-1,3-pn) are isostructural, having a plane containing two bromine atoms and two $\mathrm{N}$ atoms from bidentate ethylenediamine in the former and 1,3-propandiamine in the latter. The mean Pt-Br and Pt-N bond lengths are 2.452 and $2.045 \AA$, respectively. The axial positions contain the remaining two $\mathrm{Br}$ atoms to give distorted octahedron about the $\mathrm{Pt}(\mathrm{IV})$ atoms $\left(\mathrm{PtBr}_{4} \mathrm{~N}_{2}\right)$. The mean $\mathrm{Pt}-\mathrm{Br}$ length (trans to $\mathrm{Br}$ ) is $2.457 \AA$, which is about $0.005 \AA$ longer than the value for $\mathrm{Br}$ trans to N. Each of the chelating ligands form a metallocycle, five-membered (en) or six-membered (1,3-pn) with the N-Pt-N bite angles of 83.1 ${ }^{\circ}$ and $95^{\circ}$, respectively.

Four $\mathrm{Br}$ atoms located in a plane about $\mathrm{Pt}(\mathrm{IV})$ in trans-derivative with two $\mathrm{Me}_{2} \mathrm{~S}$ ligands in axial positions $\left(\mathrm{PtBr}_{4} \mathrm{~S}_{2}\right)$. The mean $\mathrm{Pt}-\mathrm{Br}$ length is $2.471 \AA$ and the mean Pt-S value is $2.363 \AA$, giving compressed tetragonal bipyramidal geometry. In another trans-derivative a compressed tetragonal bipyramidal environment about $\mathrm{Pt}(\mathrm{IV})$ consisting of a tetradentate $\left(\mathrm{Se}_{4}\right)$ ligand in plane with two axial $\mathrm{Cl}$ atoms. The mean Pt-Se distance is $2.499 \AA$ and the mean Pt-Cl value is $2.315 \AA$. The Se-Pt-Se bite angle is $88.4^{\circ}$ (six-membered ring).

A similar structure is found in another trans-derivative formed by two unidentate Si ligands plus one bidentate $(\mathrm{Si}, \mathrm{Si})$ ligand in plane and $\mathrm{Bu}^{\mathrm{t}} \mathrm{NC}$ ligands in axial positions $\left(\mathrm{PtSi}_{4} \mathrm{C}_{2}\right)$. The mean Pt-Si bond length is $2.47 \AA$ and the Si-Pt-Si bite angle value is $68.6^{\circ}$ (four-membered ring). The mean Pt-C value is $1.91 \AA$. A distorted cis-octahedral geometry is found in a derivative with a pair of bidentate (Si,Si') ligands and two $\mathrm{PEt}_{3}$ molecules. Each bidentate ligand forms a five-membered metallocycle with mean Si-Pt-Si bite angle of $83.2^{\circ}$. The mean Pt-Si bond length (trans to P) is $2.429 \AA$, about $0.049 \AA$ longer than those trans to $\mathrm{Si}$ atom (2.380 $\AA$ ) indicating a greater trans influence for $\mathrm{P}$ over Si.

There are two trans-derivatives have a pair of bidentate-As,As' ligands in a plane with mean Pt-As bond length $2.452 \AA$. The $\mathrm{Cl}$ or I atoms occupy axial positions to complete tetragonal bipyramidal geometry $\left(\mathrm{PtAs}_{4} \mathrm{Cl}_{2}\right.$; $\left.\mathrm{PtAs}_{4} \mathrm{I}_{2}\right)$. In four cis-PtI $\left(\eta^{2}-\mathrm{NL}\right)$ complexes one bidentate-N,N'-ligand with four iodine atoms form a pseudooctahedral geometry about the Pt(IV) atom $\left(\mathrm{PtI}_{4} \mathrm{~N}_{2}\right)$. There are two different Pt-I distances, mean value $2.667 \AA$ (trans to I) and $2.609 \AA$ (trans to N), indicating a larger trans influence for I over N, as expected. The mean Pt-N bond lengths are $2.10 \AA$ and the mean N-Pt-N bite angle is $79.7^{\circ}$ (four-membered ring).

Inpection of the data in $\mathrm{PtA}_{4} \mathrm{X}_{2}$ type derivatives showed several types of chromophore: $\mathrm{PtF}_{4} \mathrm{Cl}_{2} ; \mathrm{PtO}_{4} \mathrm{X}_{2}(\mathrm{X}=$ N, Cl, S, Br or I); $\mathrm{PtN}_{4} \mathrm{X}_{2}\left(\mathrm{X}=\mathrm{F}, \mathrm{O}, \mathrm{Cl}, \mathrm{Br}\right.$ or I); $\mathrm{PtCl}_{4} \mathrm{X}_{2}\left(\mathrm{X}=\mathrm{O}, \mathrm{N}, \mathrm{S}, \mathrm{P}\right.$ or S); $\mathrm{PtS}_{4} \mathrm{X}_{2}\left(\mathrm{X}=\mathrm{As}\right.$ or I); $\mathrm{PtBr}_{4} \mathrm{X}_{2}$ $(\mathrm{X}=\mathrm{N}$ or $\mathrm{S}) ; \mathrm{PtSe}_{4} \mathrm{Cl}_{2} ; \mathrm{PtSi}_{4} \mathrm{C}_{2} ; \mathrm{PtAs}_{4} \mathrm{X}_{2}\left(\mathrm{X}=\mathrm{Cl}\right.$ or I) and $\mathrm{PtI}_{4} \mathrm{~N}_{2}$. The ligands are uni-, bi-, ter- and tetradentate. The effect of both steric and electronic factor can be seen in the opening of the L-Pt-L bond angles of the metallocycles which they form. The five-membered metallocyclic rings open in the order: $83.2^{\circ}\left(\mathrm{OC}_{2} \mathrm{O}\right) \sim\left(\mathrm{NC}_{2} \mathrm{~N}\right) \sim$ $\left(\mathrm{SiC}_{2} \mathrm{Si}\right)<84.5^{\circ}\left(\mathrm{OC}_{2} \mathrm{~N}\right)<87.6^{\circ}\left(\mathrm{SeC}_{2} \mathrm{Se}\right)<99.5^{\circ}$ (SAsSAs). For six-membered rings the order is: $88.5^{\circ}$ $\left(\mathrm{SeC}_{3} \mathrm{Se}\right)<91.5^{\circ}(\mathrm{SAsSAsS})<94.3^{\circ}\left(\mathrm{NC}_{3} \mathrm{~N}\right)<95^{\circ}\left(\mathrm{OC}_{3} \mathrm{O}\right)$.

There are ten derivatives with $\mathrm{PtA}_{3} \mathrm{X}_{3}$ chromophores. Two derivatives fac- and mer- $\left[\mathrm{PtF}_{3} \mathrm{Cl}_{3}\right]^{2-}$, have three $\mathrm{F}$ and three $\mathrm{Cl}$ atoms creating an octahedral environment about $\mathrm{Pt}(\mathrm{IV})$ atoms. The sum of all six Pt-L bond distances in the fac-derivative is $12.74 \AA$, somewhat higher than in the mer-derivative at $12.71 \AA$. In the former the mean Pt-F and Pt-Cl distances, all hetero-trans are 1.977 and $2.272 \AA$, respectively. In the mer-derivative there are two types of Pt-L bond distance, hetero-trans (F-Pt-Cl) and homo-trans (e.g. F-Pt-F), with mean values of $1.972 \AA(\mathrm{F})$ and $2.271 \AA(\mathrm{Cl})$; in the former and $1.937 \AA(\mathrm{F})$ and $2.298 \AA(\mathrm{Cl})$ in the latter.

There are five derivatives with a $\mathrm{PtN}_{3} \mathrm{Cl}_{3}$ inner coordination sphere, four with mer- and one with fac-arrangement of donor atoms. In three of mer- only unidentate ligands are involved, and in a fourth mer- a bidentate ethylenediamine, unidentate $\mathrm{N}$ ligand and three $\mathrm{Cl}$ atoms are involved. The bidentate ligand forms five-membered metallocycle (N-Pt-N, $83.4^{\circ}$ ). In the fac-derivative a terdentate diethylenetriamine ligand and three $\mathrm{Cl}$ atoms are found, and the terdentate ligand forms two five-membered metallocycles (N-Pt-N, $84.4^{\circ}$ ). The sum of all six bond distances in the mer-derivative is $13.14 \AA$ somewhat smaller than the value for the fac-derivative at 13.17 $\AA$. The mean Pt-N bond distance elongated in the order: $2.045 \AA$ (bi-) $<2.068 \AA$ (uni-) $<2.075 \AA$ (terdentate). The mean Pt-Cl distance is $2.322 \AA$. One fac-derivative has a terdentate diethylene-triamine ligand with three iodine atoms around a $\mathrm{Pt}(\mathrm{IV})$ atom $\left(\mathrm{PtN}_{3} \mathrm{I}_{3}\right)$. The mean N-Pt-N bite angle is $82.9^{\circ}$, with mean Pt-N and Pt-I bond distances of 2.10 and $2.629 \AA$, respectively.

Another two derivatives mer- and fac- have $\mathrm{PtCl}_{3} \mathrm{~S}_{3}$ chromophore and only unidentate ligands. In the mer-derivatives two different Pt-Cl and Pt-S bond distances are present with mean values of 2.318 and $2.376 \AA$, respectively, for the homo-trans positions, and 2.346 and $2.329 \AA$ for the hetero-trans positions. The mean Pt-Cl and Pt-S bond distances for the fac-derivative are 2.359 and $2.361 \AA$. The sum of all six bond distances is $14.16 \AA$ for the mer-and $14.01 \AA$ for the fac-derivative. 
Two derivatives contain $\left[\mathrm{Pt}\left(\eta^{2}-\mathrm{en}\right)_{2}(\mathrm{CN}) \mathrm{X}\right]^{+2}$ cations $(\mathrm{X}=\mathrm{Br}$ or $\mathrm{I})$ in which pair of ethylenediamine ligands with two five-membered metallocycles form a plane. The $\mathrm{CN}$ and $\mathrm{X}$ ligands are in axial positions completing an asymmetrical tetragonal bipyramid about the $\mathrm{Pt}(\mathrm{IV})$ atom $\left(\mathrm{PtN}_{4} \mathrm{CBr}, \mathrm{PtN}_{4} \mathrm{CI}\right)$.

There are three derivatives in which the $\mathrm{Pt}(\mathrm{IV})$ atom has a $\mathrm{PtCl}_{4} \mathrm{ON}$ inner coordination sphere. In addition to four $\mathrm{Cl}$ atoms the distorted octahedron is completed by heterobidentate $(\mathrm{O}, \mathrm{N})$ ligand. Each derivative has three types of Pt-Cl location with bond distances $2.306 \AA$ (trans to O), $2.308 \AA$ (trans to N) and $2.316 \AA$ (trans to Cl). The chelating ligand forms five-membered in two derivatives and six-membered in the third one with the O-Pt-N bite angles of $84.0^{\circ}$ (ave.) and $89.9^{\circ}$, respectively. Another two derivatives have four $\mathrm{Cl}$ atoms plus $\mathrm{N}$ and $\mathrm{S}$ atom about $\mathrm{Pt}(\mathrm{IV})$ to give the $\mathrm{PtCl}_{4} \mathrm{NS}$ chromophore. In one only unidentte ligands are involved and in the other one a heterobidentate-N,S donor ligand forming a five-membered metallocycle (N-Pt-S, $86.9^{\circ}$ ). There are also three types of Pt-Cl bond distances $2.307 \AA$ (trans to N), $2.356 \AA$ (trans to S) and $2.312 \AA$ (trans to $\mathrm{Cl}$ ). In another derivative four bromine atoms with hetero-bidentate $(\mathrm{O}, \mathrm{N})$ ligand forms a $\mathrm{PtBr}_{4} \mathrm{ON}$ chromophore. The heterobidentate ligand forms a five-membered metallocycle (O-Pt-N, $\left.85.6^{\circ}\right)$. Three different $\mathrm{Pt}-\mathrm{Br}$ bond lengths elongated in the order: $2.405 \AA$ (trans to $\mathrm{O}$ ) $<2.439 \AA$ (trans to $\mathrm{N}$ ) $<2.462 \AA$ (trans to $\mathrm{Br}$ ).

\section{3. $\mathrm{PtA}_{3} \mathrm{X}_{2} \mathrm{Y}, \mathrm{PtA}_{2} \mathrm{X}_{2} \mathrm{Y}_{2}, \mathrm{PtCl}_{3} \mathrm{ONS}, \mathrm{PtA}_{2} \mathrm{X}_{2} \mathrm{YZ}$}

A derivative with inner coordination sphere of $\mathrm{PtO}_{3} \mathrm{~N}_{2} \mathrm{Cl}$ contains three unidentate O-donor ligands, a bidentate $\left(\mathrm{N}, \mathrm{N}^{\prime}\right)$ ligand and a $\mathrm{Cl}$ atom. The bidentate ligand forms a six-membered metallocycle with N-Pt-N angle of 91.6 $6^{\circ}$. Two chelating ligands, one bidentate $\left(\mathrm{N}, \mathrm{N}^{\prime}\right)$ and the other terdentate $\left(\mathrm{N}, \mathrm{O}, \mathrm{O}^{\prime}\right)$ plus a $\mathrm{Cl}$ atom give a pseudo-octahedron about the $\mathrm{Pt}(\mathrm{IV})\left(\mathrm{PtN}_{3} \mathrm{O}_{2} \mathrm{Cl}\right)$. There are three five-membered metallocycles with N-Pt-N angle of $82.7^{\circ}$ and two O-Pt-N angles of $83.7^{\circ}$ (ave). A homo-terdentate diethylenetriamine ligand plus a $\mathrm{Cl}$ atoms and S-donor ligand create a distorted octahedron about the $\mathrm{Pt}(\mathrm{IV})\left(\mathrm{PtN}_{3} \mathrm{Cl}_{2} \mathrm{~S}\right)$. There are two equal five-membered metallocycle (N-Pt-N, $83.4^{\circ}$ ). In another derivative a heteroterdentate (N,N',S) ligand forms two five-membered metallocycles (N-Pt-N and N-Pt-S) and with three $\mathrm{Br}$ atoms create a distorted octahedron about $\mathrm{Pt}(\mathrm{IV}$ ) $\left(\mathrm{PtBr}_{3} \mathrm{~N}_{2} \mathrm{~S}\right)$. There are two Pt-Br locations with the bond distances of $2.456 \AA$ (average trans to N) and $2.477 \AA$ (trans to $\mathrm{S}$ ), indicating a greater trans influence of $\mathrm{S}$ over $\mathrm{N}$ as might be anticipated.

In $\left[\mathrm{PtBr}_{3}\left(\eta^{3}-\mathrm{S}_{4} \mathrm{~N}_{4}\right)\right]^{-}$anion the $\mathrm{Pt}(\mathrm{IV})$ atom is facially coordinated by three $\mathrm{Br}$ atoms together with two $\mathrm{S}$ atoms and one $\mathrm{N}$ atom from $\mathrm{S}_{4} \mathrm{~N}_{4}^{-2}$ ligand (Figure 11) [16]. The five-membered ring (NSNS) is essentially planar with N-Pt-S bite angle of $89.9^{\circ}$, whereas the six-membered rings (SNSNS) is planar except for the coordinated $\mathrm{S}$ atom common to both rings, with S-Pt-S bite angle of $98.8^{\circ}$. The Pt-Br bond lengths are $2.476 \AA$ (trans to N) and $2.495 \AA$ (average trans to S).

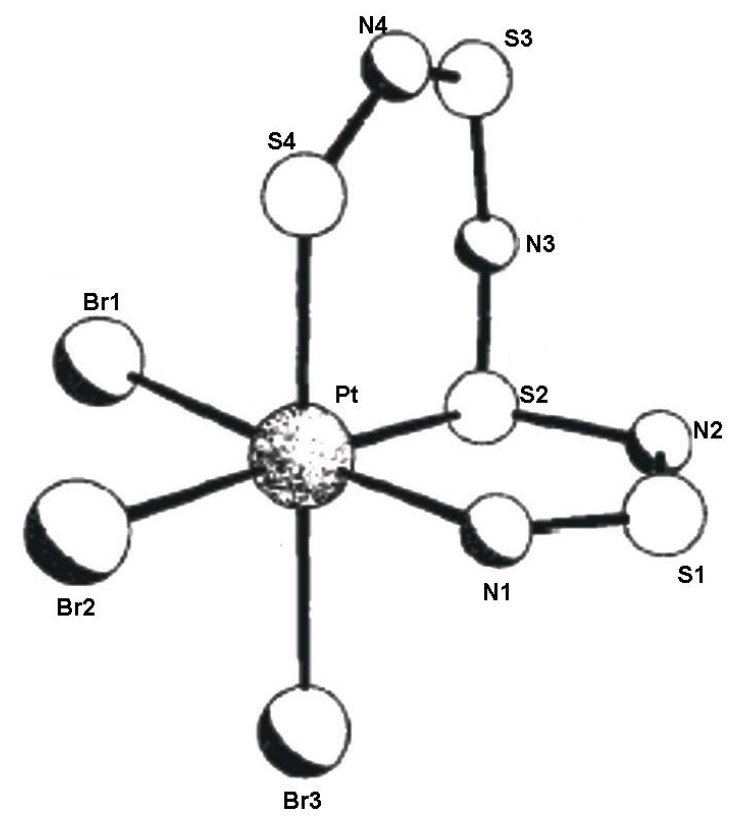

Figure 11. Structure of $\left[\mathrm{PtBr}_{3}\left(\eta^{3}-\mathrm{S}_{4} \mathrm{~N}_{4}\right)\right]^{-}[16]$. 
Another derivative has three unidentate Si donor ligands, a bidentate $\left(\mathrm{P}, \mathrm{P}^{\prime}\right)$ ligand and a hydrogen atom about the $\mathrm{Pt}(\mathrm{IV})$ atom $\left(\mathrm{PtSi}_{3} \mathrm{P}_{2} \mathrm{H}\right)$. The homobidentate ligand forms a five-membered metallocycle (P-Pt-P, $\left.84.9^{\circ}\right)$. The Pt-Si bond distances of $2.375 \AA$ (mean trans to $\mathrm{P}$ ) and $2.406 \AA$ (trans to $\mathrm{H}$ ) strongly suggests a greater trans influence of $\mathrm{H}$ over $\mathrm{P}$.

Eighteen derivatives contain a $\mathrm{PtO}_{2} \mathrm{~N}_{2} \mathrm{Cl}_{2}$ inner coordination sphere. Six of these use only unidentate ligands, with the two O-donor ligands trans to each other and the $\mathrm{N}$-donor ligands trans to chlorine. Another four derivatives utilize a homobidentate ( $\left.\mathrm{N}, \mathrm{N}^{\prime}\right)$ ligand with the other ligands unidentate, $\mathrm{O}$ trans to $\mathrm{O}$ and $\mathrm{N}$ trans to $\mathrm{Cl}$. Heterobidentate $(\mathrm{N}, \mathrm{O})$ ligands plus two $\mathrm{Cl}$ atoms create a distorted octahedral arrangement about the Pt(IV) atom in another six derivatives. In the above derivatives there are three types of Pt-Cl bond distance with the mean values of $2.307 \AA$ (trans to $\mathrm{Cl}$ ), $2.288 \AA$ (trans to O) and $2.313 \AA$ (trans to $\mathrm{N}$ ). The mean Pt-O distances are: $2.02 \AA$ (trans to $\mathrm{O}$ ) and $2.02 \AA$ (trans to N). The mean L-Pt-L bite angles open in the order: $83.6^{\circ}\left(\mathrm{OC}_{2} \mathrm{~N}\right)<$ $84.7^{\circ}\left(\mathrm{NC}_{2} \mathrm{~N}\right)<97.0^{\circ}\left(\mathrm{OC}_{3} \mathrm{O}\right) \sim\left(\mathrm{NC}_{3} \mathrm{~N}\right)<98.7^{\circ}\left(\mathrm{NC}_{4} \mathrm{~N}\right)$.

A chelating ethylenediamine $\left(\mathrm{N}, \mathrm{N}^{\prime}\right)$, two unidentate acetate $(\mathrm{O})$ units and two iodine atoms form a distorted octahedron about the Pt(IV) atom $\left(\mathrm{PtO}_{2} \mathrm{~N}_{2} \mathrm{I}_{2}\right)$. There are two hetero-trans axes (N-L) with mean Pt-N and Pt-I bond lengths of 2.090 and $2.627 \AA$, respectively. Both O-atoms are trans oriented with a mean Pt-O bond distance of $2.029 \AA$. The N-Pt-N bite angle is $82.3^{\circ}$. Another distorted octahedral environment is found with heterobidentate $(\mathrm{N}, \mathrm{S})$ ligands and two $\mathrm{Cl}$ atoms $\left(\mathrm{PtN}_{2} \mathrm{Cl}_{2} \mathrm{~S}_{2}\right)$ for which only unit cell dimensions are available. A similar arrangement is found in $\mathrm{PtCl}_{2}\left(\mathrm{PEt}_{3}\right)_{2} \mathrm{Br}_{2}$, with three homo-trans axis.

There are four derivatives which contain four different hetero atoms in the inner coordination sphere. One derivative contains three $\mathrm{Cl}$ atoms, a hetero-bidentate $(\mathrm{O}, \mathrm{N})$ ligand and S-donor ligand $\left(\mathrm{PtCl}_{2} \mathrm{ONS}\right)$. There are two hetero-trans axes $\mathrm{O}-\mathrm{Cl}$ and $\mathrm{N}-\mathrm{S}$, and one homo-trans axes $(\mathrm{Cl}-\mathrm{Cl})$. The $\mathrm{Pt}-\mathrm{Cl}$ bond lengths are $2.314 \AA$ (trans to $\mathrm{Cl}$ ) and $2.323 \AA$ (trans to O). The O-Pt-N bite angle is $91.6^{\circ}$.

In $\mathrm{PtCl}_{2}\left(\eta^{3}-\mathrm{S}_{4} \mathrm{~N}_{4}\right)(\mathrm{PMe} 2 \mathrm{Ph})$, the terdentate meridional $\mathrm{S}_{4} \mathrm{~N}_{4}$ divalent anion coordinated via two $\mathrm{S}$ atoms and one $\mathrm{N}$ atom. The anion forms two metallocycles, five- and six-membered, with N-Pt-S and S-Pt-S bie angles of $85.0^{\circ}$ and $90.1^{\circ}$, respectively. There are two hetero-trans axes, N-S and S-P, with the Pt-S bond distances of $2.335 \AA$ and $2.394 \AA$, respectively. The $\mathrm{Cl}$ atoms are trans oriented with mean Pt-Cl bond length of $2.322 \AA$. In $\left[\mathrm{Pt}\left(\mathrm{PMe}_{2} \mathrm{Ph}\right)_{2} \mathrm{Br}_{2}\left\{\eta^{2}-\mathrm{N}(\mathrm{H}) \mathrm{SNS}\right\}\right]^{+}$cation the chelating ligand forms a five-membered metallocycle with N-Pt-S bite angle of $84.7^{\circ}$. The mean Pt-P bond distances are $2.327 \AA$ (trans to $\mathrm{N}$ ) and $2.346 \AA$ (trans to $\mathrm{Br}$ ). The mean Pt-Br bond distances are $2.496 \AA$ (trans to S) and $2.556 \AA$ (trans to P). The mean Pt-N length is $2.096 \AA$ (trans to $\mathrm{P}$ ) and the Pt-S length is $2.327 \AA$ (trans to $\mathrm{Br}$ ).

\section{Isomers}

The huge area of almost two thousand monomeric platinum coordination compounds has been surveyed [2]-[5] with over 200 isomeric examples, which were detailed analyzed by us [17]. The platinum oxidation state in these isomers are found in the oxidation state of zero, +2 (the more common), +3 and +4 . In this section will be briefly outline view of the isomers. Isomers can be broadly classed into two major categories, structural and stereoisomers. The former can be divided into ionization, hydrate, coordination, linkage and polymerization subcategories, and the latter can be divided into geometric (cis-trans, fac-mer), optical and distortion isomerism. The analyzed of the isomers to show that stereoisomers are more common than structural isomers, and surprisingly, that distortion isomerism is more common that the better known cis-trans isomerism. Platinum(II) has a strongly preference for square-planar coordination geometry. The kinetic inertness of these compounds has allowed their extensive use in the characterization of geometrical isomerism and reaction mechanistic.

\subsection{Distortion Isomerism}

The coexistence of two or more species differing only by degree of distortion of M-L bond distances and L-M-L bond angles is typical of the general class of distortion isomers [18]. The $\mathrm{Pt}\left(\mathrm{PPh}_{3}\right)_{3}$ and $\mathrm{Pt}\left(\eta^{2} \text {-dppp }\right)_{2}$ complexes are only examples of $\mathrm{Pt}(0)$ distortion isomers. In the former three $\mathrm{Ph}_{3}$ ligands form about $\mathrm{Pt}(0)$ atom trigonal planar geometry about the $\mathrm{Pt}(0)$ atom to give triclinic and monoclinic forms. The Pt-P bond distances range from 2.26 to $2.28 \AA$ in triclinic, and from 2.26 to $2.27 \AA$ in monoclinic, and the P-Pt-P bond angles from $11.5^{\circ}$ to $122^{\circ}$, and from $117^{\circ}$ to $128^{\circ}$, respectively. In two monoclinic $\mathrm{Pt}\left(\eta^{2}-\mathrm{dppp}\right)_{2}$ isomers a pair of bis(diphenylphosphino)propane ligands create a square-planar geometry $\left(\mathrm{PtP}_{4}\right)$ about the $\mathrm{Pt}(0)$ atom. The mean Pt-P bond distances and the mean P-Pt-P bond angles within the six-membered rings are $2.292 \AA$ and $97.9^{\circ}$ (in one isomer), 
and $2.296 \AA$ and $97.7^{\circ}$ (in another one).

There are over $125 \mathrm{Pt}(\mathrm{II})$ distortion isomers which can be divided into several subgroups. The trans$\mathrm{PtCl}_{2}\left\{\mathrm{P}\left(\mathrm{Bu}^{\mathrm{t}}\right)_{2} \mathrm{Ph}\right\}_{2}$ exists in three isomeric forms, two monoclinic and one orthorhombic. There are over thirty examples exsist in two isomeric forms with homo- as well as hetero-crystal classes. In twenty derivatives both isomeric classes belong to the homo-monoclinic (10 examples), orthorhombic (6 examples) and triclinic (4 examples). The remaining examples differ from each other not only by degree of distortion but also by crystal class. In six of these one isomer is monoclinic and the other triclinic. In three examples one is monoclinic and the other orthorhombic. Of the remainder the mixture is monoclinic and tetragonal, triclinic and orthorhombic, orthorhombic and trigonal.

Over seventy five examples contain two crystallographically independent molecules within the same crystal. Another six derivatives contain three such molecules, and three derivatives have four such molecules. There is even example $\left(\mathrm{NH}_{4}\right)\left[\mathrm{Pt}\left(\eta^{2}-\mathrm{oxp}\right)_{2}\right] \mathrm{H}_{2} \mathrm{O}$ which contains five such molecules within the same crystal. There are several examples in Pt(II) chemistry which exist in two isomeric forms where one form contains two crystallographically independent molecules ( 8 examples), three such molecules (1 example) and four such molecules (2 examples).

Two Pt(III) derivatives contain three such molecules within the same crystal. In the chemistry of Pt(IV) there are twenty derivatives do this class of isomerism. Nine exist in two isomeric forms, orthorhombic (4 examples), triclinic (3 examples), and monoclinic (2 examples). Ten Pt(IV) derivatives contain two crystallographically independent molecules within the same crystal. One examples, $\mathrm{PtCl}_{4}\left(\eta^{2}\right.$-dach), contains three such molecules. The trans-Pt $\left(\eta^{2} \text {-bcd }\right)_{2} \mathrm{I}_{2}$ exists in two isomeric forms, one of which contain two crystallographically independent molecules within the same crystal. The isomeric forms as well as the respective molecules differ from each other by degree of distortion. In this series of distortion isomers the predominant square-planar configuration about the platinum atom is cis rather than trans.

\subsection{Cis-Trans Isomerism}

There are almost thirty examples of Pt(II) complexes which exist in two isomeric forms, cis and trans. Some pair of isomers belongs to the monoclinic class (8 examples), orthorhombic (2 examples) or the triclinic class (3 examples). The remaining derivatives differ in crystal class. Six examples have monoclinic cis isomers and triclinic trans isomers. Two examples have monoclinic cis and orthorhombic trans, three have orthorhombic cis and monoclinic trans, and two have triclinic cis and monoclinic trans.

\subsection{Mixes Isomerism (Cis-Trans and Distortion)}

Two Pt(II) complexes belong to this unusual combination of isomerism. The $\mathrm{PtCl}_{2}(\mathrm{py})(\mathrm{dmso})$ complex exists as monoclinic cis and triclinic trans isomers. In addition, the trans isomer contains two crystallographically independent molecules. Each $\mathrm{Pt}(\mathrm{II})$ atom has a square-planar geometry $\left(\mathrm{PtCl}_{2} \mathrm{NS}\right)$ with different degree of distortion. The mean Pt-Cl (mean), Pt-N and Pt-S bond distances in the cis isomer are 2.313, 2.027 and $2.209 \AA$, respectively. In the trans isomer the values are 2.288, 2.052 and $2.224 \AA$ (molecule 1) and 2.300, 2.061 and $2.225 \AA$ (molecule 2), respectively.

The $\mathrm{Pt}\left(\mathrm{MeNH}_{2}\right)_{2} \mathrm{Cl}_{2}$ exists in three different cis isomeric forms and in a trans form. Two of the cis forms are monoclinic and one is orthorhombic. The cis isomers are differ from each other. One of the monoclinic forms contains a single molecule while the other contains three crystallographicaly independent molecules. The orthorhombic cis form contains two such molecules. The differences are found in the degrees of distortion.

\subsection{Ligand Isomerism}

There are five Pt(II) complexes which exhibit this type of isomerism $\mathrm{Pt}\left(\eta^{2}-4,44^{\prime}-\mathrm{Me}_{2} \mathrm{bpy}\right)(\mathrm{NCO})_{2}$; and $\mathrm{Pt}\left(\eta^{2}-5,5^{\prime}-\right.$ $\mathrm{Me}_{2}$ bpy $)(\mathrm{NCO})_{2} ; \operatorname{Pt}\left(\eta^{2}-3,3^{\prime}-\mathrm{Me}_{2} \mathrm{bpy}\right) \mathrm{Cl}_{2}$ and $\mathrm{Pt}\left(\eta^{2}-5,5^{\prime}-\mathrm{Me}_{2} \mathrm{bpy}\right) \mathrm{Cl}_{2} ; \mathrm{Pt}\left(\eta^{2}-3,3^{\prime}-\mathrm{Bu}_{2} \mathrm{bpy}\right) \mathrm{Cl}_{2}$ and $\mathrm{Pt}\left(\eta^{2}-5,5-\mathrm{Bu}_{2} \mathrm{bpy}\right) \mathrm{Cl}_{2}$; trans-PtCl 2 (2,3-Me $\left.\mathrm{Me}_{2} \mathrm{Pyr}\right)$. ( $\left.\mathrm{PMe}_{2} \mathrm{Ph}\right)$ and $\mathrm{PtCl}_{2}\left(2,5-\mathrm{Me}_{2} \mathrm{pyr}\right)\left(\mathrm{PMe}_{2} \mathrm{Ph}\right)$. Each $\mathrm{Pt}(\mathrm{II})$ atom has a square-planar geometry with differing degrees of distortion. The mean Pt-N ( $\left.\mathrm{R}_{2} \mathrm{bpy}\right)$ bond distance reflects the position of the $\mathrm{R}_{2}$ bpy group and elongated in the order: $1.985 \AA(5,5-)<2.011 \AA\left(3,3^{\prime}-\right)<2.030 \AA\left(4,4^{\prime}-\right)$. The mean Pt-N ( $\mathrm{Me}_{2} \mathrm{pyr}$ ) bond distance also reflects the position of the $\mathrm{Me}_{2} \mathrm{R}$ group, elongated in the order: $2.120 \AA$ (2,5-) < $2.133 \AA(2,4-)<2.153 \AA(2,3-)$. 


\section{Conclusions}

The coordination chemistry of platinum covers a huge field, as shown by a recent survey covering the crystallographic and structural data of almost two thousand monomeric examples [2]-[5]. About $10 \%$ of these complexes exist as isomers and were detail analyzed [17]. In this review the respective data are briefly summarized. Therefore, the reviews [2]-[5] cover almost two thousand references with over six hundred pages whit almost 2000 references cited therein. In this review we prefer without detail references (see the reviews for detail data and references).

Monomeric platinum coordination complexes crystallized in wide variations of crystal classes: rhombohedral $(0.1 \%)<$ cubic and trigonal each $(0.2 \%)<$ hexagonal $(0.3 \%)<$ tetragonal $(2.5 \%)<$ orthorhombic $(18 \%)<$ triclinic $(24.7 \%)<$ monoclinic $(54 \%)$. The platinum exists in oxidation states zero, $+1,+2,+3$ and +4 , from which +2 by far prevails.

In the chemistry of monomeric coordination complexes of "soft" platinum is found a wide variety of uni-, bi-, ter- and tetradentate ligands forming variable inner coordination spheres about the platinum.

The $\mathrm{Pt}(0)$ atoms are two- $\left(\mathrm{PtP}_{2}\right)$ linear or almost linear; three- $\left(\mathrm{PtP}_{3}, \mathrm{PtP}_{2} \mathrm{~S}\right)$, $\mathrm{Y}$-shape; and four- $\left(\mathrm{PtP}_{4}, \mathrm{PtP}_{3} \mathrm{~S}\right.$, $\mathrm{PtO}_{2} \mathrm{~S}_{2}, \mathrm{PtN}_{2} \mathrm{P}_{2}, \mathrm{PtS}_{2} \mathrm{P}_{2}, \mathrm{PtP}_{2} \mathrm{ON}, \mathrm{PtP}_{2} \mathrm{NS}$ and $\mathrm{PtP}_{2} \mathrm{CS}$; mostly tetrahedral), coordinated.

The $\mathrm{Pt}(\mathrm{I})$ atoms are four-( $\mathrm{PtN}_{4}$ and $\mathrm{PtP}_{4}$, square-planar), coordinated.

The Pt(II) atoms are four-PtA $\left(\mathrm{A}=\mathrm{O}, \mathrm{N}, \mathrm{C}, \mathrm{Cl}, \mathrm{S}, \mathrm{P}, \mathrm{Br}\right.$, Se or As); $\mathrm{PtO}_{3} \mathrm{X}\left(\mathrm{X}=\mathrm{N}, \mathrm{P}, \mathrm{Br}\right.$ or I); $\mathrm{PtN}_{3} \mathrm{~S}(\mathrm{X}=\mathrm{O}$, $\mathrm{C}, \mathrm{Cl}, \mathrm{S}, \mathrm{Br}$ or I); $\mathrm{PtCl}_{3} \mathrm{X}(\mathrm{X}=\mathrm{N}, \mathrm{S}$ or $\mathrm{P})$; $\mathrm{PtS}_{3} \mathrm{X}\left(\mathrm{X}=\mathrm{O}, \mathrm{N}, \mathrm{Cl}, \mathrm{P}\right.$, As or I); $\mathrm{PtP}_{3} \mathrm{X}(\mathrm{X}=\mathrm{H}, \mathrm{F}, \mathrm{Cl}, \mathrm{S}, \mathrm{Br}$ or I); $\mathrm{PtBr}_{3} \mathrm{X}\left(\mathrm{X}=\mathrm{N}, \mathrm{Cl}, \mathrm{S}, \mathrm{P}\right.$ or As); $\mathrm{PtO}_{2} \mathrm{X}_{2}\left(\mathrm{X}=\mathrm{N}, \mathrm{Cl}, \mathrm{S}, \mathrm{P}\right.$ or As); $\mathrm{PtN}_{2} \mathrm{X}_{2}\left(\mathrm{X}=\mathrm{C}, \mathrm{Cl}, \mathrm{S}, \mathrm{P}, \mathrm{Br}\right.$ or I); $\mathrm{PtC}_{2} \mathrm{X}_{2}(\mathrm{X}=$ $\mathrm{Cl}$, S, P or I); $\mathrm{PtB}_{2} \mathrm{P}_{2} ; \mathrm{PtCl}_{2} \mathrm{X}_{2}\left(\mathrm{X}=\mathrm{S}\right.$ or P); $\mathrm{PtS}_{2} \mathrm{X}_{2}\left(\mathrm{X}=\mathrm{P}, \mathrm{Br}\right.$, I or As); $\mathrm{PtP}_{2} \mathrm{X}_{2}\left(\mathrm{X}=\mathrm{Br}\right.$, Se, Si, I or Te), $\mathrm{PtAs}_{2} \mathrm{I}_{2}$; $\mathrm{PtI}_{2} \mathrm{Te}_{2} ; \mathrm{PtO}_{2} \mathrm{NX}\left(\mathrm{X}=\mathrm{Cl}\right.$, P or I) $\mathrm{PtO}_{2} \mathrm{ClS}$; $\mathrm{PtN}_{2} \mathrm{OX}\left(\mathrm{X}=\mathrm{Cl}\right.$ or S); $\mathrm{PtN}_{2} \mathrm{ClX}\left(\mathrm{X}=\mathrm{S}\right.$ or P); $\mathrm{PtN}_{2} \mathrm{SP}$; $\mathrm{PtN}_{2} \mathrm{PSe}$; $\mathrm{PtC}_{2} \mathrm{NS}$; $\mathrm{PtCl}_{2} \mathrm{OX}\left(\mathrm{X}=\mathrm{N}\right.$, S or P); $\mathrm{PtCl}_{2} \mathrm{NX}\left(\mathrm{X}=\mathrm{S}\right.$, P, Se, As or Te); $\mathrm{PtCl}_{2} \mathrm{SX}\left(\mathrm{X}=\mathrm{P}\right.$ or Te); $\mathrm{PtS}_{2} \mathrm{NX}(\mathrm{X}=\mathrm{Cl}, \mathrm{P}$ or $\mathrm{Br}$ ); $\mathrm{PtS}_{2} \mathrm{ClX}\left(\mathrm{X}=\mathrm{P}, \mathrm{Br}\right.$ or I); $\mathrm{PtS}_{2} \mathrm{CI}, \mathrm{PtS}_{2} \mathrm{BrI} ; \mathrm{PtS}_{2} \mathrm{HX}\left(\mathrm{X}=\mathrm{O}, \mathrm{N}, \mathrm{Cl}, \mathrm{S}, \mathrm{B}\right.$, Si or I); $\mathrm{PtP}_{2} \mathrm{OX}(\mathrm{X}=\mathrm{N}, \mathrm{Cl}, \mathrm{S}$, $\mathrm{Br}$ or Si); $\mathrm{PtP}_{2} \mathrm{NX}$ (X = Cl, S, Br, Se, I or Te); $\mathrm{PtP}_{2} \mathrm{BCl}$; $\mathrm{PtP}{ }_{2} \mathrm{ClX}$ (X = S, Si or Te); $\mathrm{PtP}_{2} \mathrm{BrSi} ; \mathrm{PtP}_{2} \mathrm{SiTe} ; \mathrm{PtBr}_{2} \mathrm{NS}$; $\mathrm{PtBr}_{2} \mathrm{NP}, \mathrm{PtBr}_{2} \mathrm{ClP}$, $\mathrm{PtSe}_{2} \mathrm{ClP}$, PtAs $\mathrm{ClS}_{2}$, PtI $\mathrm{NX}_{2} \mathrm{X}=\mathrm{S}$ or P), PtI $2 \mathrm{SP}, \mathrm{PtTe}_{2} \mathrm{NCl}$; PtONClS, PtONClP, PtNClSP, PtNSPBr, PtNCCIP and PtNSPI-distorted square planar, coordinated; and five- $\mathrm{PtP}_{5}, \mathrm{PtP}_{4} \mathrm{X}(\mathrm{X}=\mathrm{H}$ or $\mathrm{N})$, $\mathrm{PtAs}_{4} \mathrm{I}, \mathrm{PtCl}_{3} \mathrm{~S}_{2}, \mathrm{PtP}_{3} \mathrm{NAs}$ - trigonal-bipyramidal coordinated.

The Pt(III) atoms are four-PtA 4 ( $\mathrm{A}=\mathrm{N}$, S or Se) and $\mathrm{PtCl}_{3} \mathrm{~N}$ - square-planar coordinated.

The Pt(IV) atoms are four-PtA $\mathrm{A}_{4}(\mathrm{~A}=\mathrm{N}$ or $\mathrm{S})$ - square-planar coordinated; and six-PtA $\mathrm{A}_{6}(\mathrm{~A}=\mathrm{O}, \mathrm{N}, \mathrm{Cl}, \mathrm{S}, \mathrm{P}$, $\mathrm{Br}$, Se or I); $\mathrm{PtF}_{5} \mathrm{Cl}, \mathrm{PtN}_{5} \mathrm{X}\left(\mathrm{X}=\mathrm{O}\right.$ or $\mathrm{Cl}$ ); $\mathrm{PtCl}_{5} \mathrm{X}(\mathrm{X}=\mathrm{O}, \mathrm{N}, \mathrm{S}$ or $\mathrm{P}), \mathrm{PtBr}_{5} \mathrm{Cl}_{2} \mathrm{PtF}_{4} \mathrm{Cl}_{2} ; \mathrm{PtO}_{4} \mathrm{X}_{2}(\mathrm{X}=\mathrm{N}, \mathrm{Cl}, \mathrm{S}, \mathrm{Br}$ or I); $\mathrm{PtN}_{4} \mathrm{X}_{2}\left(\mathrm{X}=\mathrm{F}, \mathrm{O}, \mathrm{Cl}, \mathrm{Br}\right.$ or I); $\mathrm{PtC}_{4} \mathrm{~N}_{2}, \mathrm{PtCl}_{4} \mathrm{X}_{2}\left(\mathrm{X}=\mathrm{O}, \mathrm{N}, \mathrm{S}\right.$, Se or As); $\mathrm{PtS}_{4} \mathrm{I}_{2} ; \mathrm{PtBr}_{4} \mathrm{X}_{2}(\mathrm{X}=\mathrm{N}$ or S), $\mathrm{PtSe}_{4} \mathrm{Cl}_{2}, \mathrm{PtSe}_{4} \mathrm{C}_{2} ; \mathrm{PtAs}_{4} \mathrm{X}_{2}\left(\mathrm{X}=\mathrm{Cl}\right.$ or I); $\mathrm{PtI}_{4} \mathrm{~N}_{2} ; \mathrm{PtF}_{3} \mathrm{Cl}_{3} ; \mathrm{PtN}_{3} \mathrm{X}_{3}\left(\mathrm{X}=\mathrm{Cl}\right.$ or I), $\mathrm{PtCl}_{3} \mathrm{~S}_{3} ; \mathrm{PtN}_{4} \mathrm{CX}(\mathrm{X}=\mathrm{Br}$ or I), $\mathrm{PtCl}_{4} \mathrm{ON}, \mathrm{PtCl}_{4} \mathrm{NS}, \mathrm{PtBr}_{4} \mathrm{ON}, \mathrm{PtO}_{3} \mathrm{~N}_{2} \mathrm{Cl}, \mathrm{PtN}_{3} \mathrm{O}_{2} \mathrm{Cl}, \mathrm{PtN}_{3} \mathrm{Cl}_{2} \mathrm{~S}, \mathrm{PtBr}_{3} \mathrm{~N}_{2} \mathrm{~S}, \mathrm{PtBr}_{3} \mathrm{~S}$ N, PtSe $\mathrm{P}_{2} \mathrm{H}, \mathrm{PtO}_{2} \mathrm{~N}_{2} \mathrm{Cl}_{2}$, $\mathrm{PtN}_{2} \mathrm{Cl}_{2} \mathrm{~S}_{2}, \mathrm{PtCl}_{2} \mathrm{P}_{2} \mathrm{Br}_{2}, \mathrm{PtCl}_{3} \mathrm{ONS}, \mathrm{PtCl}_{2} \mathrm{~S}_{2} \mathrm{NP}$ and $\mathrm{PtP}_{2} \mathrm{Br}_{2} \mathrm{NS}$ - pseudo-octahedral coordinated.

One can see already from the inner coordination sphere how rich the platinum chemistry is. There is wide variety not only of unidentate ligands: H, F, OL, NL, CN, Cl, SL, PL, SeL, Br, SiL, I, TeL, from which by far prevail $\mathrm{P}$ and $\mathrm{N}$ donor ligands. The bi-, ter- and tetradentate (homo- as well as hetero-donors) are very rich which can be see from the wide variety of metallocycles and the effects of both steric and electronic factors can be seen from the values of the L-Pt-L bite angles. The mean L-Pt( $(0)$ - $\mathrm{L}$ bite angle opens in the orders: $40.0^{\circ}(\mathrm{ON})<42.0^{\circ}$ $(\mathrm{OO})<43.0^{\circ}(\mathrm{NS})<45.5^{\circ}(\mathrm{CS})<52.8^{\circ}(\mathrm{SP})<53.0^{\circ}(\mathrm{PP}) ; 79.2^{\circ}\left(\mathrm{NC}_{2} \mathrm{~N}\right.$, unsaturated $)<82.7^{\circ}\left(\mathrm{PC}_{2} \mathrm{P}\right)<96.8^{\circ}$ $\left(\mathrm{PC}_{3} \mathrm{P}\right)<115.3^{\circ}\left(\mathrm{PC}_{6} \mathrm{P}\right)$.

The mean L-Pt(II)-L bite angle opens in the order: $65.0^{\circ}(\mathrm{OCO}, \mathrm{SCSi})<70.0^{\circ}(\mathrm{NCS})<70.2^{\circ}(\mathrm{NCP})<70.4^{\circ}$ $(\mathrm{PNP})<70.7^{\circ}(\mathrm{PCSi})<71.5^{\circ}(\mathrm{OPO})<72.8^{\circ}(\mathrm{PCP})<73.4^{\circ}(\mathrm{SCP})<73.6^{\circ}(\mathrm{PCB})<74.3^{\circ}(\mathrm{OSeO})<74.5^{\circ}(\mathrm{SCS})$ $<74.7^{\circ}(\mathrm{PBP})<77.0^{\circ}(\mathrm{SeCSe})<78.0^{\circ}(\mathrm{NCSe})<78.2^{\circ}(\mathrm{PPP})<81.0^{\circ}(\mathrm{SSS})<82.2^{\circ}(\mathrm{SPS})<85.3^{\circ}(\mathrm{SePSe})<$ $88.2^{\circ}(\mathrm{TeCTe})<88.5^{\circ}(\mathrm{PCTe})$;

$76.4^{\circ}\left(\mathrm{NN}_{2} \mathrm{~N}\right)<78.0^{\circ}\left(\mathrm{ON}_{2} \mathrm{O}\right)<79.7^{\circ}(\mathrm{NCPN})<79.8^{\circ}\left(\mathrm{NC}_{2} \mathrm{~N}\right.$, unsaturated $)<80.0^{\circ}$ (NONP) $<80.6^{\circ}(\mathrm{OCNO})$ $<81.5^{\circ}\left(\mathrm{OC}_{2} \mathrm{~N}\right)<81.7^{\circ}\left(\mathrm{OC}_{2} \mathrm{O}, \mathrm{NCON}\right)<82.2^{\circ}\left(\mathrm{SeC}_{2} \mathrm{Se}\right)<82.5^{\circ}(\mathrm{NCSN})<82.6^{\circ}\left(\mathrm{OCNS}, \mathrm{OC}_{2} \mathrm{P}\right)<83.3^{\circ}$ $\left(\mathrm{PC}_{2} \mathrm{Si}\right)<83.5^{\circ}(\mathrm{ONCS})<83.8^{\circ}(\mathrm{NCNSe})<84.2^{\circ}\left(\mathrm{NC}_{2} \mathrm{~N}\right)$, saturated $)<84.8^{\circ}(\mathrm{NSNTe})<85.0^{\circ}\left(\mathrm{PC}_{2} \mathrm{P}\right)<85.2^{\circ}$ $\left(\mathrm{NSNS}, \mathrm{OC}_{2} \mathrm{~S}\right)<85.5^{\circ}(\mathrm{NSNSe})<85.7^{\circ}\left(\mathrm{NC}_{2} \mathrm{~S}, \mathrm{PCNS}, \mathrm{OPNP}\right)<86.5^{\circ}\left(\mathrm{NCNP}, \mathrm{SCPS}, \mathrm{NC}_{2} \mathrm{Se}\right)<87.0^{\circ}\left(\mathrm{SC}_{2} \mathrm{P}\right.$, $\left.\mathrm{NSeNSe})<87.4^{\circ}\left(\mathrm{SC}_{2} \mathrm{As}\right)<89.0^{\circ}\left(\mathrm{SC}_{2} \mathrm{~S}\right), \mathrm{SP}_{2} \mathrm{~S}, \mathrm{NC}_{2} \mathrm{Te}\right)<89.8^{\circ}(\mathrm{SSNS})<90.4^{\circ}\left(\mathrm{PC}_{2} \mathrm{Se}, \mathrm{SPNP}\right)<91.0^{\circ}(\mathrm{SPCP})$ $<91.3^{\circ}\left(\mathrm{SS}_{2} \mathrm{~S}\right)<91.5^{\circ}\left(\mathrm{SC}_{2} \mathrm{Te}\right)$;

$\left.79.6^{\circ}(\mathrm{PNCNP})<86.5^{\circ}\left(\mathrm{NC}_{2} \mathrm{NP}, \mathrm{NC}_{3} \mathrm{Se}, \mathrm{PNPNP}\right)<88.3^{\circ}(\mathrm{NSNSN})<88.5^{\circ}\left(\mathrm{NC}_{2} \mathrm{NS}\right), \mathrm{PCHCP}\right)<89.0^{\circ}$ $\left(\mathrm{SC}_{3} \mathrm{P}, \mathrm{NCPCN}\right)<89.4^{\circ}\left(\mathrm{NC}_{2} \mathrm{NP}\right)<89.7^{\circ}\left(\mathrm{PC}_{3} \mathrm{Si}, \mathrm{NCNPN}\right)<90.0^{\circ}\left(\mathrm{OC}_{3} \mathrm{~S}\right)<91.0^{\circ}\left(\mathrm{NC}_{3} \mathrm{~N}, \mathrm{NNC}_{2} \mathrm{P}\right)<91.5^{\circ}$ 
$\left(\mathrm{NC}_{2} \mathrm{NS}\right)<91.8^{\circ}\left(\mathrm{OC}_{3} \mathrm{O}, \mathrm{NC}_{3} \mathrm{P}\right)<92.3^{\circ}\left(\mathrm{OC}_{3} \mathrm{~N}, \mathrm{PC}_{3} \mathrm{P}\right)<93.0^{\circ}\left(\mathrm{SC}_{3} \mathrm{As}\right)<93.3^{\circ}(\mathrm{NCNCS})<93.5^{\circ}\left(\mathrm{SC}_{3} \mathrm{~S}\right)<$ $94.0^{\circ}\left(\mathrm{NC}_{3} \mathrm{Se}\right)<96.3^{\circ}$ (SPNPS);

$87.3^{\circ}\left(\mathrm{NC}_{4} \mathrm{~N}\right.$, unsaturated $)<89.7^{\circ}\left(\mathrm{OC}_{4} \mathrm{O}\right)<92.2^{\circ}\left(\mathrm{SC}_{4} \mathrm{~S}\right)<98.8^{\circ}\left(\mathrm{NC}_{4} \mathrm{~N}\right.$, saturated $)<99.0^{\circ}\left(\mathrm{PC}_{4} \mathrm{P}\right) ; 89.5^{\circ}$ $\left(\mathrm{NC}_{5} \mathrm{~N}\right)<90.3^{\circ}\left(\mathrm{PC}_{5} \mathrm{P}\right)<102.4^{\circ}\left(\mathrm{SC}_{2} \mathrm{SC}_{2} \mathrm{~S}\right) ; 87.0^{\circ}\left(\mathrm{SC}_{8} \mathrm{~S}\right)<95.0^{\circ}\left(\mathrm{PC}_{6} \mathrm{P}\right)<99.0^{\circ}\left(\mathrm{PC}_{15} \mathrm{P}, \mathrm{PC}_{17} \mathrm{P}\right)<104.9^{\circ}\left(\mathrm{PC}_{9} \mathrm{P}\right)$ $<174.2^{\circ}\left(\mathrm{AsC}_{9} \mathrm{As}\right)<175.8^{\circ}\left(\mathrm{PC}_{11} \mathrm{P}\right)<176.2^{\circ}\left(\mathrm{PC}_{9} \mathrm{P}\right)$.

The mean L-P(III)-L bite angle opens in the order: 77.0 $\left(\mathrm{NC}_{2} \mathrm{~N}\right.$, unsaturated $)<84.6^{\circ}\left(\mathrm{NC}_{2} \mathrm{~N}\right.$, saturated $)<$ $89.5^{\circ}\left(\mathrm{SC}_{2} \mathrm{~S}\right)<90.2^{\circ}\left(\mathrm{SeC}_{2} \mathrm{Se}\right)$. The mean L-Pt(IV)-L bite angle opens in the orders: $52.6^{\circ}(\mathrm{PP})<64.8^{\circ}(\mathrm{NCN})<$ $68.6^{\circ}(\mathrm{SiCSi})<73.5^{\circ}(\mathrm{SCS}) ; 80.8^{\circ}\left(\mathrm{NC}_{2} \mathrm{~N}\right.$, unsaturated $)<83.2^{\circ}\left(\mathrm{OC}_{2} \mathrm{O}, \mathrm{SiC}_{2} \mathrm{Si}\right)<83.8^{\circ}\left(\mathrm{NC}_{2} \mathrm{~N}\right.$, saturated, $\left.\mathrm{OC}_{2} \mathrm{~N}\right)$ $<84.8^{\circ}\left(\mathrm{NC}_{2} \mathrm{~S}\right)<85.0^{\circ}\left(\mathrm{PC}_{2} \mathrm{P}\right)<87.7^{\circ}\left(\mathrm{SC}_{2} \mathrm{~S}, \mathrm{SeC}_{2} \mathrm{Se}\right)<91.4^{\circ}(\mathrm{SAsSAs})<94.9^{\circ}\left(\mathrm{SeSe}_{2} \mathrm{Se}\right)<99.0^{\circ}$ (NSNS); $90.0^{\circ}\left(\mathrm{PC}_{3} \mathrm{P}\right)<90.8^{\circ}\left(\mathrm{OC}_{3} \mathrm{~N}\right)<91.2^{\circ}\left(\mathrm{SC}_{3} \mathrm{~S}\right)<92.8^{\circ}\left(\mathrm{NC}_{3} \mathrm{~N}\right)<93.7^{\circ}\left(\mathrm{OC}_{3} \mathrm{O}\right)<99.0^{\circ}$ (SNSNS, SAsSAsS).

Noticeable, the oxidation state of the platinum also influence on the L-Pt-L bite angle as well. In the series of the metallocycles: SCS, $\mathrm{NC}_{2} \mathrm{~N}, \mathrm{OC}_{2} \mathrm{~N}, \mathrm{NC}_{2} \mathrm{~S}, \mathrm{SC}_{2} \mathrm{~S}, \mathrm{OC}_{3} \mathrm{~N}, \mathrm{SC}_{3} \mathrm{~S}, \mathrm{PC}_{3} \mathrm{P}$ and $\mathrm{PC}_{6} \mathrm{P}$, the respective L-Pt-L bite angle closses with an increasing oxidation state of platinum, however in the series: $\mathrm{PP}, \mathrm{OC}_{2} \mathrm{O}, \mathrm{PC}_{2} \mathrm{P}, \mathrm{NSNS}$, $\mathrm{SeC}_{2} \mathrm{Se}, \mathrm{OCl}_{3} \mathrm{O}$ and $\mathrm{NC}_{3} \mathrm{~N}$, opposite is true.

As can be seen chelating homo- as well as hetero-donor ligands form metallocyclic rings with varying atoms and number of atoms in the ring. The homo-chelating ligands have the mean $\mathrm{L}-\mathrm{Pt}(0)-\mathrm{L}$ bite angles open in the sequence: $47.5^{\circ}$ (three-) $<80.9^{\circ}$ (five-) $<96.8^{\circ}$ (six-) $<115.3^{\circ}$ (nine-membered rings). However the mean $\mathrm{L}-\mathrm{Pt}(0)-\mathrm{L}$ ' bite angle is $45.3^{\circ}$ (three-membered rings). The homo-chelating ligands have the mean L-Pt(II)-L bite angles open in the sequence: $76.5^{\circ}$ (four-) $<83.6^{\circ}$ (five-) $<89.7^{\circ}$ (six-) $<93.4^{\circ}$ (seven-) $<94.0^{\circ}$ (eight-) $<95.0^{\circ}$ (nine-membered rings). In the hetero-chelating ligands the sequence is: $73.7^{\circ}$ (four-) $<86.0^{\circ}$ (five-) $<90.8^{\circ}$ (sixmembered rings). The mean L-Pt(IV)-L bite angles open in the order: $52.6^{\circ}$ (three-) $<69.0^{\circ}$ (four-) $<85.8^{\circ}$ (five-) $<94.3^{\circ}$ (six-) $<98.0^{\circ}$ (seven-membered rings) for homo-ligands; and $89.2^{\circ}$ (five-) $<90.8^{\circ}$ (six-membered rings) for hetero-ligands.

There are at least two contributing factors to the size of the L-Pt-L chelate bond angles, bond ligand based. One is the steric constraint imposed on the ligand and the other is the need to accommodate the imposed ring size. Comparing the bidentate P-Pt(II)-P angles, there is an increase in the value of the angle as the number of ring atoms increasis. This parallels an increase in the $\mathrm{Pt}(\mathrm{II})-\mathrm{P}$ bond distance: $74.0^{\circ}$ and $2.218 \AA$ (four-) $<86.7^{\circ}$ and $2.220 \AA$ (five-) $<95.6^{\circ}$ and $2.230 \AA$ (six-) $<97.0^{\circ}$ and $2.235 \AA$ (seven-) $<102.2^{\circ}$ and $2.240 \AA$ (eight-membered ring).

Although platinum preferentially bond to "soft" donor ligands such as H, C, S, P, As, I, it can also be found bonded to "borderline" (e.g. bromide) and "hard" donor atoms (F, O, N, Cl). In general the "soft" atoms have a larger trans effect than the borderline or hard atoms [2]-[5]. The Pt-L values for soft and bordeline ligands are observed to increase with covalent radius of the donor atom. A similar trend is observed for the hard ligands, but there is no overlap.

In the series of two thousand of monomeric platinum coordination complexes for which structural parameters are available were analyzed [2]-[5] and in this part only shortly outline. About $10 \%$ of these complexes exist as isomers and were detail analyzed [17] and shortly outline in this part of paper. There are at least four types of isomerism: distortion (65\%), cis-trans (30\%), mixed isomers and ligand isomers. Distortion isomers, differing only by degree of distortion in Pt-L and L-Pt-L angles, are the most numerous. They are also spread over a wide range of oxidation state of platinum (zero, $+2,+3$ and +4$)$, than cis-trans isomers $(+2$ and +4 only), or mixed isomers ( +2 only) and ligand isomerism ( +2 only).

\section{References}

[1] Rosenberg, B., Van Camp, L., Trasko, Y.E. and Mansour, V.H. (1969) Platinum Compounds: A New Class of Potent Antitumour Agents. Nature, 222, 385-386. http://dx.doi.org/10.1038/222385a0

[2] Holloway, C.E. and Melník, M. (2002) Structural Aspects of Platinum Coordination Compounds: Part I. Monomeric $\mathrm{Pt}^{0}, \mathrm{Pt}^{\mathrm{I}}$ and $\mathrm{Pt}^{\mathrm{II}} \mathrm{A}_{4}$ Derivatives. Reviews in Inorganic Chemistry, 22, 163-284. (ref's cited therein).

[3] Otsuka, S., Yoshida, T., Matsamoto, M. and Nakatsu, K. (1976) Bis(Tertiary Phosphine)Palladium(0) and -Platinum(0) Complexes: Preparations and Crystal and Molecular Structures. Journal of the American Chemical Society, 98, 58505858. http://dx.doi.org/10.1021/ja00435a017

[4] Cheng, P.T., Cook, C.D., Nyburg, S.C. and Wan, R.Y. (1971) The Crystal and Molecular Structure of $\left(\mathrm{PPh}_{3}\right)_{2} \mathrm{PtO}_{2}$. 2CHCl 3 . Canadian Journal of Chemistry, 49, 3772-3777. http://dx.doi.org/10.1139/v71-630 
[5] Holloway, C.E. and Melník, M. (2003) Structural Aspect of Platinum Coordination Compounds: Part II. Monomeric $\mathrm{Pt}^{\mathrm{II}}$ Compounds with $\mathrm{PtA}_{3} \mathrm{~B}$ and $\mathrm{PtA}_{2} \mathrm{~B}_{2}$ Composition. Reviews in Inorganic Chemistry, 23, 125-287. (ref's cited therein)

[6] Cusumano, M., DiPietro, M.L., Gianneto, A., Nicolo, F. and Rotondo, E. (1998) Noncovalent Interactions of Platinum(II) Square Planar Complexes Containing Ligands Out-of-Plane with DNA. Inorganic Chemistry, 37, 563-568. http://dx.doi.org/10.1021/ic9705406

[7] Champness, M.R., Kelly, P.F., Levason, W., Reid, G., Lawin, A.M.Z. and Wiliams, D.J. (1995) Selenoether Macrocyclic Chemistry: Syntheses, NMR Studies, Redox Properties, and Single-Crystal Structures of $\left[\mathrm{M}\left([16] \mathrm{aneSe}_{4}\right)\right]\left(\mathrm{PF}_{6}\right)_{2}$. cntdot.2MeCN (M = Pd, Pt; [16]aneSe ${ }_{4}=$ 1,5,9,13-Tetraselenacyclohexadecane). Inorganic Chemistry, 34, 651-657. http://dx.doi.org/10.1021/ic00107a019

[8] Holloway, C.E. and Melník, M. (2004) Structural Aspect of Platinum Coordination Compounds: Part III. Monomeric Square Planar (Pt A(2)XY and PtABXY) and Trigonal Bipyramidal Pt-II Coordination Compounds. Reviews in Inorganic Chemistry, 24, 135-299. (ref's cited therein)

[9] Jennette, K.W., Giel, J.T., Sadownick, J.A. and Lippard, S.J. (1976) Metallointercalation Reagents. Synthesis, Characterization, and Structural Properties of Thiolato(2,2',2"-Terpyridine)Platinum(II) Complexes. Journal of the American Chemical Society, 98, 6159-6168. http://dx.doi.org/10.1021/ja00436a016

[10] Holloway, C.E. and Melník, M. (2004) Structural Aspect of Platinum Coordination Compounds: Part IV. Monomeric Square $\mathrm{Pt}^{\mathrm{III}}$ and $\mathrm{Pt}^{\mathrm{IV}}$ coordination compounds. Reviews in Inorganic Chemistry, 24, 301-400. (ref's cited therein)

[11] Shamsuddin, S. and Khokhar, A.R. (1994) Synthesis and Crystal Structure of a New Antitumor Agent: [Pt(cis-1,4Diaminocyclohexane)(1,1-Cyclobutanedicarboxylate)]. Journal of Coordination Chemistry, 33, 83-91. http://dx.doi.org/10.1080/00958979408024265

[12] Parkin, I.P., Slawin, A.M.Z., Wiliams, D.J. and Woollins, J.D. (1989) Facile Synthesis of SN and S-N-O Complexes in Liquid Ammonia; $X$-Ray Structure of $\mathrm{Pt}\left[(\mathrm{HN})_{2} \mathrm{SO}_{2}\right]\left(\mathrm{PPh}_{2} \mathrm{Me}\right)_{2}$. Journal of the Chemical Society, Chemical Communications, 15, 1060-1061. http://dx.doi.org/10.1039/c39890001060

[13] Lesueur, W., Rogers, A.J., Floriani, C., Chiesi-Villa, A. and Rizzoli, C. (1998) Role of o-Methylene-Bridged Bis(aniline) as a Spectroscopic Probe for the Metal Coordination Environment. Inorganic Chemistry, 37, 44-49. http://dx.doi.org/10.1021/ic9706010

[14] Vaira, M.D., Sacconi, L. and Stoppioni, P. (1983) Structural Correlations and NMR Properties of Mononuclear Cyclic Triphosphorus Complexes. Journal of Organometallic Chemistry, 250, 183-195. http://dx.doi.org/10.1016/0022-328X(83)85049-9

[15] Chou, J.H. and Kanatzidis, M.G. (1994) $\mathrm{Pt}^{2+}$ vs. $\mathrm{Pt}^{4+}$ in $\mathrm{AsS}_{3}{ }^{3-}$ Solutions and Isolation of the Clusters $\left[\mathrm{Pt}\left(\mathrm{As}_{3} \mathrm{~S}_{5}\right)_{2}\right]^{2-}$ and $\left[\mathrm{Pt}_{3}\left(\mathrm{AsS}_{4}\right)_{3}\right]^{3-}$. Observation of Unique Thioarsenate ligands and Pt-As Bonds. Inorganic Chemistry, 33, 5372-5373. http://dx.doi.org/10.1021/ic00102a003

[16] Gin, V.C., Kelly, P.F., Slawin, A.M.Z., Wiliams, D.J. and Woolins, J.D. (1993) The Preparation and X-Ray Structure of $\left[\mathrm{NBu}_{4}\right]\left[\right.$ fac- $\left.\mathrm{PtBr}_{3}\left(\mathrm{~S}_{4} \mathrm{~N}_{4}\right)\right]$. Polyhedron, 12, 1135-1139. http://dx.doi.org/10.1016/S0277-5387(00)88202-9

[17] Melník, M. and Holloway, C.E. (2006) Stereochemistry of Platinum Coordination Compounds. Coordination Chemistry Reviews, 250, 2261-2271. (ref's cited therein)

[18] Melník, M. (1982) Structural Isomerism of Copper(II) Compounds. Coordination Chemistry Reviews, 47, $239-261$. http://dx.doi.org/10.1016/0010-8545(82)85033-9 
Scientific Research Publishing (SCIRP) is one of the largest Open Access journal publishers. It is currently publishing more than 200 open access, online, peer-reviewed journals covering a wide range of academic disciplines. SCIRP serves the worldwide academic communities and contributes to the progress and application of science with its publication.

Other selected journals from SCIRP are listed as below. Submit your manuscript to us via either submit@scirp.org or Online Submission Portal.
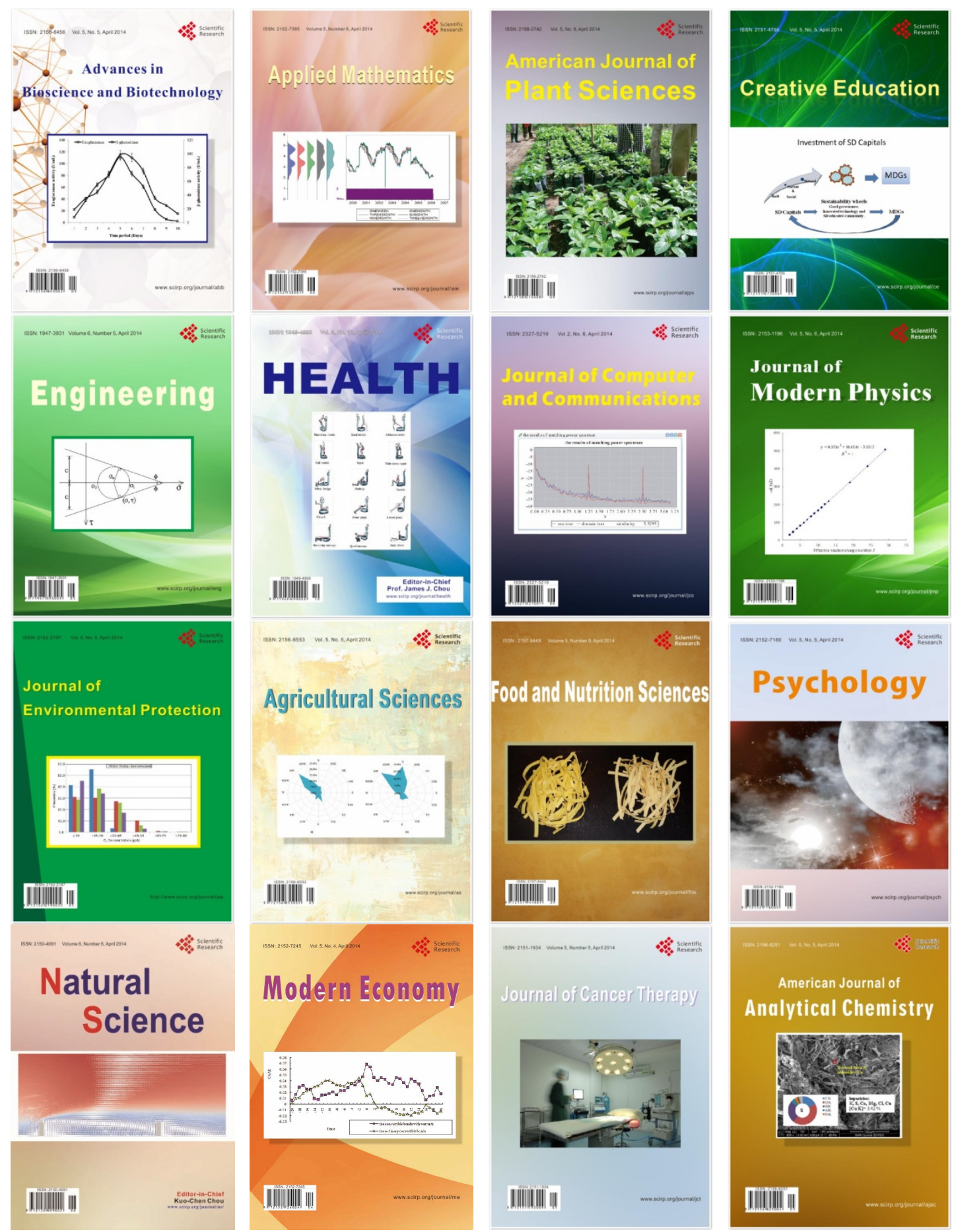